GABRIELA CAMPANHOLLE

\title{
O PAPEL DO RECEPTOR B1 DA BRADICININA EM \\ MODELOS EXPERIMENTAIS DE LESÃO PULMONAR \\ AGUDA DIRETA E INDIRETA
}

Tese apresentada ao Programa de PósGraduação em Imunologia do Instituto de Ciências Biomédicas da Universidade de São Paulo, para obtenção do Título de Doutor em Ciências 


\section{GABRIELA CAMPANHOLLE}

\section{O PAPEL DO RECEPTOR B1 DA BRADICININA EM MODELOS EXPERIMENTAIS DE LESÃO PULMONAR AGUDA DIRETA E INDIRETA}

Tese apresentada ao Programa de PósGraduação em Imunologia do Instituto de Ciências Biomédicas da Universidade de São Paulo, para obtenção do Título de Doutor em Ciências

Área de concentração: Imunologia

Orientador: Niels Olsen Saraiva Câmara 


\section{UNIVERSIDADE DE SÃO PAULO \\ INSTITUTO DE CIÊNCIAS BIOMÉDICAS}

Candidato (a): $\quad$ Gabriela Campanholle

Título da Dissertação: O Papel do receptor B1 da bradicinina em modelos experimentais de lesão pulmonar aguda direta e indireta

Orientador(a): $\quad$ Niels Olsen Saraiva Câmara

A Comissão Julgadora dos trabalhos de Defesa da Tese de Doutorado, em sessão pública realizada a , considerou

\section{( ) Aprovado (a) ( ) Reprovado (a)}

Examinador (a):

Assinatura:...

Nome:

Instituição:

Examinador (a):

Assinatura:

Nome:

Instituição:

Examinador (a): Assinatura:

Nome:

Instituição:.

Examinador (a): Assinatura:

Nome:

Instituição:.

Presidente:

Assinatura:

Nome:

Instituição: 


\section{Certificado}

Certificamos que o protocolo registrado sob $\mathrm{n}^{\circ} 009$ nas fls. 42 do livro 2 para uso de animais em experimentação, sob a responsabilidade de Niels Olsen Saraiva Camara Coordenador(a) da Linha de pesquisa "Papel dos receptores da bradicinina nos danos teciduais extra-renais desencadeados pela lesão de isquemia e reperfusão renal: Estudo da ação citoprotetora da biliverdina" do qual participou(aram) o(s) alunos Gabriela Campanholle está de acordo com os Princípios Éticos de Experimentação Animal adotado pelo Colégio Brasileiro de Experimentação Animal (COBEA) e foi aprovado pela COMISSÃO DE ÉTICA EM EXPERIMENTAÇÃO ANIMAL (CEEA) em 27.02.2007.

São Paulo, 27 de fevereiro de 2007.

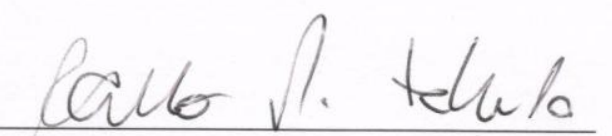

Prof. Dr. CARlos PElleschi TABORDA Vice - Coordenador da CEEA - ICB/USP

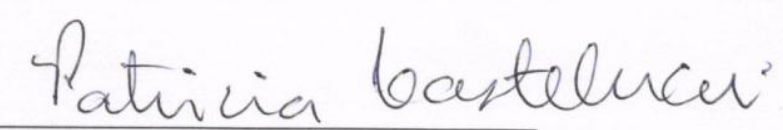

Profa. Dra. PATRÍCIA CASTELUCCI

Secretária da

CEEA - ICB/USP 


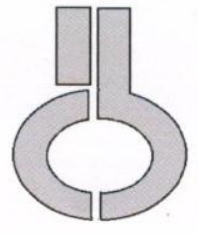

\section{Certificado}

Certificamos que o protocolo registrado sob $\mathrm{n}^{\circ} \mathbf{1 0 9}$ nas fls. 62 do livro 02 para uso de animais em experimentação, sob a responsabilidade de Niels olsen Saraiva Câmara, Coordenador(a) da Linha de pesquisa "Envolvimento dos receptores da bradicinina na lesão pulmonar causada por LPS' do qual participou(aram) o(s) Gabriela Campanholle, está de acordo com os Principios Éticos de Experimentação Animal adotado pelo Colégio Brasileiro de Experimentação Animal (COBEA) e foi aprovado pela COMISSÃO DE ÉTICA EM EXPERIMENTAÇÃO ANIMAL (CEEA) em 26.11.08, com validade de 3 anos.

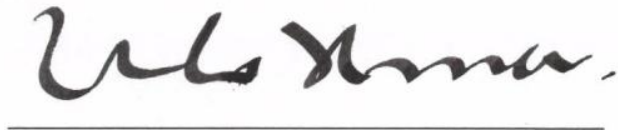

Prof. Dr. Wothan TAVAREs DE Lima Coordenador CEEA - ICB/USP
São Paulo, 26 de novembro de 2008.

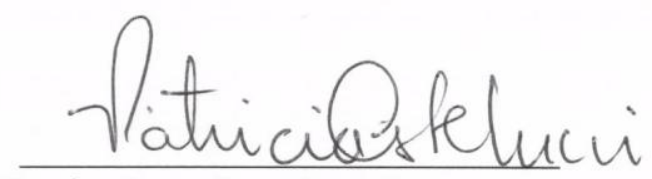

Profa. Dra. PATRÍcIA CASTELUCCI Secretária CEEA - ICB/USP 
À minha mãe, pai e irmão por todo amor, dedicação e apoio em todos os momentos da minha vida.

À minha querida família, tios, primos e meu avô por todo carinho e por estarem sempre presentes.

À memória de meus queridos avós, Ivo, Gennyl e Wilma que tanto contribuíram para minha educação. 


\section{AGRADECIMENTOS}

Ao meu querido orientador, professor e amigo, Niels, por tudo que me ensinou durante esses anos de orientação na iniciação científica e doutorado, por toda paciência, dedicação, incentivo e sábios conselhos, que foram indispensáveis para minha formação científica e pessoal.

Ao Richardt pela ajuda e colaboração na realização dos experimentos.

À amiga e colega de laboratório, Mary, por toda ajuda e paciência durante esses anos de doutorado, inclusive na impressão das teses.

Aos antigos colegas e amigos de laboratório, Rafa, Vanessa, Rebecca, Jean, Mayra e Daniel pela agradável convivência e ajuda durante o doutorado.

À Claudinha, pela companhia e ajuda em manter a organização do laboratório.

Aos professores Sônia Jancar e Momtchilo Russo pela colaboração neste projeto.

À amiga Érica Borducchi pela ajuda na realização dos experimentos de hiperreatividade pulmonar.

Ao colega Joilson Martins pela ajuda na realização dos experimentos de western blot.

Aos professores da minha banca de qualificação, Vera, Wothan e Soriano pelas construtivas sugestões para a melhora deste trabalho.

Ao orientador da minha iniciação científica Alvaro Pacheco-Silva, aos antigos colegas de laboratório da nefrologia, Pamella, Patrícia, Carla, Giselle, Marquinhos, e principalmente ao colega Maurício, que com seu bom humor e disposição foram fundamentais para meus primeiros aprendizados na pesquisa.

Ao Milton, professor de farmacologia durante minha graduação, por ter sido a primeira pessoa a despertar meu interesse pela pesquisa, fazendo com que muitas oportunidades boas viessem após isso.

À FAPESP, ao CNPq e CAPES pelo apoio financeiro concedido. 
O presente trabalho foi realizado com apoio da Fundação de Amparo à Pesquisa do Estado de São Paulo (FAPESP) e Coordenação de Aperfeiçoamento de pessoal de níver superior (CAPES). 
Escolha um trabalho de que gostes, e não terás que trabalhar nem um dia na tua vida.

Confúcio 


\section{RESUMO}

Campanholle G. O papel do receptor B1 da bradicinina em modelos experimentais de lesão pulmonar aguda direta e indireta [tese (Doutorado em Imunologia)]. São Paulo (Brasil): Instituto de Ciências Biomédicas da Universidade de São Paulo; 2010.

A síndrome do desconforto respiratório aguda (SDRA) é caracterizada por influxo de neutrófilos no pulmão, aumento de mediadores pró-inflamatórios, danos epiteliais e endoteliais. A SDRA pode ser classificada em lesão pulmonar direta (LPD), quando um insulto atinge diretamente o parênquima pulmonar, ou lesão pulmonar indireta (LPI) quando o insulto resulta de uma resposta inflamatória sistêmica. A LPD pode ser induzida por lipopolissacarídeos (LPS) presentes em superfícies de bactérias gramnegativas, enquanto que a LPI pode ser induzida por mediadores inflamatórios liberados por órgãos distantes após lesão de isquemia e reperfusão (IR). A bradicinina (BK) pode agir em dois receptores, um constitutivo (B2R) e um induzível (B1R). O B1R é induzido por citocinas inflamatórias e é o responsável pela maioria dos efeitos inflamatórios da BK. Nosso objetivo foi estudar o papel dos receptores da BK em modelos de LPD e LPI. A LPD foi induzida por tratamento via intra-nasal de $20 \mu \mathrm{g}$ de LPS, e a LPI foi induzida por 45 minutos de isquemia renal. Tanto na LPD como na LPI, 24 horas após o insulto, os animais apresentaram um aumento de infiltrado celular, hiperreatividade pulmonar à metacolina, extravasamento de proteínas para o lavado broncoalveolar (BAL) e aumento na expressão de citocinas pró-inflamatórias no pulmão. A expressão de B1R estava aumentada no pulmão após inalação de LPS, enquanto após a IR renal, tanto a expressão de B1R como a de B2R estavam aumentadas no pulmão. Bloqueamos então o B1R com o tratamento do antagonista R954. Na LPI induzida por IR renal, o bloqueio de B1R atenuou a lesão pulmonar, diminuindo a hiperreatividade à metacolina e extravasamento de proteínas para o BAL. Entretanto, não alterou o infiltrado celular no BAL. Na LPD induzida por LPS, o bloqueio de B1R inibiu a hiperreatividade pulmonar à metacolina, infiltrado de células no BAL, e diminuiu a presença de proteínas no BAL. Em ambos os tipos de lesões, o bloqueio de B1R diminuiu a expressão das citocinas inflamatórias IL-1 $\beta$, TNF- $\alpha$, IL-6, e da quimiocina $\mathrm{KC}$, enquanto aumentou a expressão da citocina anti-inflamatória IL-4. Assim, sugerimos que o B1R tem papel fundamental na contribuição tanto para a LPD, induzida por LPS, quanto para a LPI, induzida por IR renal.

Palavras-chave: Isquemia e reperfusão renal. LPS. Inflamação pulmonar. Bradicinina. Receptor B1. Inflamação sistêmica. Citocinas. 


\begin{abstract}
Campanholle G. The role of B1 bradykinin receptor in experimental models of direct and indirect acute lung injury. [Ph.D. Thesis (Immunology)]. São Paulo (Brasil): Instituto de Ciências Biomédicas da Universidade de São Paulo; 2010.
\end{abstract}

The adult respiratory distress syndrome (ARDS) is characterized by neutrophil infiltration in the lung, increase of inflammatory mediators and, epithelial and endothelial damages. The ARDS can be classified in direct acute lung injury (ALI), when the insult directly affects lung parenchyma, or indirect ALI, when the insult results from a systemic inflammatory response. The direct ALI can be induced by lipopolysaccharides from gram-negative bacterias, whereas indirect ALI can be induced by systemic inflammatory mediators released by distant organs after an ischemia and reperfusion injury (IRI). Bradykinin (BK) can acts in two different receptors, the constitutive one (B2R), and the inducible one (B1R). B1R is induced by inflammatory cytokines and is responsible for the most inflammatory effects of BK. We aimed to study the role of the BK receptors in experimental models of direct and indirect ALI. We induced direct ALI by $20 \mu \mathrm{g}$ of LPS instillation, and indirect ALI by 45 minutes of renal IRI. In both injuries, 24 hours after insult, the animals presented an increase in cellular infiltration, hyperreactivity to methacholine, protein leakage to bronchoalveolar lavage fluid (BALF) and an up-regulation of pro-inflammatory cytokines expression in lungs. B1R expression was up-regulated in the lung after LPS instillation, while the expression of B1R and B2R was up-regulated in the lung after renal IRI. Therefore, we blocked the B1R by treating the animals with the receptor antagonist (R954). In the indirect ALI model, induced by renal IRI, the B1R blockage attenuated the lung injury, decreasing the airway hyperreactivity to methacholine and protein leakage to BALF. However, there was no decrease in cellular infiltration in the BALF. In the direct ALI model, induced by LPS instillation, the B1R blockage prevented the airway hyperreactivity to methacholine and cellular increase in BALF. In both injuries, the B1R blockage downregulated the inflammatory cytokines expressions, such as IL- $1 \beta$, TNF- $\alpha$, IL- 6 , and the chemokine $\mathrm{KC}$, whereas up-regulated the expression of an anti-inflammatory cytokine, IL-4. Thus, we suggest that B1R has an important role in the development of both, direct ALI, induced by LPS, and indirect ALI induced by renal IRI.

Keywords: Renal ischemia and reperfusion injury. LPS. Lung inflammation. Bradykinin B1 receptor. Systemic inflammation. Cytokines. 


\section{LISTA DE ABREVIATURAS}

AP-1: proteína ativadora-1

ATP: adenosina trifosfato

B1R: receptor de bradicinina do tipo 1

B2R: receptor de bradicinina do tipo 2

BAL: lavado broncoalveolar

BK: bradicinina

cDNA: ácido desoxirribonucléico complementar

COX-2: ciclooxigenase-2

eNOS: óxido nítrico-sintase endotelial

EPM: erro padrão da média

HPRT: hipoxantina fosforibosil transferase

ICAM-1: molécula de adesão intercelular-1

IFN: interferon

IL: interleucina

iNOS: óxido nítrico-sintase induzível

IR: isquemia e reperfusão

IRA: insuficiência renal aguda

KC: quimiocina derivada de queratinócitos

$\mathrm{KO}$ : nocautes

LBP: proteína ligadora de lipopolissacarídeo 
LPA: lesão pulmonar aguda

LPD: lesão pulmonar direta

LPI: lesão pulmonar indireta

LPS: lipopolissacarídeo

MAPK: do inglês mitogen-activated protein kinase

MCP-1: proteína quimiotática de monócitos-1

MIP-2: proteína inflamatória de macrófago-2

MSH: hormônio estimulador de melanócito

Myd88: fator de diferenciação mielóide

NF-kB: fator de transcrição nuclear

NO: óxido nítrico

PAI-1: inibidor de ativação de plasminogênio

PCR: reação da cadeia da polimerase

Penh: do inglês enhanced pause (aumento da pausa respiratória)

PGE2: prostaglandina E2

RNAm: ácido ribonucléico mensageiro

SDRA: síndrome do desconforto respiratório agudo

TLR-4: do inglês Toll-like receptor

TNF: fator de necrose tumoral

UA: unidade arbitrária

VCAM-1: molécula de adesão vascular celular-1 


\section{LISTA DE FIGURAS}

Figura 1. Função Renal após 24 horas da cirurgia de isquemia e reperfusão (IR) renal.

Figura 2. Hiperreatividade pulmonar 6 e 24 horas após IR renal.

Figura 3. Número total de células no BAL 6 e 24 horas após IR renal.

Figura 4. Proteína total no BAL 6 e 24 horas após IR renal.

Figura 5. Expressão de iNOS e COX-2 no pulmão 24 horas após IR renal.

Figura 6. Dosagem de prostaglandina $\mathrm{E}_{2}\left(\mathrm{PGE}_{2}\right)$ no BAL 24 horas após IR renal.

Figura 7. Expressão dos transcritos gênicos de citocinas, quimiocinas e molécula de adesão no rim (A) e pulmão (B) 24 horas após IR renal

Figura 8. Quantificação de citocinas e quimiocina no soro 24 horas após IR renal.

Figura 9. Cinética da expressão dos transcritos gênicos dos receptores B1 e B2 no rim (A) e pulmão (B) após IR renal.

Figura 10. Função Renal 24 horas após IR renal e tratamento intra-nasal com inibidor de B1R (R954).

Figura 11. Hiperreatividade pulmonar após tratamento com inibidor de B1R (R954) em lesão induzida por IR renal.

Figura 12. Número total de células no BAL após tratamento com inibidor de B1R (R954) em lesão induzida por IR renal.

Figura 13. Proteína total no BAL após tratamento com inibidor de B1R (R954) em lesão induzida por IR renal.

Figura 14. Expressão dos transcritos gênicos de citocinas e quimiocina no pulmão após tratamento com inibidor de B1R (R954) em lesão induzida por IR renal. 
Figura 15. Hiperreatividade pulmonar 6 e 24 horas após inalação de LPS.

Figura 16. Número total e diferencial de células no BAL 6 e 24 horas após inalação de LPS.

Figura 17. Proteína total no BAL 6 e 24 horas após inalação de LPS.

Figura 18. Expressão dos transcritos gênicos dos receptores B1 e B2 no pulmão 6 e 24 horas após inalação de LPS.

Figura 19. Hiperreatividade pulmonar após tratamento com inibidor de B1R (R954) em lesão por inalação de LPS.

Figura 20. Número total de células no BAL após tratamento com inibidor de B1R em lesão por inalação de LPS.

Figura 21. Secção representativa do pulmão de animais tratados com inibidor de B1R (R954) e LPS.

Figura 22. Proteína total no BAL após tratamento com inibidor de B1R em lesão por inalação de LPS.

Figura 23. Expressão dos transcritos gênicos de citocinas e quimiocina no pulmão após tratamento com inibidor de B1R (R954) em lesão por inalação de LPS.

Figura 24. Quantificação de citocinas e quimiocina no BAL após tratamento com inibidor de B1R (R954) em lesão por inalação de LPS. 


\section{SUMÁRIO}

1 INTRODUÇÃO

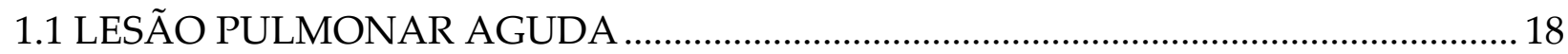

1.2 LESÃO PULMONAR DIRETA INDUZIDA POR LPS ……………………..................... 19

1.3 LESÃO PULMONAR INDIRETA INDUZIDA POR ISQUEMIA E REPERFUSÃO .. 21

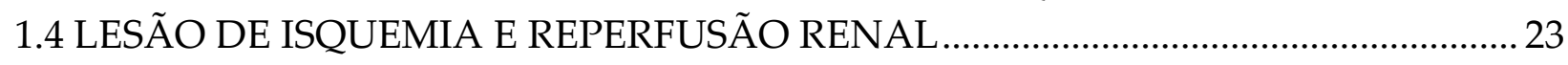

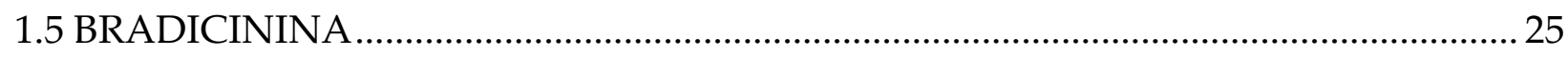

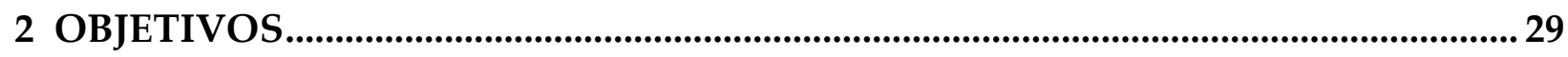

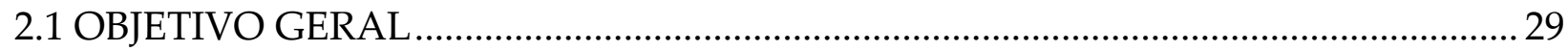

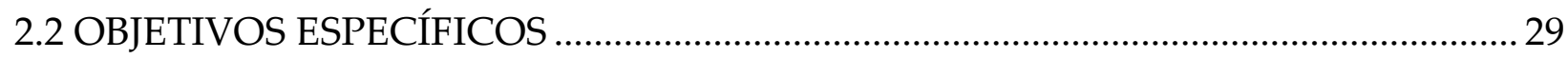

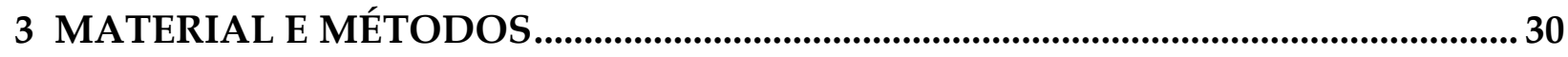

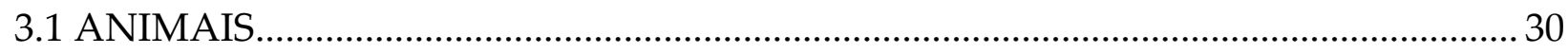

3.2 MODELO DE LESÃO PULMONAR INDUZIDA POR ISQUEMIA E REPERFUSÃO

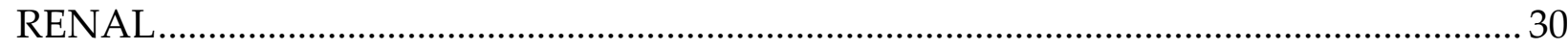

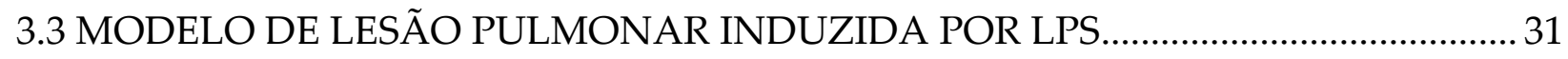

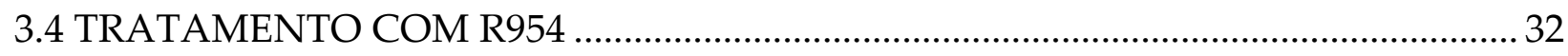

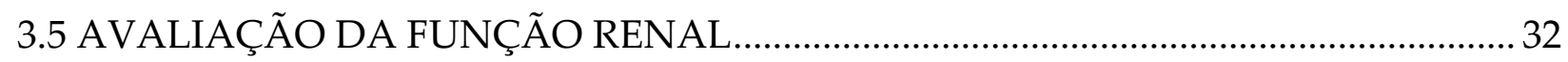

3.6 AVALIAÇÃO DOS PARÂMETROS FUNCIONAIS PULMONARES ........................... 33

3.6.1 Lavagem broncoalveolar ..................................................................................................... 33

3.6.2 Contagem total e diferencial das células ................................................................... 33

3.6.3 Proteína total do lavado broncoalveolar......................................................................... 33

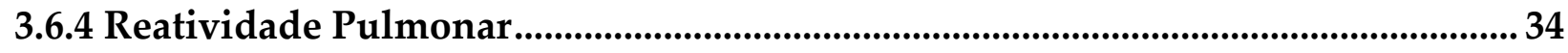

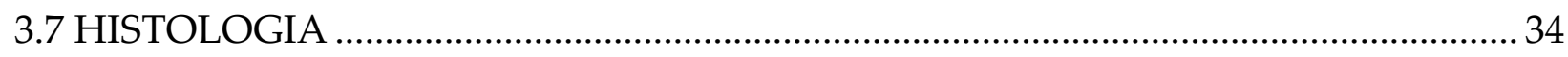

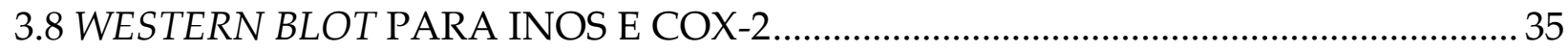

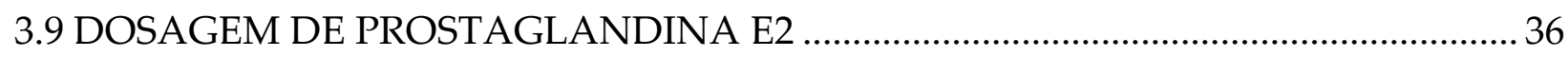

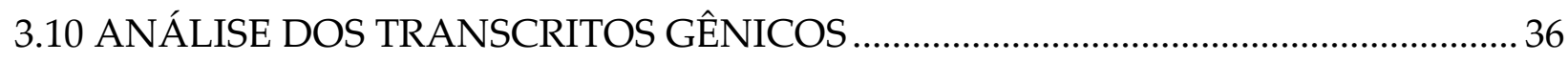

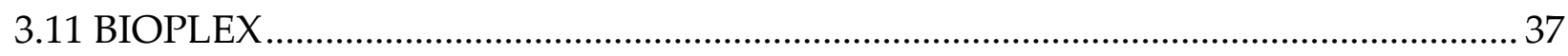

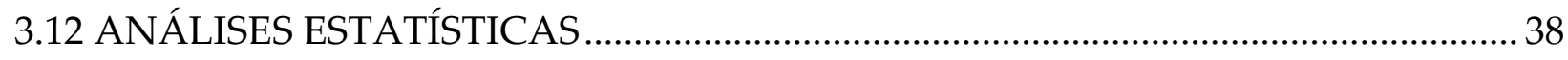

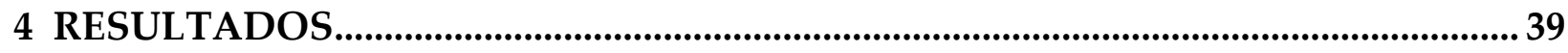

4.1 LESÃO PULMONAR INDIRETA INDUZIDA POR IR RENAL ………..................... 39

4.1.1 Estabelecimento do modelo de lesão renal por isquemia e reperfusão................... 39

4.1.2 Avaliação da Função Pulmonar após lesão induzida por IR renal ............................ 41

4.1.2.1 Hiperreatividade pulmonar....................................................................................... 41

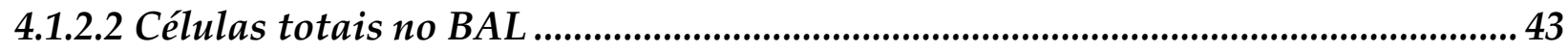

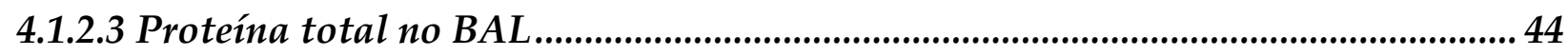

4.1.3 Expressão de iNOS e COX-2 no pulmão e prostaglandina no BAL .......................... 45

4.1.4 Expressão de transcritos gênicos de citocinas, quimiocinas e molécula de adesão

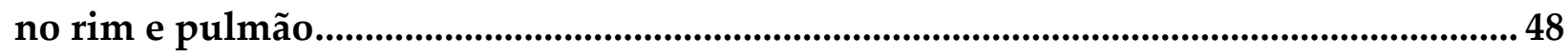

4.1.5 Dosagem de citocinas e quimiocina no soro após IR renal..........................................50 50 
4.1.6 Expressão dos receptores B1 e B2 no rim e pulmão após lesão de IR renal 51 4.1.7 Avaliação pulmonar após tratamento com antagonista de B1R (R954) na lesão induzida por IR renal 53

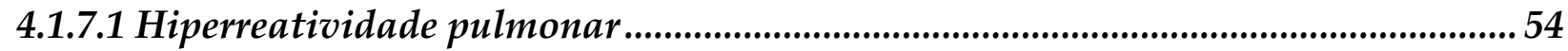

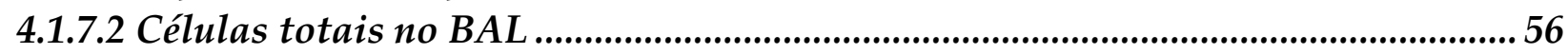

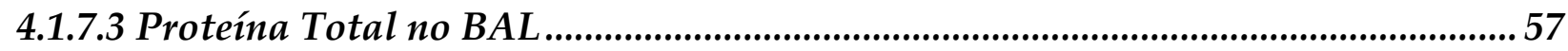

4.1.8 Expressão gênica de citocinas e quimiocina após tratamento com antagonista de

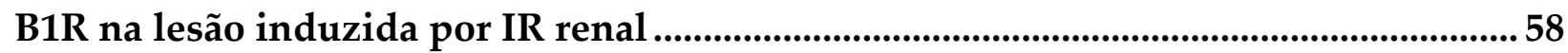

4.2 LESÃO PULMONAR DIRETA INDUZIDA POR INALAÇÃO DE LPS …………....... 60

4.2.1 Estabelecimento do modelo de lesão induzida por LPS................................................. 60

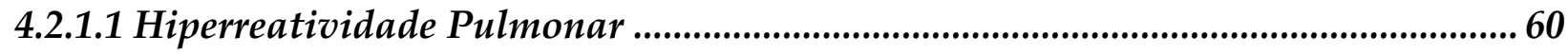

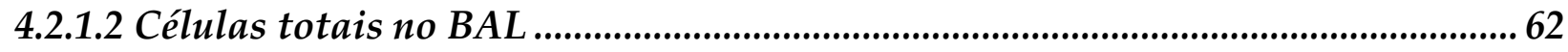

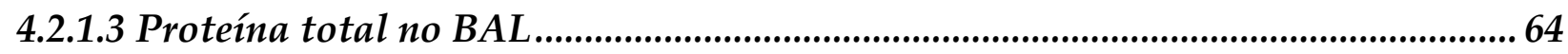

4.2.2 Expressão dos receptores B1 e B2 no pulmão após lesão direta induzida por LPS

4.2.3 Avaliação da função pulmonar após tratamento com antagonista de B1R na lesão

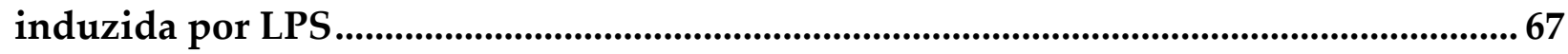

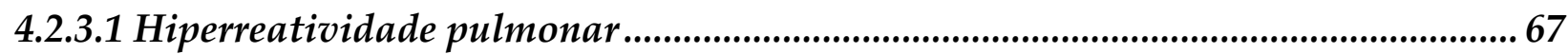

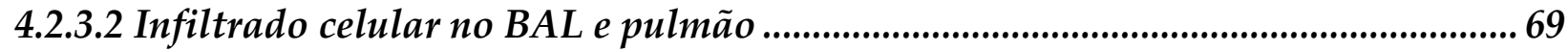

4.2.3.3 Proteína total no BAL.................................................................................................. 71

4.2.4 Expressão gênica de citocinas e quimiocina após tratamento com antagonista de

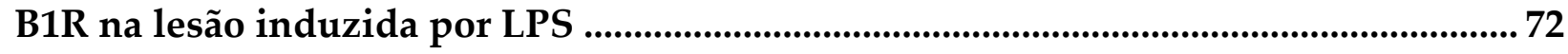

4.2.5 Quantificação de citocinas e quimiocina no BAL após tratamento com inibidor de B1R na lesão induzida por LPS .............................................................................................. 74

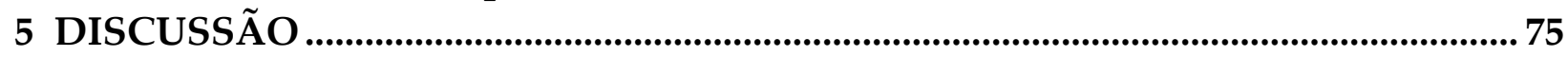

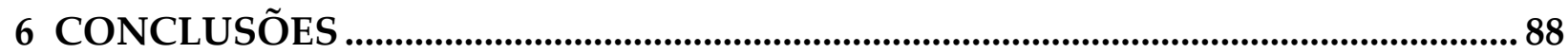

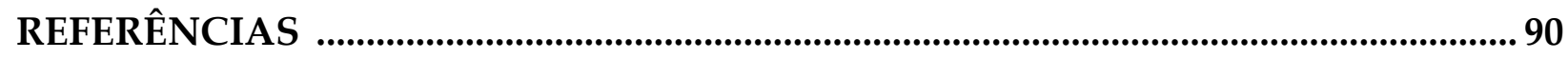

ANEXO A "Lung inflammation is induced by renal ischemia and reperfusion injury as part of the systemic inflammatory syndrome"

ANEXO B "Bradykinin inducible receptor is essential to lypopolysaccharide-induced acute lung injury in mice". 


\section{INTRODUÇÃO}

\subsection{LESÃO PULMONAR AGUDA}

A lesão pulmonar aguda (LPA), ou sua forma mais grave, a Síndrome do Desconforto Respiratório Agudo (SDRA), é uma importante causa de mortalidade na população [1]. É caracterizada por intenso influxo de neutrófilos no pulmão, aumento de mediadores pró-inflamatórios e danos epiteliais e endoteliais [2-4].

Em 1994, a “American-European Consensus Conference (AECC)" classificou a SDRA em duas categorias, de acordo com sua fisiopatologia: a primeira corresponde à SDRA direta (primária ou pulmonar), quando o insulto atinge diretamente o parênquima pulmonar, enquanto a segunda, corresponde à SDRA indireta (secundária ou extra-pulmonar), quando o insulto resulta de uma resposta inflamatória aguda sistêmica [5].

A causa mais comum de lesão pulmonar direta (LPD) é a pneumonia, seguida de aspiração de suco gástrico e trauma pulmonar [5]. Na lesão pulmonar indireta (LPI), a causa mais comum é a sepse, causada normalmente por infecções de bactérias gram-negativas [5]. A lesão de isquemia e reperfusão (IR) em órgãos como, intestino e rim, também podem levar à liberação de mediadores inflamatórios sistêmicos e causar SDRA indireta [6,7].

Embora vários casos de SDRA resultem em uma condição patológica uniforme nos estágios mais tardios, alguns estudos indicam que a fisiopatologia precoce pode ser diferente de acordo com o tipo de insulto [8-10]. Após um insulto direto, o epitélio pulmonar é a primeira estrutura a sofrer lesão. Isso leva a uma ativação do macrófago alveolar, desencadeando uma inflamação local. Além disso, causa 
acúmulo de líquido nos alvéolos, diminuição da produção de proteína surfactante e fibrose [11-14].

No caso do insulto indireto, o endotélio pulmonar é o alvo principal, e esta lesão é causada por mediadores que estão no sangue e foram liberados de focos extra-pulmonares (por exemplo: peritonite, pancreatite e órgãos isquêmicos). A ativação do endotélio pulmonar acarreta em um aumento da permeabilidade e recrutamento de monócitos, neutrófilos, plaquetas, e outras células [15, 16]. Isso será detalhado adiante.

\subsection{LESÃO PULMONAR DIRETA INDUZIDA POR LPS}

Um dos principais componentes de indução da LPD é o lipopolissacarídeo (LPS) [17]. Este componente está presente na superfície de bactérias gram-negativas, como Escherichia coli, e é reconhecido pelas células hospedeiras através do Toll-like receptor-4 (TLR-4), promovendo efeitos inflamatórios e ativando o sistema imune. Após ser reconhecido e se ligar à proteína de fase aguda ligadora de LPS (LBP), este complexo liga-se à molécula CD14, esta facilita o reconhecimento do LPS pelo TLR-4 e a glicoproteína MD-2. Esta ligação do LPS ao TLR-4 resulta na ativação de uma cascata de sinalização, que começa no recrutamento de moléculas adaptadoras, como MyD88, TIRAP, TRIF e TRAM, ativação de kinases, como MAPK (do inglês mitogenactivated protein kinase), resultando na ativação de fator de transcrição nuclear (NF«B) responsáveis pela indução de vários genes pró-inflamatórios [18].

O TLR-4 é essencial para o reconhecimento de LPS por diferentes tipos celulares do hospedeiro $[19,20]$. Esta via de sinalização, TLR-4/CD14 e Myd88, é fundamental para a inflamação pulmonar resultante de inalação do LPS. Noulin e colegas demonstraram que camundongos Myd88 nocautes apresentaram diminuição 
da inflamação aguda após inalação de LPS, avaliada pela infiltração de neutrófilos, broncoconstricção, extravasamento de proteína, diminuição na produção das citocinas IL-12, fator de necrose tumoral (TNF) e da quimiocina derivada de queratinócitos (KC). Entretanto, a via de sinalização independente de Myd88, TRIF, IL-1R e IL-18R são dispensáveis para a broncoconstrição e infiltração de neutrófilos induzidas por LPS [21].

Apesar dos mecanismos de lesão pulmonar por LPS ainda não serem totalmente esclarecidos, alguns estudos já demonstraram possíveis mecanismos envolvidos na broncoconstrição e neutrofilia causado por LPS inalado. Além disso, a LPD causada por inalação de LPS induz aumento da permeabilidade dos capilares alveolares, permitindo liberação de proteína, aumento de citocinas e quimiocinas pró-inflamatórias no lavado broncoalveolar (BAL), como o TNF- $\alpha$, IL-6 e KC (quimiocina do camundongo homóloga à IL-8 humana) [17, 22].

Alguns estudos já demonstraram que a broncoconstrição é dependente de TLR-4 [23], da sinalização via p38 MAPK e da presença de TNF- $\alpha$ [24]. Isso porque, camundongos nocautes para TLR-4 e TNF- $\alpha$, ou então, tratados com inibidores de p38, não apresentam broncoconstrição causada por LPS. A neutrofilia no BAL e pulmão é também dependente de TLR-4 e p38, entretanto, não parece ser dependente de TNF- $\alpha$, uma vez que camundongos TNF- $\alpha$ nocaute apresentam infiltrado neutrofílico no BAL e pulmão. Com isso, entende-se que a broncoconstrição causada pelo LPS é dependente de TNF- $\alpha$ e não depende de neutrofilia, enquanto que a neutrofilia, independe da presença de TNF- $\alpha$ [24].

Outro indício de que a neutrofilia pode não estar envolvida com a broncoconstrição, é um estudo que mostra que as plaquetas teriam um papel mais importante do que os neutrófilos na broncoconstrição causada por tratamento intratraqueal de LPS em cobaias. Este estudo demonstra que utilizando drogas para 
depletar neutrófilos, a broncoconstrição não se alterava, entretanto, quando se utilizou drogas para depletar plaquetas, a broncoconstrição foi atenuada [25].

Um dos mecanismos que pode estar envolvido na migração de neutrófilos para o pulmão após inalação de LPS, é o aumento de expressão do inibidor de ativação de plasminogênio (PAI-1). O PAI-1 é uma molécula com propriedades fibrinolíticas, pois inibe a ativação do plasminogênio, e, conseqüentemente, a atividade da plasmina [26]. Estudos já descreveram seu potencial em regular a migração celular por três diferentes maneiras: 1) modulando a degradação da matriz extracelular por regular os níveis de plasmina; 2) regulando a adesão celular; e, 3) modificando o gradiente de quimiocinas [27]. Um estudo demonstrou que camundongos que inalaram LPS apresentavam um aumento da expressão de PAI-1 pulmonar e que animais nocautes para PAI-1 tinham diminuição de migração de neutrófilos no pulmão e BAL após administração intra-traqueal de LPS [28].

\subsection{LESÃO PULMONAR INDIRETA INDUZIDA POR ISQUEMIA E REPERFUSÃO}

A LPI pode ser causada por lesão de IR de órgãos como rim, intestino e fígado. Estudos demonstraram que a isquemia hepática resulta em uma ativação pulmonar de NF- $\mathrm{KB}$, aumento de expressão de TNF- $\alpha, \mathrm{KC}$, proteína quimiotática de monócitos1 (MCP-1), proteína inflamatória de macrófago-2 (MIP-2), infiltrado de neutrófilos e aumento de permeabilidade pulmonar [29, 30]. Além disso, um estudo demonstrou que o tratamento com IL-10, uma citocina anti-inflamatória, foi capaz de atenuar essa lesão pulmonar [31]. A LPI após IR intestinal é caracterizada pelo aumento de permeabilidade microvascular, evidências histológicas de lesão endotelial dos capilares alveolares e infiltrado de neutrófilos [32, 33]. Durante uma lesão de IR, muitos mediadores inflamatórios são liberados, incluindo o TNF- $\alpha$, IL-1 $\beta$ e óxido 
nítrico (NO), sendo possíveis candidatos para mediar a disfunção pulmonar resultante de IR intestinal [34, 35]. Alguns estudos já mostraram que a IL-1 $\beta$ e o TNF- $\alpha$, após a IR intestinal podem causar danos pulmonares através do ducto torácico linfático, já que quando este ducto é bloqueado, os níveis séricos de IL-1 $\beta$ diminuem, assim como o dano pulmonar [36,37]. Também foi demonstrado que a adesão de neutrófilos à célula endotelial mediada pela molécula de adesão intercelular-1 (ICAM-1) pode ser um passo limitante na patogênese da lesão pulmonar induzida pela IR intestinal [38].

Um estudo feito por Cavriani e colaboradores demonstrou o papel do NO na lesão pulmonar após IR intestinal. O estudo sugere que o NO endógeno tem efeito importante para conter os efeitos inflamatórios causados pela IR, enquanto que o NO induzível exerce um efeito pró-inflamatório. Ainda mais, este papel do NO parece ter diferentes efeitos sobre o aumento de permeabilidade vascular ou infiltração de neutrófilos [39]. Assim como na isquemia intestinal, outro estudo também mostrou o aumento da expressão de óxido nítrico-sintase induzível (iNOS) e diminuição da expressão de óxido nítrico-sintase endotelial (eNOS) no pulmão após isquemia hepática [40].

A LPI também pode ser induzida após IR renal, embora ainda não é totalmente esclarecido os mecanismos pelo qual isso ocorre. Um dos mecanismos pode ser a liberação de citoquinas pró-inflamatórias pelo rim que através do sangue chegam ao pulmão ativando a inflamação local. Um aumento das citocinas IL-6, IL-8 e IL-10 no plasma de pacientes com insuficiência renal aguda está associada com maior chance de mortalidade [41]. Um estudo demonstrou o papel de macrófagos na modulação da lesão pulmonar após isquemia bilateral em ratos. Neste estudo, a lesão renal levou a um aumento de permeabilidade vascular pulmonar mediada por macrófagos, uma vez que o tratamento com inibidor destas células foi capaz de 
atenuar essa lesão [6]. Outro estudo mostrou que o tratamento com $\alpha$-MSH (hormônio estimulador de melanócito), citocina anti-inflamatória, foi capaz de reduzir a lesão pulmonar, infiltração de leucócitos, e diminuir a expressão de citocinas pulmonares como TNF- $\alpha$ e ICAM-1. Entretanto, neste estudo a lesão renal também foi atenuada pelo tratamento com $\alpha-\mathrm{MSH}$, ficando difícil explicar se a diminuição da lesão pulmonar não é devida à melhora na lesão primária renal [42]. As alterações pulmonares são dependentes da severidade envolvida na lesão renal. Isquemias de 30 minutos levaram a pouquíssimas alterações da histologia pulmonar 6 horas após a isquemia e, apresentando-se completamente normal após 36 horas. Entretanto, uma isquemia de 60 minutos causou alterações pulmonares e aumento de celularidade com 6 horas após IR permanecendo por 36 horas [43].

A SDRA e a IR renal freqüentemente co-existem nas unidades de tratamento intensivo e essa combinação é associada com uma alta mortalidade. Por isso, estudos que visam entender melhor este mecanismo de lesão são necessários.

\subsection{LESÃO DE ISQUEMIA E REPERFUSÃO RENAL}

A insuficiência renal aguda (IRA) afeta $5 \%$ de todos os pacientes hospitalizados com um alto grau de mortalidade devido à ausência de terapias específicas, apesar dos avanços das estratégias preventivas e medidas de suporte [44, 45]. A lesão de IR renal é a principal causa da IRA intrínseca de rins nativos e está associada a uma mortalidade acima de 50\% [44]; nos rins transplantados, a lesão de IR implica na diminuição da sobrevida tanto a curto, quanto a longo prazo do enxerto $[46,47]$.

O rim é composto por milhares de unidades denominadas néfron. Os néfrons são divididos em diferentes segmentos: glomérulo, túbulo proximal, alça de henle, 
túbulo distal e ducto coletor, que juntos são responsáveis pela filtração do sangue, eliminando metabólitos através da urina, reabsorvendo nutrientes, ajudando na manutenção do pH e pressão arterial, entre outras funções. O túbulo proximal é responsável pela reaborção de importantes nutrientes, e altamente dependente de adenosina trifosfato (ATP) para o funcionamento das bombas de sódio e potássio [48].

Numa lesão de IR, a diminuição do suprimento de oxigênio e consequentemente diminuição de ATP, leva a alterações celulares principalmente das células do túbulo proximal. A diminuição de ATP causa alterações na expressão e distribuição de moléculas de adesão nestas células, levando a perda da permeabilidade e polaridade, fazendo com que haja uma descamação das células epiteliais causando obstrução tubular e redução na taxa de filtração glomerular [49]. Quando a depleção de ATP é prolongada, isso pode levar a alterações bioquímicas irreversíveis causando então morte celular por necrose [50].

Além da morte celular causada pelo período da isquemia, as consequências após a reperfusão, contribuem ainda mais para o dano renal. A inflamação é atualmente aceita como o principal componente na patogênese da lesão de IR renal [51].

As células endoteliais iniciam a inflamação após a IR renal. Um estudo utilizando microscópio intravital, demonstrou que a lesão de isquemia altera a integridade e a barreira endotelial, aumentando a permeabilidade vascular e facilitando o infiltrado neutrofílico para o parênquima renal [52]. Além disso, as células endoteliais produzem mediadores como quimiocinas (IL-8 e MCP-1) e moléculas de adesão (ICAM-1 e VCAM-1), contribuindo ainda mais para adesão e influxo de leucócitos para o tecido renal [53]. 
Além da contribuição dos leucócitos e células endoteliais para a inflamação na IR renal, as células tubulares epiteliais têm uma importante participação neste processo. Muitos mediadores inflamatórios são produzidos pelas células epiteliais tubulares, aumentando ainda mais a inflamação local. Estes mediadores incluem o TNF- $\alpha$, IL-1 $\beta$, IL-6, e quimiocinas, como IL-8 e MCP-1 [54-57].

Diferentes subgrupos de leucócitos contribuem para a lesão de IR. Alguns estudos demonstraram que o bloqueio e migraçao de neutrófilo para o rim, melhora a lesão de IR renal [58,59], assim como, o bloqueio de macrófagos [60, 61]. Um estudo demonstrou que camundongos duplo nocaute CD4 e CD8 são protegidos de lesão de IR renal. Em outro estudo, CD4 nocautes, mas não CD8, foram protegidos contra IRA, e a transferência adotiva destas células, reestabeleu a lesão [62, 63]. Diversos estudos, inclusive do nosso laboratório, demonstraram que o padrão de células Th1 (produtoras de interferon $\gamma$ ) é deletério na IRA enquanto o padrão de células Th2 (produtoras de IL-4) é protetor [64-66].

Em geral, muitos estudos demonstraram que diminuindo a inflamação, seja por diminuir infiltrado celular, diminuir produção de mediadores pró- inflamatórios, ou por aumentar mediadores anti-inflamatórios, a lesão de IR renal é diminuída [67, 68]. Um dos trabalhos realizados no nosso laboratório mostrou que, inibindo o receptor B1 de bradicinina, receptor responsável pelos efeitos inflamatórios deste mediador, a lesão de isquemia foi atenuada [69].

\subsection{BRADICININA}

A cascata plasmática de formação das cininas pode ser ativada pelas células endoteliais após diversos insultos, tais como lesão de IR. As cininas são responsáveis por vários efeitos fisiológicos, incluindo controle da pressão sanguínea, contração e 
relaxamento da musculatura lisa, permeabilidade vascular e mecanismos de transmissão de dor. As cininas, que têm como sua principal molécula a bradicinina, são formadas a partir de um precursor, o cininogênio, que sofre ação de enzimas plasmáticas ou teciduais, denominadas calicreína [70]. Ao agir no endotélio, a bradicinina $(\mathrm{BK})$ e seus fragmentos promovem uma série de efeitos biológicos, como liberação de NO e prostaciclina. Em situações inflamatórias, alergia, ou após traumas, as cininas podem promover a migração de células para os tecidos, promover ativação de mastócitos, fibroblastos, macrófagos e várias células do sistema imunológico [71]. Suas ações são mediadas pela estimulação de dois subtipos de receptores transmembrânicos acoplados à proteína-G, denominados B1 e B2. Os receptores B2 (B2R) se ligam preferencialmente à BK e são constitutivamente expressos em diversos tecidos e considerados como os principais mediadores dos efeitos fisiológicos da BK. Diferentemente dos B2R, os receptores B1 (B1R), se ligam ao metabólito da BK (des-Arg9-bradicinina) e são normalmente ausentes nos tecidos não-traumatizados, sendo expressos sob condições particulares, como após lesões ou infecções teciduais [72-74].

Citocinas inflamatórias, como IL-1 $\beta$ e TNF- $\alpha$, e ativação de componentes da família MAPK, estão envolvidos na regulação e superexpressão do gene para B1R [75]. A região promotora do gene para B1R tem sítios de ligações para diversos fatores de transcrição, dentre eles o NF- $\kappa$ B e fator de transcrição de ativação de proteína (AP-1) [76]. Ambos os fatores estão presentes em situações de inflamação, e podem estar relacionados com a indução do B1R por citocinas inflamatórias,

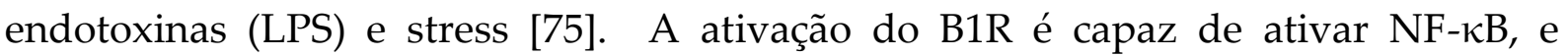
também de promover uma série de efeitos pró-inflamatórios, como migração leucocitária, edema, dor, liberação de prostaglandinas [77], citocinas (IL-1 $\beta$ ) [78, 79], quimiocinas e leucotrienos [80,81]. 
A BK agindo nas células endoteliais está envolvida na liberação de NO através da indução das enzimas NOS. A BK ao se ligar no B2R de células endoteliais, promove ativação de eNOS através de fosforilação pela Akt e elevação de $\mathrm{Ca}^{2+}$ intracelular, levando a um aumento transiente de NO. Entretanto, num ambiente inflamatório, o metabólito da BK age no B1R, levando à fosforilação e ativação de iNOS, através da via de sinalização ERK/MAPK, o que leva a um aumento prolongado de $\mathrm{NO}$ [82].

O papel benéfico ou deletério destes receptores é dependente do modelo de lesão estudado e ainda é controverso na literatura. Em alguns modelos, o bloqueio de B2R esta envolvido numa melhora da lesão. Por exemplo, em modelo de isquemia intestinal e transplante pulmonar canino, o bloqueio de B2R através do tratamento com antagonista foi capaz de melhorar a lesão tecidual [83, 84]. Este mesmo efeito de proteção através do bloqueio de B2R também foi observado em um modelo de isquemia cerebral em ratos [85]. Entretanto, uma grande maioria dos estudos já demonstrou o papel deletério de B1R em diferentes lesões. Outros estudos utilizando modelo de isquemia e reperfusão cerebral em ratos ou camundongos nocautes para os receptores de bradicinina mostraram que o B1R contribui para a lesão cerebral enquanto o B2R é benéfico $[85,86]$. Este efeito deletério de B1R também foi demonstrado em um modelo de colite e tumor cerebral [87, 88].

Em modelos de alergia pulmonar o papel de B1R e B2R também é controverso. Enquanto alguns estudos demonstraram que o bloqueio do receptor B1R diminui a lesão pulmonar prevenindo a secreção de muco, hiperreatividade pulmonar e infiltração de eosinófilos em modelos de asma [89, 90], outros estudos demonstraram que a maioria dos efeitos observados na asma como broncoconstrição, e aumento de permeabilidade vascular parecem ser mediados através de B2R [91]. 
Nosso laboratório demonstrou anteriormente que o B1R também está envolvido numa pior lesão renal em modelo de isquemia e reperfusão. Após 24 e 48 horas de reperfusão, os animais nocautes de B1R apresentaram menores níveis de creatinina plasmática, e menor alteração histológica, indicando menor dano renal comparado com animais selvagens. Além disso, a proteção renal dos animais nocautes do B1R foi também associada com menor expressão de citocinas próinflamatórias e maior expressão de IL-4 e IL-10 no rim [69, 92]. Outro estudo demonstrou que o B1R está associado a lesão renal aguda não só em modelos causados por IR renal. Neste estudo, os autores analisaram o perfil dos transcritos gênicos em um modelo de lesão renal aguda induzida por LPS em animais selvagens e nocautes de B1R e demonstraram que, genes relacionados à inflamação, adesão celular e apoptose estavam aumentados nos animais selvagens, enquanto genes relacionados a crescimento e proliferação celular estavam diminuídos. Esta expressão é invertida nos animais nocautes, que apresentam menor expressão de genes relacionados à inflamação e maior expressão de genes relacionados a proliferação celular [93].

Como o componente inflamatório é o grande responsável pela SDRA, tanto direta como indireta, acreditamos que a bradicinina possa ser um importante mediador inflamatório envolvido nesta lesão. 


\section{OBJETIVOS}

\subsection{OBJETIVO GERAL}

O objetivo deste trabalho foi estudar o papel dos receptores da bradicinina na lesão pulmonar direta (LPD) induzida por LPS, e na lesão pulmonar indireta (LPI) secundária à IR renal.

\subsection{OBJETIVOS ESPECÍFICOS}

Nos modelos de LPD e LPI, os objetivos específicos foram:

- Verificar a expressão dos receptores B1 e B2 no pulmão;

- Avaliar a função pulmonar, através de hiperreatividade brônquica à metacolina, do infiltrado de células e do extravasamento de proteína para o BAL; e

- Estudar a participação do B1R nas lesões pulmonares através da modulação farmacológica deste receptor. 


\section{MATERIAL E MÉTODOS}

\subsection{ANIMAIS}

Os estudos foram aprovados pela Comissão de Ética em Experimentação Animal (CEEA) do Instituto de Ciências Biomédicas da Universidade de São Paulo (ICB-USP) em 27.02.2007, registrado sob protocolo (009-fls 42, livro 2). Foram usados camundongos machos C57Bl/6, com idade entre 6 e 8 semanas, pesando de 20 a $28 \mathrm{~g}$ que foram fornecidos pelo Biotério de Camundongos Isogênicos da USP. Após os procedimentos cirúrgicos e tratamentos, os animais foram mantidos no laboratório, em estante ventilada, acondicionados em caixas coletivas, contendo no máximo cinco animais por caixa, com ciclo artificial claro/escuro de 12 horas, a uma temperatura ambiente constante de $22{ }^{\circ} \mathrm{C}$ e com suprimentos de água e alimento autoclavados disponíveis todo o tempo.

\subsection{MODELO DE LESÃO PULMONAR INDUZIDA POR ISQUEMIA E REPERFUSÃO RENAL}

Camundongos C57B1/6 foram submetidos à cirurgia de IR renal e a função pulmonar analisada após 6 ou 24 horas de reperfusão. Brevemente, os animais foram anestesiados com $350 \mu \mathrm{L}$ (via i.p.) da mistura de cloridrato de ketamina (0,5\%, Agribands, São Paulo, Brasil) e cloridrato de xilazina (0,3\%, Agribands) em PBS. Uma incisão mediana foi realizada e ambos os pedículos renais foram ligados de forma reversível. Durante o procedimento cirúrgico, os animais foram mantidos hidratados com soro fisiológico e à constante temperatura $\left(\sim 37^{\circ} \mathrm{C}\right)$ através de aquecimento indireto. Após quarenta e cinco minutos de isquemia, os clampes microcirúrgicos 
foram removidos. O abdômen foi fechado em duas camadas e os animais foram acondicionados em gaiolas, aquecidos por luz indireta até a completa recuperação da anestesia. Os animais controles (sham) passaram por todo o procedimento cirúrgico, exceto a colocação dos clampes.

Com 30 minutos, 6, 12, 24 e 48 horas após a reperfusão renal os animais foram sacrificados para coleta de sangue e avaliação da função renal através da dosagem de creatinina e uréia. Nos grupos de 6 e 24 horas de reperfusão, a função pulmonar foi avaliada. Para isso, analisamos a hiperreatividade pulmonar e, no sacrifício, o BAL foi coletado para contagem total de células, e seu sobrenadante utilizado para dosagem de proteína total. O pulmão foi coletado para extração de RNA mensageiro (RNAm) e a análise de transcritos gênicos foi feita através de PCR em tempo real.

\subsection{MODELO DE LESÃO PULMONAR INDUZIDA POR LPS}

Camundongos C57B1/6 foram anestesiados com cetamina e xilazina e tratados com $20 \mu \mathrm{g} /$ animal de LPS obtido de E. coli (O111:B4 Sigma-Aldrich) por via intranasal diluído em salina a um volume final de $20 \mu \mathrm{l}$. Os animais controle receberam apenas salina. Após 6 ou 24 horas, a hiperreatividade pulmonar foi avaliada e, em seguida, os animais foram sacrificados para coleta do BAL e pulmão. O BAL foi utilizado para contagem de células totais, e seu sobrenadante para dosagem de proteína total e quantificação de citocinas pela técnica de bioplex. O pulmão foi coletado para extração de RNAm e quantificação da expressão de DNA complementar (cDNA) de moléculas pró e anti inflamatórias através de PCR em tempo real. 


\subsection{TRATAMENTO COM R954}

Os animais submetidos à IR renal receberam por via intra-nasal, $200 \mu \mathrm{g} / \mathrm{kg}$ de antagonista de B1R (R954), gentilmente doado pelo Dr. Pierre Sirois da Universidade de Sherbrooke, Quebec, Canadá, diluído em $20 \mu \mathrm{l}$ de salina, 30 minutos após reperfusão, e receberam uma segunda dose 6 horas após a reperfusão [69, 90]. Os animais submetidos à lesão por inalação de LPS receberam apenas uma dose de 200 $\mu \mathrm{g} / \mathrm{kg}$ de R954 por via intra-nasal 30 minutos após o tratamento com LPS.

\subsection{AVALIAÇÃO DA FUNÇÃO RENAL}

Os níveis de creatinina e uréia sérica foram usados para avaliar a função renal após a IR renal. Nos devidos tempos de reperfusão, amostras de sangue foram coletadas da veia cava abdominal inferior imediatamente antes da indução de morte. O sangue foi centrifugado 20 minutos a $1500 \mathrm{~g}$ para obtenção do soro. As concentrações de creatinina sérica foram dosadas pelo método de Jaffé modificado. Brevemente, foi adicionado $100 \mu \mathrm{l}$ de ácido sulfúrico 1,84\%, $100 \mu \mathrm{l}$ de tungstato de sódio $10 \%$ e $200 \mu \mathrm{l}$ de água a $100 \mu \mathrm{l}$ de soro. As amostras foram centrifugadas por 10 minutos a 4000g. $200 \mu \mathrm{l}$ do sobrenadante foi transferido para uma placa de 96 poços e foi acrescentado $80 \mu \mathrm{l}$ de ácido pícrico $2 \%$ e $20 \mu \mathrm{l}$ de hidróxido de sódio a $10 \%$. A absorbância foi lida num espectofotômetro de leitor de placas (Spectra-max190Molecular Devices, Sunnyvale, CA, USA) a 520nm. A concentração foi calculada em relação a curva padrão de creatinina e os resultados foram expressos em mg de creatinina/dl. Para a dosagem da uréia, foi utilizado o kit comercial colorimétrico de urease (Lab Test). O método foi realizado de acordo com as instruções do fabricante. 


\subsection{AVALIAÇÃO DOS PARÂMETROS FUNCIONAIS PULMONARES}

\subsubsection{Lavagem broncoalveolar}

Os animais foram anestesiados com uma injeção de cetamina/xilazina. A cânula traqueal foi inserida via incisão médio-cervical e as vias respiratórias foram lavadas duas vezes com $1 \mathrm{ml}$ de tampão fosfato (PBS, pH 7,4 a $4{ }^{\circ} \mathrm{C}$ ).

\subsubsection{Contagem total e diferencial das células}

O fluído do lavado broncoalveolar foi centrifugado a $170 \mathrm{~g}$ por $10 \mathrm{~min}$ a $4^{\circ} \mathrm{C}$, o sobrenadante foi removido e o botão celular ressuspendido em 0,5 ml de PBS. Um volume de uma solução contendo $0,5 \%$ de cristal violeta dissolvido em $30 \%$ ácido acético foi adicionado a nove volumes da suspensão celular. A contagem total das células foi determinada por câmara de Neubauer. As células foram centrifugadas em Citocentrifuga e coradas com hematoxilina e eosina para a contagem diferencial.

\subsubsection{Proteína total do lavado broncoalveolar}

O sobrenadante obtido da centrifugação do BAL foi utilizado para dosagem de proteína total. Para a dosagem, foi utilizado o kit Dc-Protein da (Bio-Rad Laboratories, Inc., Hercules, CA, USA). Brevemente, o ensaio foi feito de acordo com especificações do fabricante, a absorbância lida em 650nm em espectrofotômetro (Spectra-max190-Molecular Devices, Sunnyvale, CA, USA), e a concentração determinada através de utilização de curva padrão de albumina sérica bovina (BSA). Os resultados foram expressos em $\mu \mathrm{g}$ de proteína/ml. 


\subsubsection{Reatividade Pulmonar}

Os animais conscientes e livres, foram colocados em câmaras pletismográficas (BUXCO Eletronics, USA) e os parâmetros respiratórios foram medidos por 5 minutos antes e após nebulização por 2,5 minutos com doses de concentração crescente de metacolina (3, 6, 12 e $25 \mathrm{mg} / \mathrm{ml}$; Sigma, St Louis, USA) [94]. A resistência respiratória é expressa como aumento da pausa respiratória (Penh), calculada segundo instruções do fabricante como:

Penh $=($ Te $/$ Tr-1) $\times$ Pef/Pif

Onde, Penh: "enhanced pause"; Te: tempo expiratório (segundos); Tr: tempo de relaxamento (segundos); Pef: pico de fluxo expiratório e Pif: pico de fluxo inspiratório.

Os resultados foram expressos na média dos valores obtidos do penh com diferentes concentrações de metacolina, ou sob a forma de área sob a curva da dose resposta com metacolina.

\subsection{HISTOLOGIA}

Após a realização da coleta do BAL, os pulmões foram perfundidos com 10ml de PBS através do ventrículo direito para remover o excesso de sangue. Os pulmões foram então fixados a $10 \%$ de formalina em PBS durante a noite. Foram então colocados em $70 \%$ de etanol até serem embebidos em parafina. Os cortes foram feitos com $5 \mu \mathrm{m}$ de espessura e as lâminas foram coradas com hematoxilina e eosina. As imagens foram analisadas com um aumento de 400X. 


\subsection{WESTERN BLOT PARA INOS E COX-2}

Para avaliação da expressão de iNOS e COX-2 em homogenatos pulmonares, o pulmão foi perfundido após coleta do BAL, com PBS gelado e homogenizado em 2 $\mathrm{ml}$ de tampão de lise gelado (10\% Nonodiet P40, $150 \mathrm{mM} \mathrm{NaCl}, 10 \mathrm{mM}$ Tris $\mathrm{HCl} \mathrm{pH}$ 7,6, $2 \mathrm{mM}$ PMSF, $5 \mu \mathrm{M}$ Leupeptin) por 5 passagens por um homogenizador motorizado à média velocidade. Após centrifugação $\left(16.000 \mathrm{~g}, 10 \mathrm{~min}, 4^{\circ} \mathrm{C}\right), \mathrm{o}$ conteúdo protéico de cada sobrenadante foi determinado pelo método BCA (BCA ${ }^{\mathrm{TM}}$

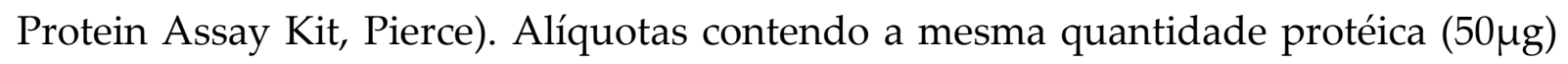
foram fervidas com tampão Laemmli (100 mM DTT, 0.1\% Bromofenol Blue) por 4 min e submetidas a eletroforese em um gel de poliacrilamida a $10 \%$. As proteínas foram eletroforeticamente transferidas para uma membrana de nitrocelulose e bloqueadas com 5\% de leite desnatado diluído em tampão Tris-HCl-Tween (TBS-T, TrisHCl $10 \mathrm{mM}, \mathrm{NaCl} 150 \mathrm{mM}$, tween 20 0.1\%) a temperatura ambiente por 1 hora. Após lavagem com TBS-T, a membrana foi incubada com o anticorpo primário durante a noite a $4^{\circ} \mathrm{C}$ (anticorpo monoclonal IgG anti NOS2, COX2 ou $\beta$-actina a 1:2000). As membranas foram lavadas com TBS-T e incubadas com anticorpo secundário (anticorpo anti-camundongo IgG conjugado com peroxidase a 1:10.000) por 1 hora a temperatura ambiente. As bandas foram visualizadas por um kit de quimiluminescência seguindo as instruções do fabricante e expostos ao filme fotográfico (Kodak, Brazil). A análise densitométrica das bandas foi realizada por escaneamento a laser e processado pelo programa AlphaEaseFc ${ }^{\mathrm{TM}}$. Os resultados foram expressos em unidades arbitrárias. 


\subsection{DOSAGEM DE PROSTAGLANDINA E2}

As concentrações de prostaglandina $\mathrm{E}_{2}\left(\mathrm{PGE}_{2}\right)$ no BAL foram determinadas usando o kit EIA (Cayman Chemical Co, MI, USA). Brevemente, diluições do sobrenadante do BAL (1:10 e 1:100) foram incubadas com o conjugado acetilcolinesterase-PGE2 e com o anticorpo de coelho anti-PGE2 em placas de 96 poços revestidas com anticorpos anti-imunoglobulina de coelho. O método é baseado na competição entre a PGE2 livre e a $\mathrm{PGE}_{2}$ conjugada por uma limitada concentração de anticorpo. Como a concentração de $\mathrm{PGE}_{2}$ conjugada é sempre constante, a coloração do poço irá depender da concentração de PGE2 livre da amostra. Após 18 horas de incubação a $4{ }^{\circ} \mathrm{C}$, as placas foram lavadas e o substrato da enzima (Ellman's Reagent) foi adicionado por $60-120 \mathrm{~min}$ a $25{ }^{\circ} \mathrm{C}$. A absorbância foi lida em 420nm em leitor de microplaca, e a concentração de prostaglandina foi determinada em relação a curva padrão. A coloração é inversamente proporcional a quantidade de PGE2 na amostra.

\subsection{ANÁLISE DOS TRANSCRITOS GÊNICOS}

Foram analisados os transcritos gênicos do rim e pulmão para diferentes citocinas inflamatórias, IL-1 $\beta$, TNF- $\alpha$, IFN- $\gamma$, IL-6, citocina anti-inflamatória, IL-4, quimiocinas, MCP-1, KC e proteína inflamatória de macrófago- $1 \alpha$ ( MIP-1 $\alpha / C C L 3)$, molécula de adesão, ICAM-1, e dos receptores B1 e B2. Os tecidos (pulmão e rim) foram rapidamente congelados em nitrogênio líquido. O RNA total foi isolado dos tecidos renais e pulmonares usando o método de TRIzol (Invitrogen, EUA) e a concentração do RNA foi determinada pela leitura da absorbância em $260 \mathrm{~nm}$ pelo nanodrop (ND1000 Thermo Scientific, Delaware USA). O cDNA foi sintetizado pela transcriptase reversa MML-V (Promega, EUA). O PCR em tempo real foi realizado 
usando o ensaio do PCR quantitativo SYBR Green ou Taqman (Applied Biosystem, EUA). A seqüência dos primers foi desenhada de acordo com a seqüência do RNA publicada no genebank. As condições de termociclamento foram determinadas para cada primer. A análise dos resultados foi feita pelo programa Sequence Detection

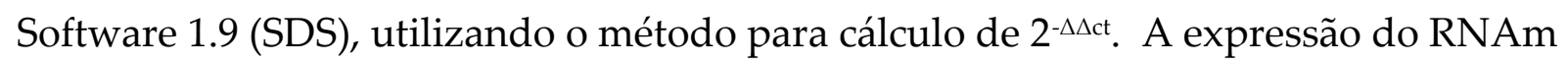
foi normalizada pela abundância do gene endógeno hipoxantina fosforibosil transferase (HPRT). E em seguida normalizados em relação ao grupo controle. Subseqüentemente, todos os resultados foram expressos em unidades arbitrárias em número de vezes em relação ao respectivo grupo controle.

\subsection{BIOPLEX}

O sobrenadante do BAL foi armazenado em $-80^{\circ} \mathrm{C}$ até o momento do uso. $\mathrm{O}$ painel utilizado foi o LINCOplex (Millipore -Billerica, MA, USA). O ensaio foi desenvolvido de acordo com o protocolo do fabricante. Brevemente, o filtro da placa de 96 poços foi lavado com Bioplex Assay Buffer (Bio Rad, Hercules, CA). Em seguida, foram adicionados as beads conjugadas com anticorpos anti-citocinas, lavados com Bioplex Wash Buffer, sendo posteriormente adicionadas as amostras do BAL ou do soro. Seguido de uma incubação de $2 \mathrm{~h}$, a placa foi novamente lavada com o Bioplex Wash Buffer, sendo então adicionado a cada poço o anticorpo de detecção biotinilado para um epítopo diferente da citocina, formando então um sanduíche de anticorpos, incubado por 1h. Após esse período, novas lavagens com o Bioplex Wash Buffer foram realizadas, sendo então adicionada estreptavidina conjugada com PE, que se liga ao anticorpo biotinilado, por 30 minutos. Novas lavagens foram realizadas e as beads foram ressuspensas com Bioplex Assay Buffer e analisadas no Bioplex 200 Suspension Array System/ Luminex (Bio Rad, Hercules, CA) através do Software Bio-Plex 
Manager, versão 4.1 (Bio Rad, Hercules, CA). Os dados apresentados são referentes a no mínimo 100 beads por citocina. Os limites de detecção para as seguintes citocinas analisadas foram: TNF- $\alpha$ 3,36; IFN- $\gamma$ 5,53; IL-1 3 5,56 e MCP-1 20,6 pg/ml.

\subsection{ANÁLISES ESTATÍSTICAS}

Todos os dados foram apresentados através da média \pm erro padrão da média (EPM). Para a análise estatística foi utilizado o teste não paramétrico Mann-Whitney quando dois grupos foram comparados, e o teste de análise de variância (ANOVA) seguido pelo teste de Tukey quando mais de dois grupos foram comparados. A diferença foi considerada significante quando $\mathrm{p}<0,05$. Toda a análise estatística foi realizada pelo programa estatístico GraphPad Prism 4.0. 


\section{RESULTADOS}

\subsection{LESÃO PULMONAR INDIRETA INDUZIDA POR IR RENAL}

\subsubsection{Estabelecimento do modelo de lesão renal por isquemia e reperfusão}

Antes de avaliarmos a LPI propriamente dita, estabelecemos o modelo de lesão renal após a cirurgia de isquemia e reperfusão. Para isso, realizamos cirurgias de isquemia em animais C57Bl/6 por 45 minutos, seguida de reperfusão de diferentes tempos: 6, 12, 24 e 48 horas. Os animais controle (sham) passaram por todo o processo cirúrgico, exceto pelo clampeamento do pedículo renal.

A disfunção renal após a lesão por IR foi avaliada pelas dosagens de creatinina e uréia séricas e pode ser observada na figura 1. A uréia estava aumentada nos animais isquemiados em comparação ao controle (sham) em todos os tempos de reperfusão, 6h (120 \pm 11 vs $52 \pm 1 \mathrm{mg} / \mathrm{dl}), 12 \mathrm{~h}(166 \pm 8$ vs $41 \pm 7 \mathrm{mg} / \mathrm{dl} ; \mathrm{p}<0,05), 24 \mathrm{~h}$ ( $215 \pm 34$ vs $48 \pm 5,5 \mathrm{mg} / \mathrm{dl} ; \mathrm{p}<0,05)$ e $48 \mathrm{~h}(164 \pm 28$ vs $58 \pm 8 \mathrm{mg} / \mathrm{dl})$. O mesmo aconteceu com a creatinina em $6 \mathrm{~h}(1,2 \pm 0,2$ vs $0,6 \pm 0,1 \mathrm{mg} / \mathrm{dl} ; \mathrm{p}<0,05), 12 \mathrm{~h}(1,7 \pm 0,2$ vs $0,5 \pm 0,2$ $\mathrm{mg} / \mathrm{dl} ; \mathrm{p}<0,05), 24 \mathrm{~h}(2.6 \pm 0,1 \mathrm{vs} 0,5 \pm 0,2 \mathrm{mg} / \mathrm{dl} ; \mathrm{p}<0,05)$ e $48 \mathrm{~h}(1,4 \pm 0,5$ vs $0,6 \pm 0,1$ $\mathrm{mg} / \mathrm{dl})$, mostrando a eficiência do modelo com relação à indução de dano renal após a IR. 

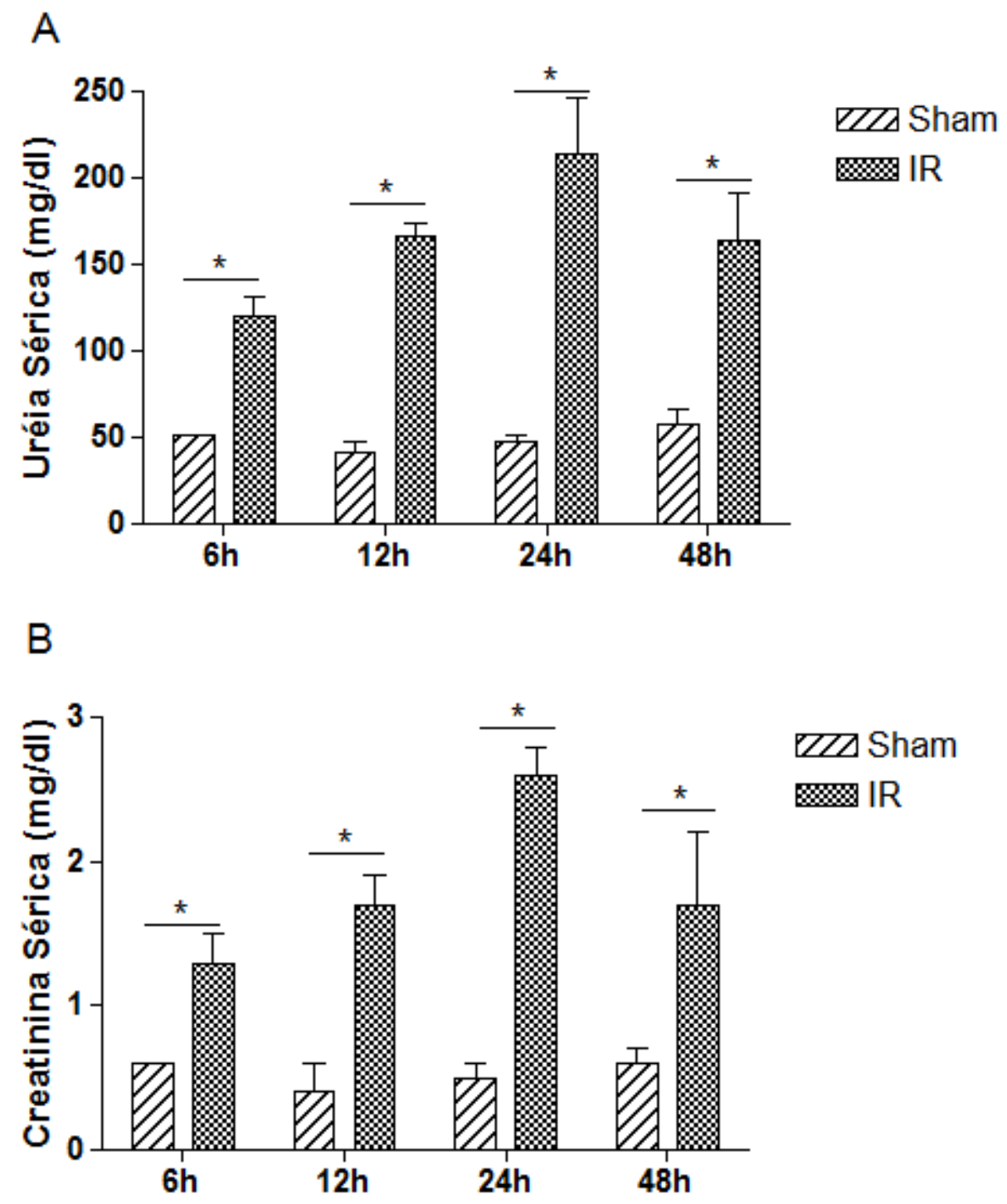

Figura 1. Função Renal após 24 horas da cirurgia de isquemia e reperfusão (IR) renal. As amostras de sangue foram coletadas 6, 12, 24 e 48 horas após a cirurgia de isquemia. (A) Concentração sérica de uréia quantificada pelo kit de dosagem de uréia da Lab Test. (B) Concentração sérica de creatinina quantificada pelo método de Jaffé modificado; Os animais isquemiados apresentaram aumento nos níveis séricos de uréia e creatinina em relação ao controle. Os valores foram expressos em média \pm EPM. ${ }^{*} \mathrm{p}<0,05, \mathrm{n}=5$. 


\subsubsection{Avaliação da Função Pulmonar após lesão induzida por IR renal}

Após estabelecermos o modelo de lesão de IR, escolhemos um tempo precoce, mas que já demonstrava presença de lesão renal pelo aumento de uréia e creatinina (6 horas), e o tempo do pico da lesão renal (24 horas) para analisarmos a função pulmonar. Para isso, realizamos cirurgia de 45 minutos de isquemia em camundongos C57Bl/6, seguida de 6 ou 24 horas de reperfusão, e analisamos a função pulmonar.

\subsubsection{Hiperreatividade pulmonar}

Antes do sacrifício dos animais, os mesmos foram colocados em câmara pletismográfica onde receberam doses de concentração crescente de metacolina $(3,6$, 12 e $25 \mathrm{mg} / \mathrm{ml}$ ), e o aumento da pausa respiratória (penh) foi obtido para análise de hiperreatividade pulmonar. Os resultados foram expressos em duas maneiras: um gráfico com a média dos valores do penh para cada dose de metacolina, e outro gráfico com a área sob a curva dos valores obtidos do penh. Conforme podemos observar na figura 2, com 6 horas após isquemia, não houve diferença significativa entre o grupo isquemiado e o grupo controle. Entretanto, a figura 2C mostra que, com 24 horas, esta diferença é significante entre o grupo isquemiado e o controle $(116 \pm 8$ vs $33 \pm 0,2, p<0,05)$, respectivamente. 

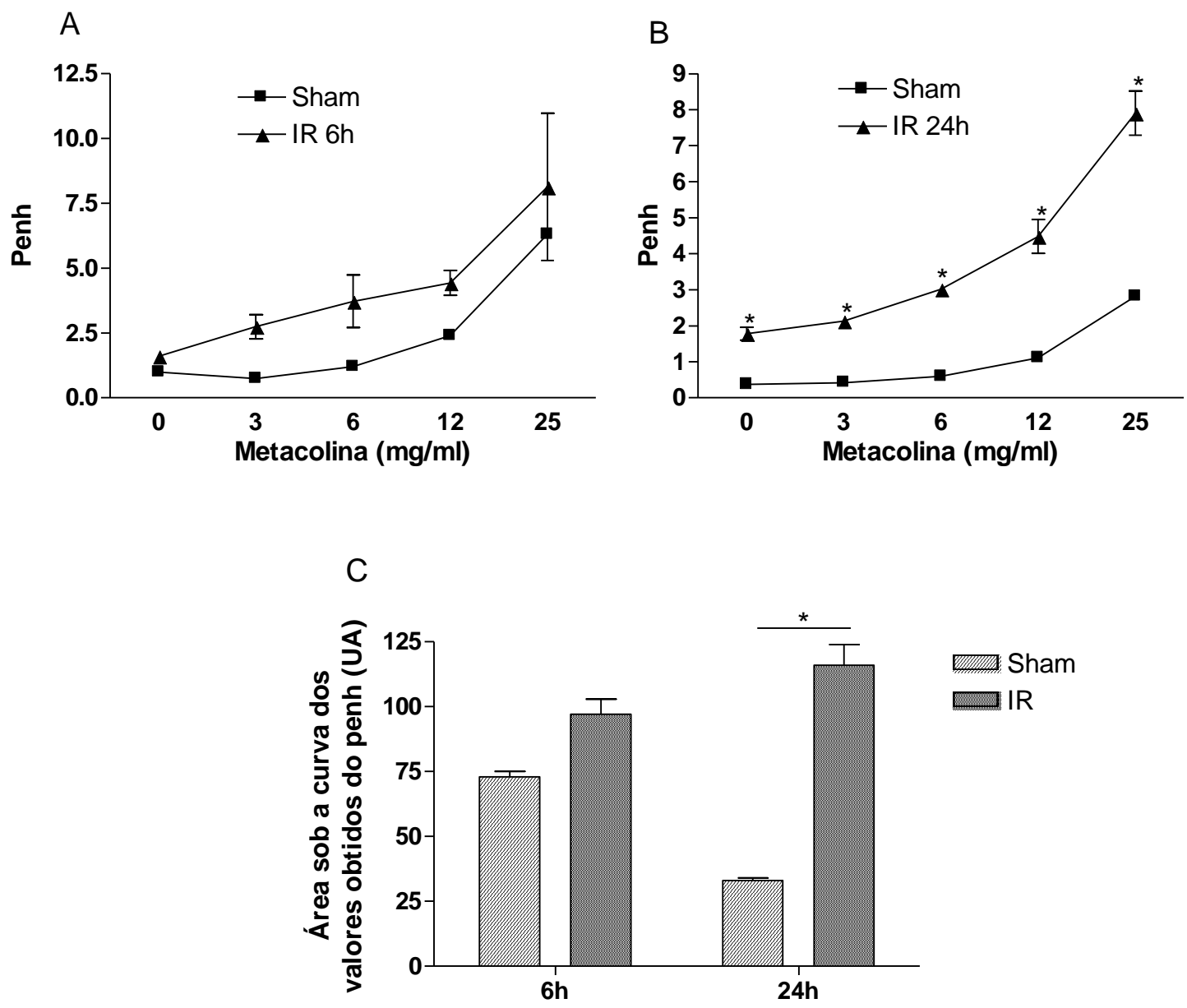

Figura 2. Hiperreatividade pulmonar 6 e 24 horas após IR renal. Animais controle e isquemiados, (A) 6 e (B) 24 horas após cirurgia, foram colocados em câmara pletismográfica (BUXCO) e após nebulização com doses crescentes de metacolina $(3,6,12$ e $25 \mathrm{mg} / \mathrm{ml})$ foi medido por 5 minutos o aumento da pausa respiratória (Penh) e feito uma média. (A) e (B) média dos valores de penh obtidos em diferentes concentrações de metacolina. (C) Os valores do penh foram expressos na forma de área sob a curva da dose resposta com metacolina. Animais isquemiados apresentaram uma maior reatividade brônquica à metacolina em relação ao sham. * $\mathrm{p}<0,05, \mathrm{n}=10$. 


\subsubsection{Células totais no BAL}

O BAL foi coletado no sacrifício dos animais, com 6 ou 24 horas após cirurgia de isquemia, para a contagem de células totais. Com 6 horas de reperfusão, não foi observada diferença entre o número de células no BAL do grupo isquemiado e sham, conforme ilustra a figura 3. Já com 24 horas, foi observado um aumento no número de células totais dos animais isquemiados em relação ao sham $\left(8 \times 10^{4} \pm 0,5\right.$ vs $\left.2 \times 10^{4} \pm 0,2, \mathrm{p}<0,05\right)$.

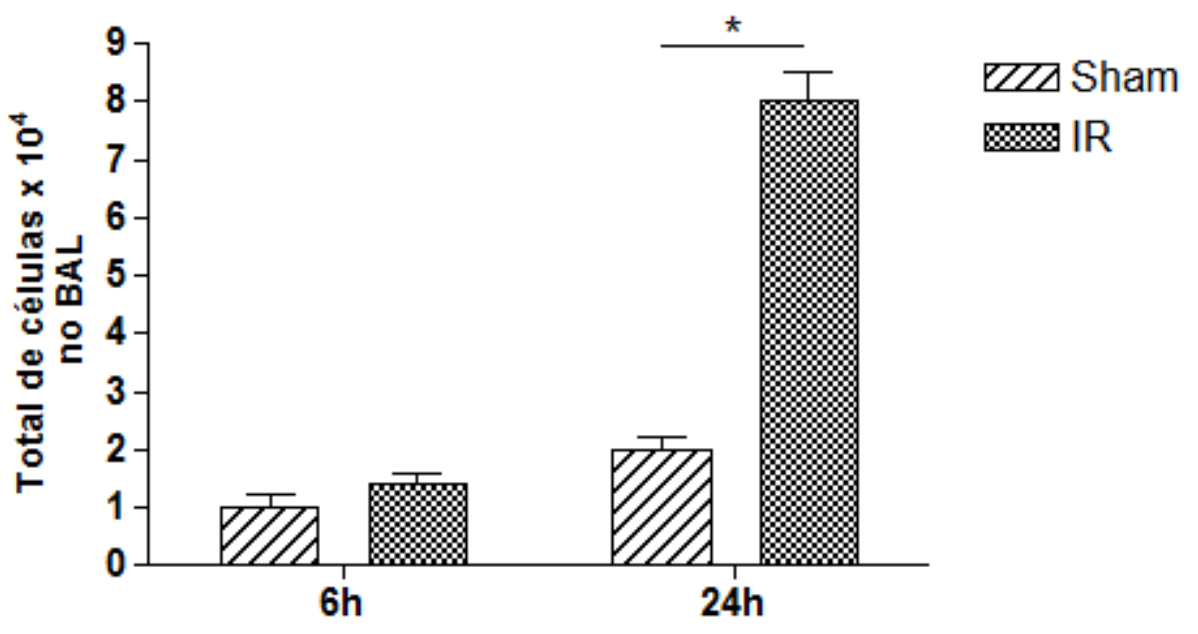

Figura 3. Número total de células no BAL 6 e 24 horas após IR renal. O BAL foi coletado após sacrifício dos animais submetidos a 6 ou 24 horas de reperfusão. As células totais foram coradas com cristal violeta e ácido acétido e contadas em câmara de neubauer. Os animais isquemiados apresentaram um aumento significativo no número de células totais em relação ao controle com $24 \mathrm{~h}$ de reperfusão. Os valores foram expressos em média \pm EPM. ${ }^{*} \mathrm{p}<0,05, \mathrm{n}=10$. 


\subsubsection{Proteína total no BAL}

O BAL coletado após sacrifício dos animais foi centrifugado e o sobrenadante foi utilizado para dosagem de proteína total. Assim como o número de células, a proteína total também não foi diferente entre os animais isquemiados e os controles com 6 horas de reperfusão. Entretanto, com 24 horas, os animais isquemiados apresentaram maior quantidade de proteína total no BAL em relação aos controles (319 \pm 70 vs $88 \pm 12 \mu \mathrm{g} / \mathrm{ml}, \mathrm{p}<0,05)$, como podemos observar na figura 4 .

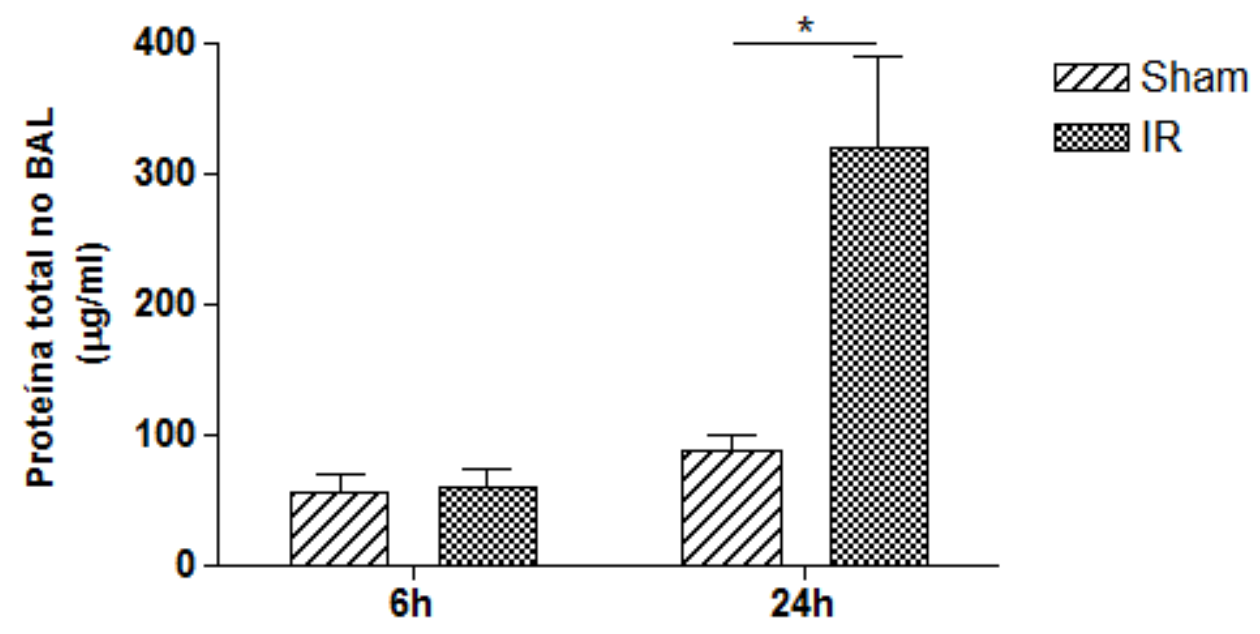

Figura 4. Proteína total no BAL 6 e 24 horas após IR renal. No sacrifício dos animais, o BAL foi coletado, centrifugado, e o sobrenadante foi utilizado para dosagem de proteína total pelo kit dc-protein da BioRad. O grupo isquemiado apresentou um aumento significativo na proteína total em relação ao grupo controle com $24 \mathrm{~h}$ de reperfusão. Os valores foram expressos em média \pm EPM. * ${ }^{*}<0,05, n=10$. 


\subsubsection{Expressão de iNOS e COX-2 no pulmão e prostaglandina no BAL}

Escolhemos o tempo onde a lesão no pulmão foi maior, 24 horas após a cirurgia de isquemia renal, e analisamos através de western blot a expressão de iNOS e COX-2 do pulmão coletado dos animais isquemiados e controle. Além disso, dosamos no BAL, um dos produtos da COX-2, a prostaglandina $\mathrm{E}_{2}\left(\mathrm{PGE}_{2}\right)$.

A iNOS é uma enzima que produz óxido nítrico, aumentando a inflamação. A COX-2 é uma enzima que age sobre o ácido araquidônico, liberando mediadores inflamatórios como prostaglandina. Ambas as enzimas são induzidas em processos inflamatórios e podem estar envolvidas com disfunção endotelial.

A densidade das bandas do western blot de iNOS e COX-2 do tecido pulmonar pode ser observada na figura 5. Com 24 horas de reperfusão, tanto a iNOS quanto a COX-2 estavam aumentadas no pulmão dos animais isquemiados em comparação ao controle (iNOS $1172 \pm 126,2$ vs $529 \pm 59$ UA ; COX-2 $1084 \pm 97,09$ vs $129 \pm 10 \mathrm{UA} ; \mathrm{p}<0,05)$. 
Sham

IRI
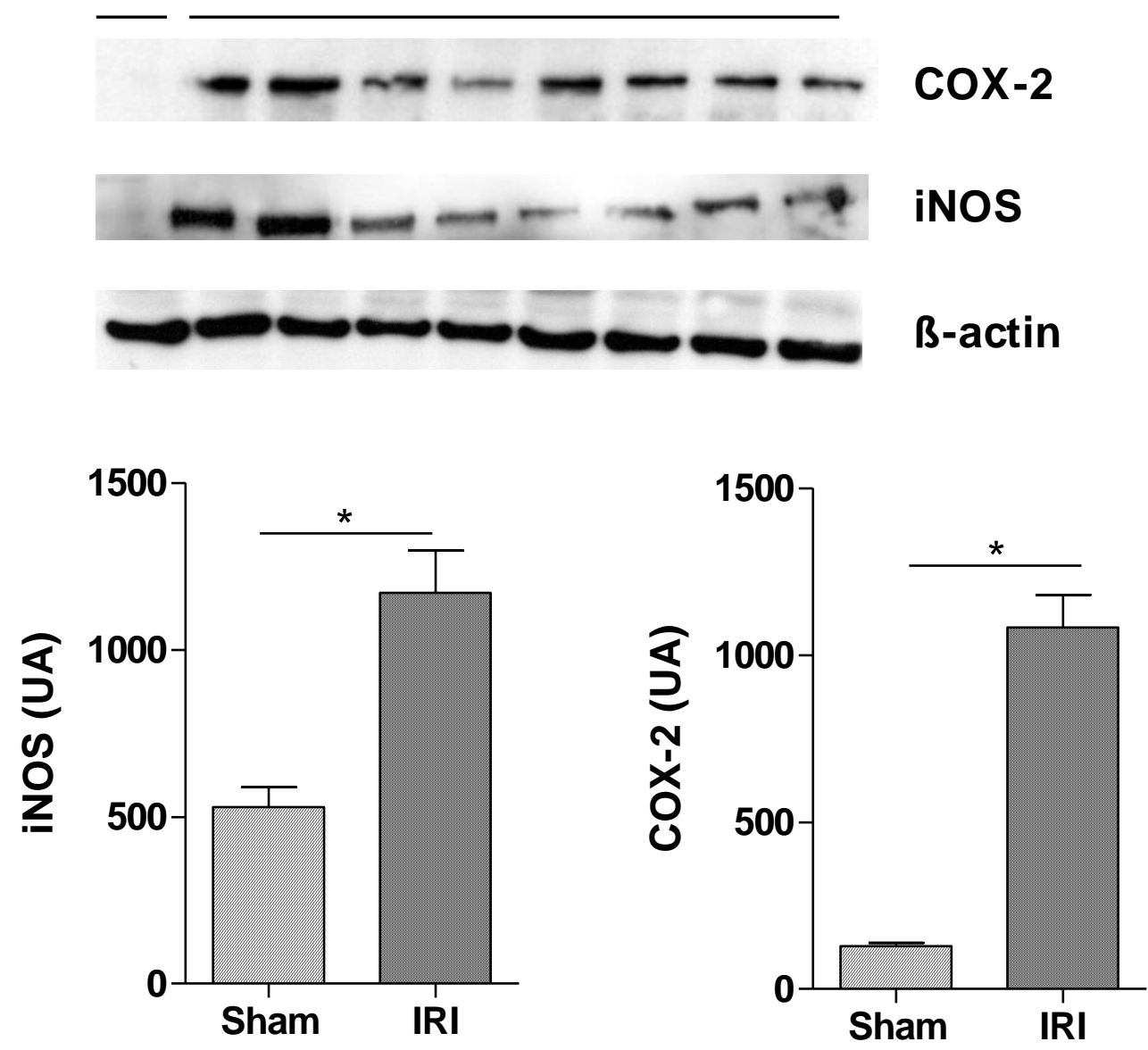

Figura 5. Expressão de iNOS e COX-2 no pulmão 24 horas após IR renal. O tecido pulmonar foi coletado 24 horas após cirurgia de IR renal para quantificação das proteínas através de western blot. Os gráficos representam a média da densidade das bandas de iNOS e COX-2 normalizadas por $\beta$-actina. Os valores foram expressos em média \pm EPM. ${ }^{*} \mathrm{p}<0,05, \mathrm{n}=8$. 
Além disso, como podemos observar na figura 6, dosamos a PGE2 no BAL 24 horas após IR renal. Os animais isquemiados apresentaram um aumento nos níveis de PGE2 quando comparados aos animais controles $(320 \pm 21$ vs $18 \pm 2 ; \mathrm{p}<0,05)$.

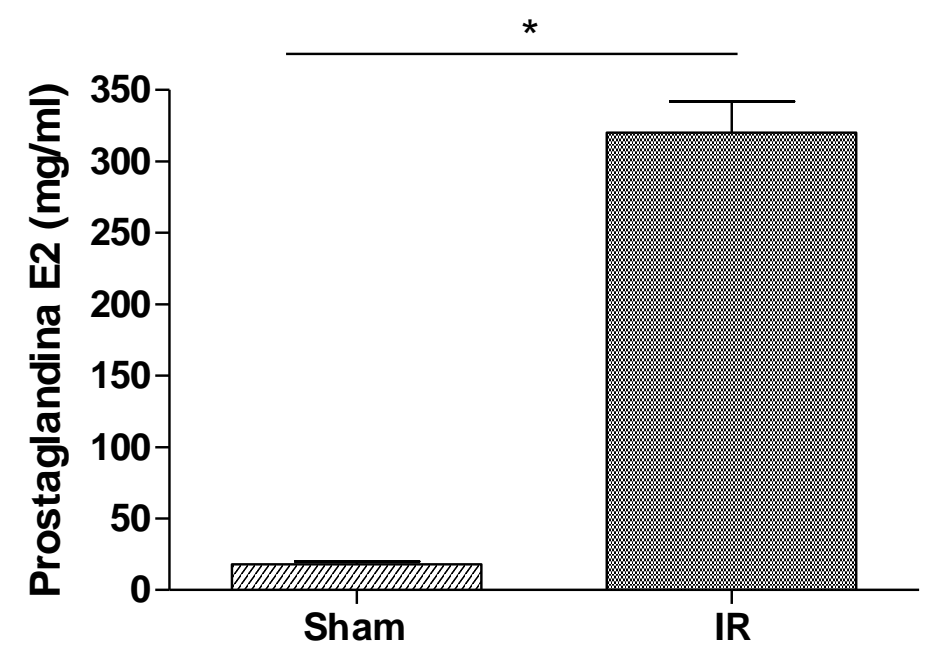

Figura 6. Dosagem de prostaglandina $\mathrm{E}_{2}\left(\mathrm{PGE}_{2}\right)$ no BAL 24 horas após IR renal. No sacrifício dos animais, o BAL foi coletado, centrifugado, e o sobrenadante foi utilizado para dosagem de PGE2. O grupo isquemiado (IR) apresentou um aumento nos níveis de $\mathrm{PGE}_{2}$ em relação ao grupo controle (sham). Os valores foram expressos em média \pm EPM. ${ }^{*} \mathrm{p}<0,05, \mathrm{n}=5$. 


\subsubsection{Expressão de transcritos gênicos de citocinas, quimiocinas e molécula de adesão no rim e pulmão}

Avaliamos diferentes transcritos gênicos de citocinas pró-inflamatórias, quimiocina, molécula de adesão e citocina anti-inflamatória no rim (figura 7A) e pulmão (figura 7B) 24 horas após IR renal. O rim e pulmão foi coletado com 24 horas de reperfusão e o RNA total foi extraído. Foi sintetizado o cDNA e realizado o PCR em tempo real para quantificação relativa dos transcritos gênicos. As amostras foram normalizadas pelo controle endógeno HPRT e em seguida pelo grupo controle,

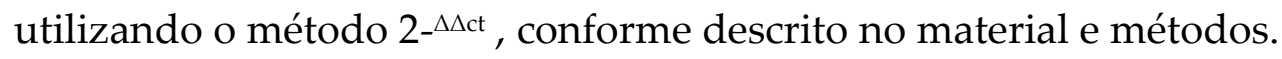

Com 24 horas de reperfusão, os animais isquemiados apresentaram um aumento na expressão das citocinas pró-inflamatórias (IL-1 $\beta$, TNF- $\alpha$, IL-6) e quimiocinas (MCP-1 e KC) em relação aos controles. Este aumento foi observado tanto no rim quanto no pulmão. Não houve nenhuma diferença significativa após IR renal na expressão da quimiocina CCL3 no rim e pulmão.

A expressão da citocina anti-inflamatória IL-4, estava diminuída no rim e pulmão nos animais isquemiados em relação ao controle.

A expressão de ICAM-1, uma molécula de adesão que é expressa no endotélio e facilita a infiltração de leucócitos, estava aumentada no pulmão dos animais isquemiados em comparação ao controle. Entretanto, no rim, a expressão de ICAM-1 estava diminuída. 

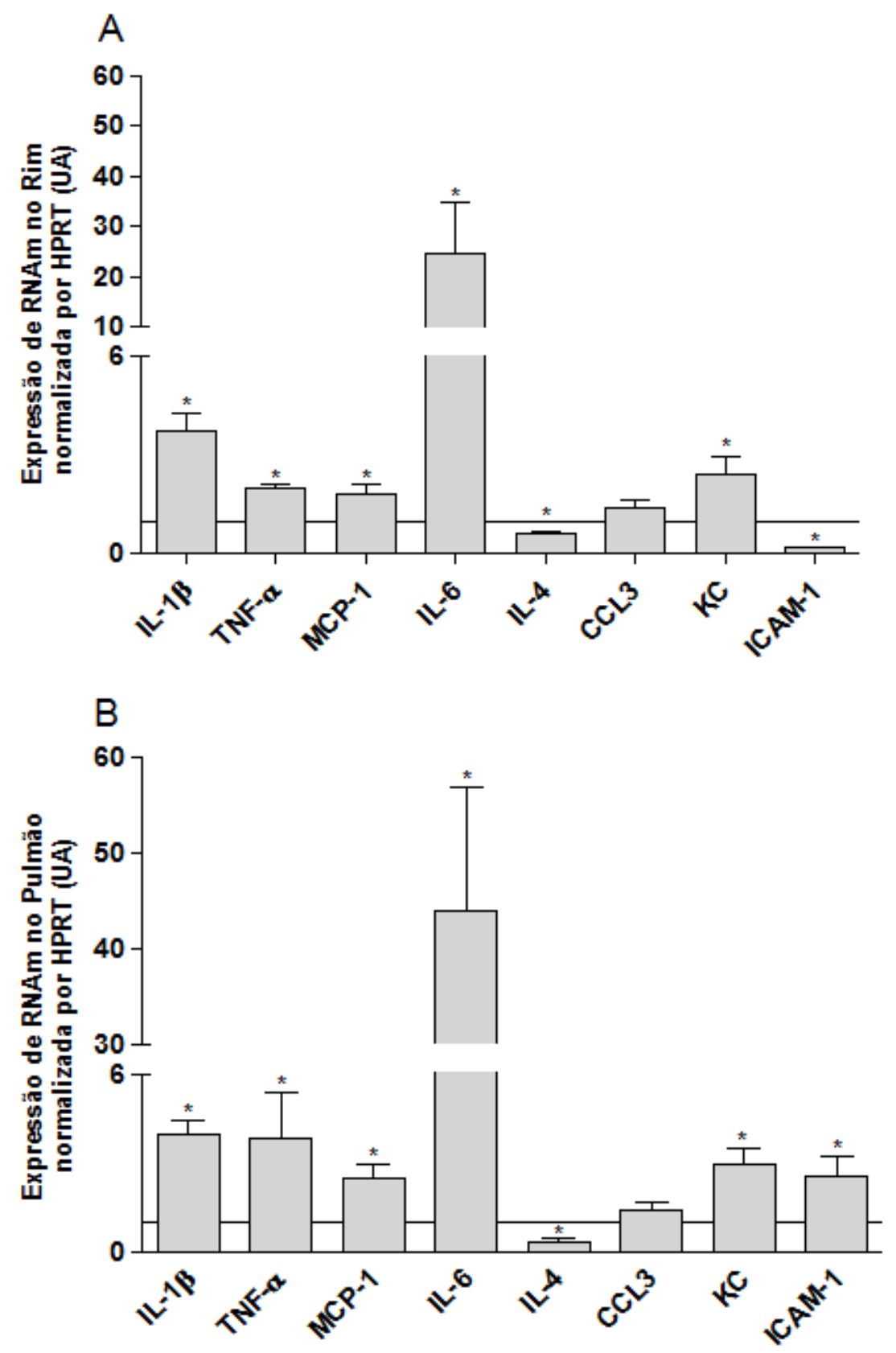

Figura 7. Expressão dos transcritos gênicos de citocinas, quimiocinas e molécula de adesão no Rim (A) e Pulmão (B) 24 horas após IR renal. O pulmão foi coletado 24 horas após a lesão de IR renal. A quantificação do RNAm foi realizada por PCR em tempo real e normalizada por HPRT. Método utilizado para cálculo 2- $\Delta \Delta$ ct. Os valores estão expressos em unidades arbitrárias em número de vezes em relação ao sham. Os valores foram expressos em média \pm EPM. ${ }^{*} \mathrm{p}<0,05, \mathrm{n}=8$. A linha corresponde ao valor do grupo controle. 


\subsubsection{Dosagem de citocinas e quimiocina no soro após IR renal}

Quantificamos algumas citocinas pró-inflamatórias e uma quimiocina no soro para avaliarmos se estes mediadores poderiam estar sendo liberados pelo rim e, sistemicamente, ativando a resposta inflamatória no pulmão. Como ilustra a figura 8, as citocinas estavam significantemente aumentadas no soro de animais isquemiados em relação aos controles 24 horas após a cirurgia (IL-1 $234 \pm 10$ vs 34ะ3; TNF- $\alpha 91 \pm 10$ vs $19 \pm 1,4, \quad \mathrm{p}<0,05)$. A quimiocina MCP-1 também estava aumentada no grupo isquemiado (MCP-1 178 \pm 26 vs 35 $\pm 3.7 \mathrm{pg} / \mathrm{ml}, \mathrm{p}<0,05)$. A IL-6 parece estar

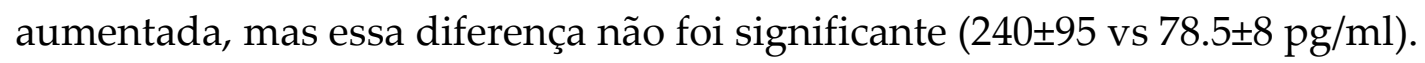

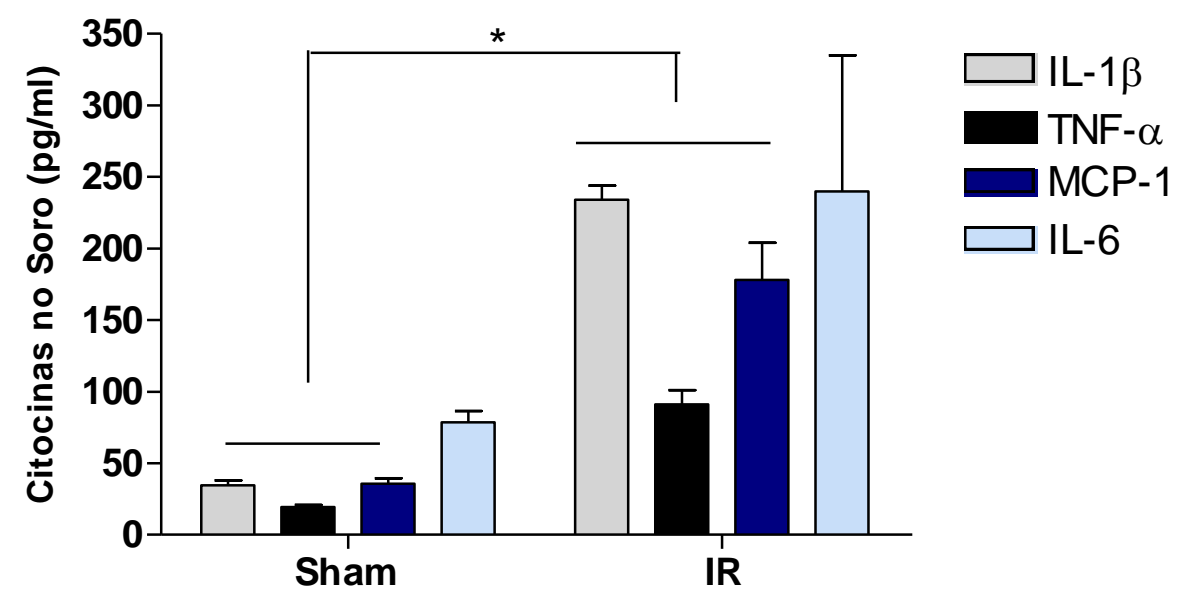

Figura 8. Quantificação de citocinas e quimiocina no soro 24 horas após IR renal. O sangue foi coletado após o sacrifício dos animais, centrifugado, e o soro foi utilizado para dosagem de citocinas e quimiocina através da técnica de Bioplex. Animais isquemiados apresentaram aumento das citocinas e quimiocina no soro 24 horas após cirurgia. Os valores foram expressos em média \pm EPM. * $\mathrm{p}<0,05, \mathrm{n}=5$. 


\subsubsection{Expressão dos receptores B1 e B2 no rim e pulmão após lesão de IR renal}

Após verificarmos que mediadores inflamatórios estavam sendo liberados pelo rim no sangue, e possivelmente ativando a inflamação no pulmão, contribuindo para uma lesão pulmonar secundária à lesão de IR renal, resolvemos estudar se os receptores de bradicinina B1 e B2 poderiam estar envolvidos nesta lesão. Sendo assim, verificamos suas expressões no rim e pulmão após cirurgia de IR renal.

Após as cirurgias de isquemia renal, o rim e o pulmão dos camundongos foram coletados em diferentes tempos de reperfusão (30 minutos, 6, 12, 24 e 48 horas) para extração de RNA total, síntese do cDNA e realização de PCR em tempo real para análise dos transcritos gênicos dos receptores B1 e B2.

No rim, a expressão do receptor B2 estava bem aumentada nos animais isquemiados em relação ao sham com $12 \mathrm{~h}(4,72 \pm 0,80$ vs $1,0 \mathrm{UA} ; \mathrm{p}<0,05)$ e 24 horas $(5,38 \pm 1,87$ vs 1,0 UA; $p<0,05)$ de reperfusão (figura 9A).

No pulmão, tanto a expressão de B1 quanto B2 estavam aumentadas com 24

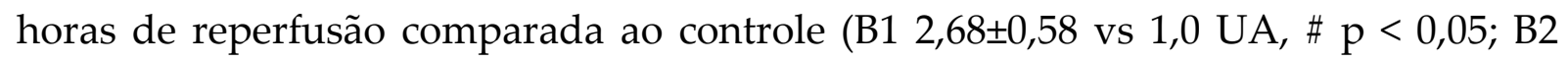
$2,77 \pm 0,63$ vs $\left.1,0 \mathrm{UA},{ }^{*} \mathrm{p}<0,05\right)$ (figura 9B). 

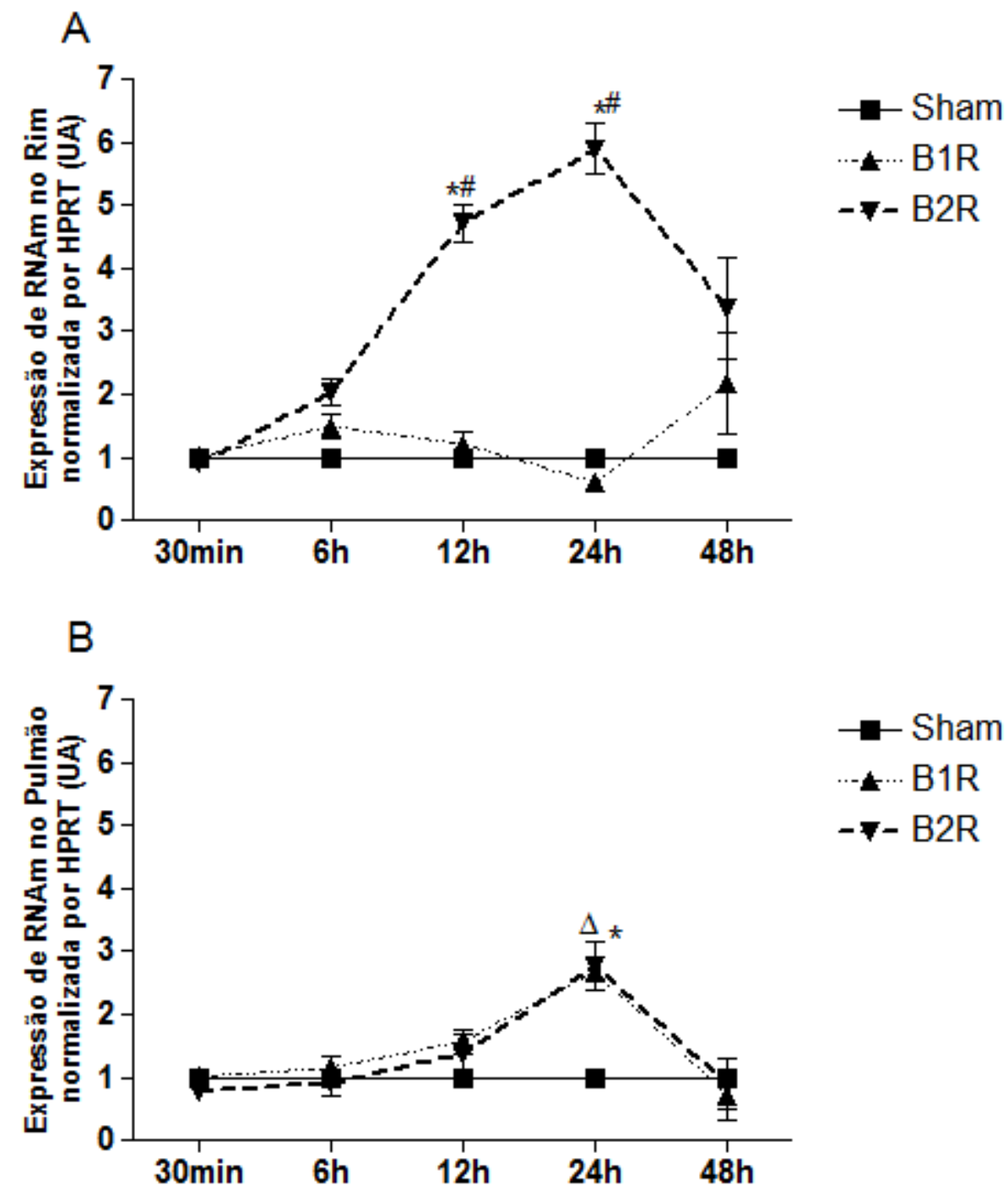

Figura 9. Cinética da expressão dos transcritos gênicos dos receptores B1 e B2 no rim (A) e pulmão (B) após IR renal. A quantificação do RNAm foi realizada por PCR em tempo real dos rins e pulmões coletados com $30 \mathrm{~min}, 6$, 12, 24 e 48h de reperfusão. Método utilizado para cálculo $2^{-\Delta \Delta c t}$. A expressão de B2R estava aumentada nos animais isquemiados 24 horas após cirurgia. No pulmão, tanto o B1R quanto o B2R estavam aumentados nos animais isquemiados. Os valores estão expressos em unidades arbitrárias em n-vezes diferente em relação ao sham. Os valores foram expressos em média \pm EPM. * B2R em relação ao sham, \# B2R em relação ao B1R, $\Delta$ B1R em relação ao sham, ${ }^{*} \# \mathrm{p}<0,05, \mathrm{n}=5$. 


\subsubsection{Avaliação pulmonar após tratamento com antagonista de B1R (R954) na lesão induzida por IR renal}

Após verificarmos que a lesão de IR foi capaz de modular a expressão dos receptores da bradicinina no pulmão, decidimos usar o antagonista do B1R para verificar se o mesmo poderia estar envolvido na lesão pulmonar após IR renal. Como os dois receptores estavam aumentados no pulmão com 24 horas após IR renal, escolhemos bloquear o receptor induzível (B1R), uma vez que nosso laboratório já havia verificado seu papel deletério na lesão de IR renal [92].

Para isso, camundongos C57Bl/6 passaram por 45 minutos de isquemia renal, e com 30 minutos e 6 horas de reperfusão foram tratados com $200 \mu \mathrm{g} / \mathrm{kg}$ de antagonista de B1R (R954) em $20 \mu \mathrm{l}$ de salina por via intra-nasal. Animais controle receberam somente salina.

Antes de avaliarmos a função pulmonar, verificamos se o inibidor de B1R administrado por via nasal, estava promovendo algum efeito sistêmico influenciando na lesão renal. Como podemos observar na figura 10, o tratamento com R954 não teve nenhum efeito na lesão renal. Ambos os grupos de animais isquemiados, tratado

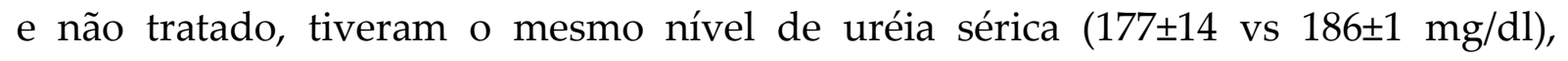
respectivamente. 


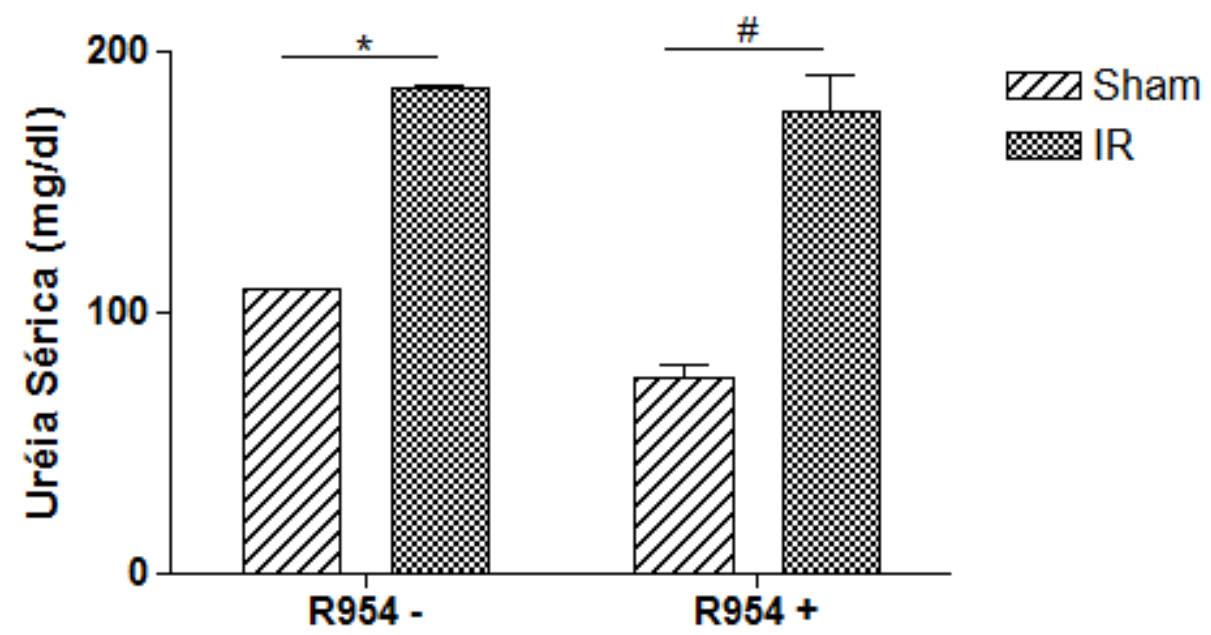

Figura 10. Função Renal 24 horas após IR renal e tratamento intra-nasal com inibidor de B1R (R954). Animais C57Bl/6 passaram por 45 minutos de cirurgia de IR e, com 30min e 6 horas de reperfusão receberam $200 \mu \mathrm{g} / \mathrm{kg}$ de inibidor de B1R (R954) por via intra-nasal. Com 24 horas os animais foram sacrificados, o sangue coletado, e a uréia dosada. Os valores foram expressos em média \pm EPM. * ${ }^{*} \mathrm{p}<0,05, \mathrm{n}=10$.

\subsubsection{Hiperreatividade pulmonar}

Ao avaliarmos a hiperreatividade pulmonar, percebemos que os animais isquemiados que receberam tratamento com R954 intra-nasal, apresentaram uma melhora significativa dos valores do penh comparado ao grupo isquemiado que recebeu apenas salina $(87 \pm 28$ vs $185 \pm 30 \mathrm{UA}, \mathrm{p}<0,05)$ respectivamente (Figura 11). 

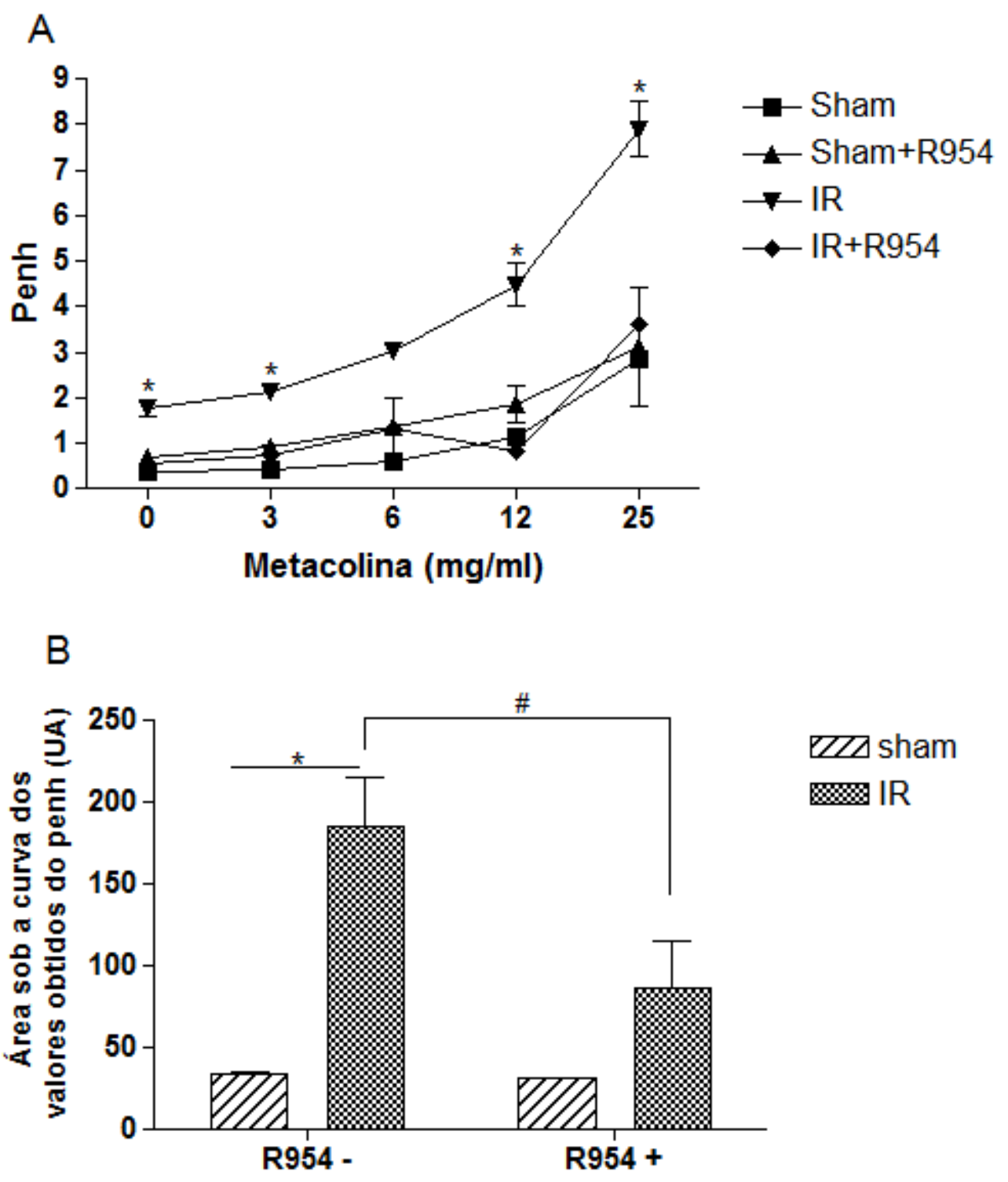

Figura 11. Hiperreatividade pulmonar após tratamento com inibidor de B1R (R954) em lesão induzida por IR renal. Animais receberam $200 \mu \mathrm{g} / \mathrm{kg}$ de R954 por via intra-nasal 30 min e 6 h após IR renal. Após 24 h de reperfusão, foram colocados em câmara pletismográfica (BUXCO) e após nebulização com doses crescentes de metacolina $(3,6,12$ e $25 \mathrm{mg} / \mathrm{ml})$ foi medido por 5 minutos o aumento da pausa respiratória (Penh) e feito uma média. (A) Média dos valores de penh obtidos em diferentes concentrações de metacolina. (B) Os valores do penh foram expressos na forma de área sob a curva da dose resposta com metacolina. Animais isquemiados que receberam tratamento apresentaram menor hiperreatividade pulmonar à metacolina em relação aos isquemiados sem tratamento. Os valores foram expressos em média \pm EPM. \#* $\mathrm{p}<0,05, \mathrm{n}=10$. 


\subsubsection{Células totais no BAL}

Apesar da melhora na hiperreatividade, podemos verificar na figura 12, que o tratamento com R954 não foi capaz de reduzir o número de células no BAL.

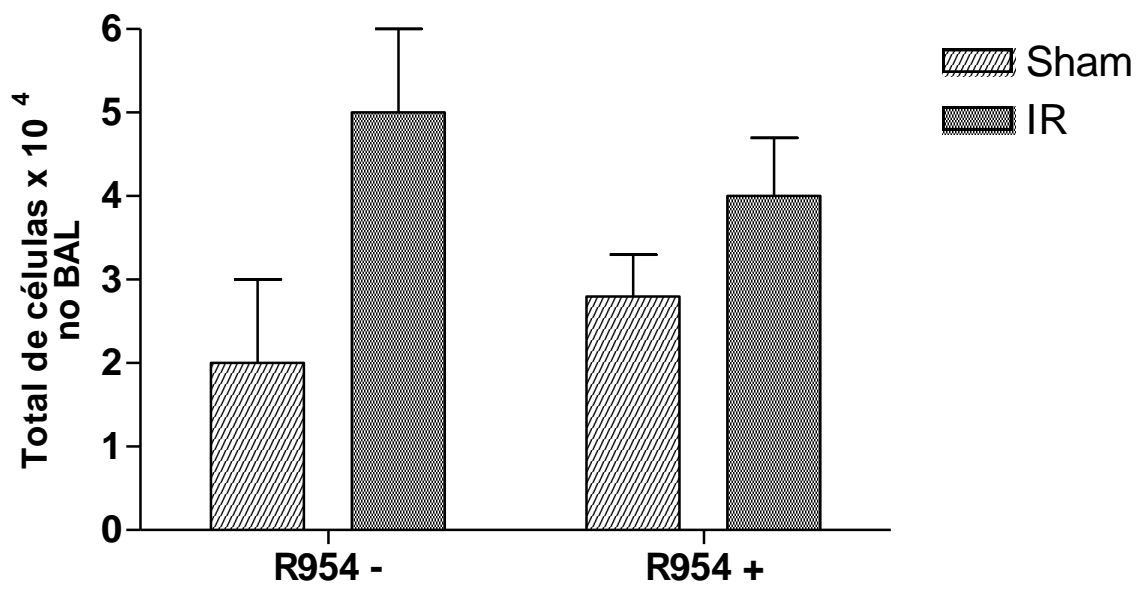

Figura 12. Número total de células no BAL após tratamento com inibidor de B1R (R954) em lesão induzida por IR renal. Animais receberam $200 \mu \mathrm{g} / \mathrm{kg}$ de R954 por via intranasal $30 \mathrm{~min}$ e $6 \mathrm{~h}$ após IR renal. Após $24 \mathrm{~h}$ de reperfusão, os animais foram sacrificados e o BAL foi coletado para contagem de células totais. Os valores foram expressos em média $\pm \mathrm{EPM}, \mathrm{n}=10$. 


\subsubsection{Proteína Total no BAL}

Podemos verificar na figura 13, que o tratamento com inibidor de B1R (R954) foi capaz de inibir o aumento nos níveis de proteína total no sobrenadante do BAL de animais isquemiados de $1011 \pm 31 \mu \mathrm{g} / \mathrm{ml}$ para $220 \pm 10 \mu \mathrm{g} / \mathrm{ml}$.

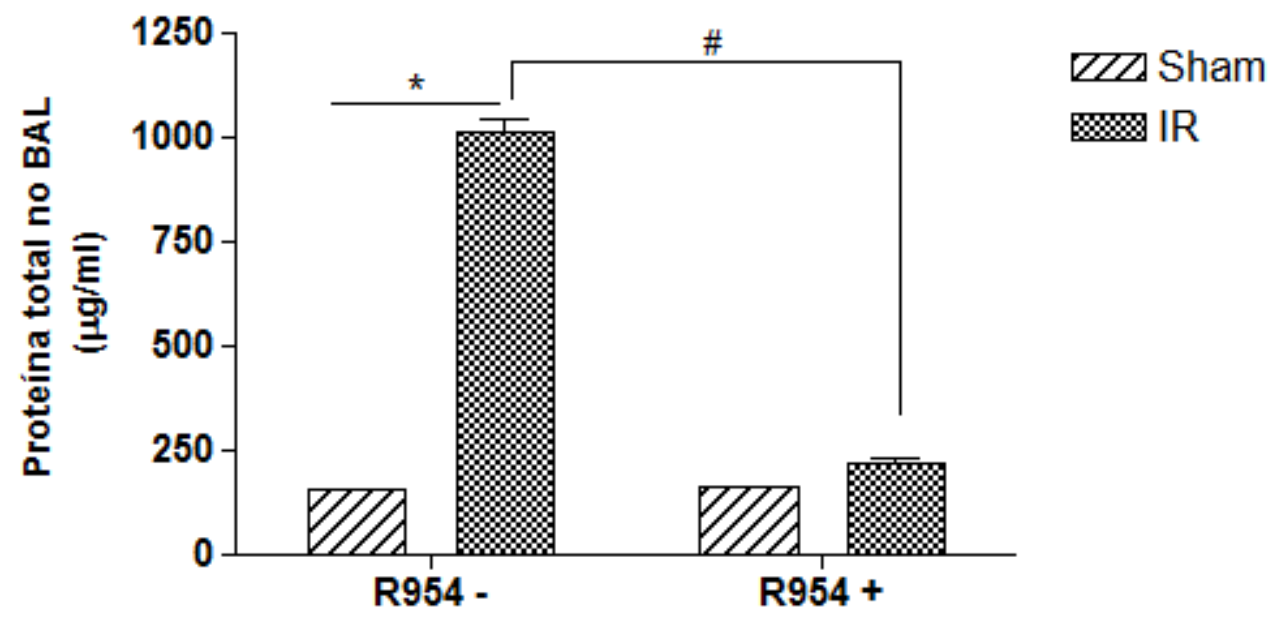

Figura 13. Proteína total no BAL após tratamento com inibidor de B1R (R954) em lesão induzida por IR renal. Animais receberam $200 \mu \mathrm{g} / \mathrm{kg}$ de R954 por via intra-nasal 30min e $6 \mathrm{~h}$ após IR renal. Após $24 \mathrm{~h}$ de reperfusão, os animais foram sacrificados, e o sobrenadante do BAL coletado foi utilizado para dosagem de proteína total . O aumento de proteína no BAL observado nos animais isquemiados foi inibido quando os animais foram tratados com antagonista de B1R. Os valores foram expressos em média \pm EPM. *\# $\mathrm{p}<0,05, \mathrm{n}=10$. 


\subsubsection{Expressão gênica de citocinas e quimiocina após tratamento com antagonista de B1R na lesão induzida por IR renal}

Analisamos alguns transcritos para as citocinas pró-inflamatórias que vimos anteriormente que estavam aumentadas no pulmão após IR renal, após tratamento com inibidor de B1R (R954). Como podemos observar na figura 14, o tratamento com o inibidor R954 diminui a expressão destas citocinas no pulmão (TNF- $\alpha 3,8 \pm 0,8$ para

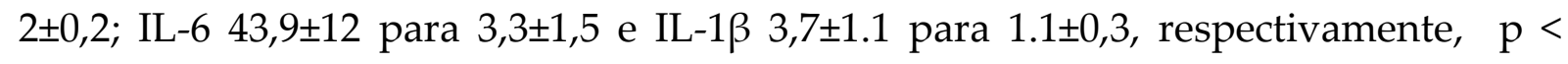
0,05). O mesmo acontece com a quimiocina $K C(1,3 \pm 0,3$ para $0,6 \pm 0,2, p<0,05)$. A expressão da citocina anti-inflamatória IL-4 que estava diminuída no pulmão após IR renal em relação ao controle $(0.2 \pm 0,1$ vs $1 \mathrm{UA}$, respectivamente, $\mathrm{p}<0,05)$ teve sua expressão aumentada com o tratamento de inibidor de B1R $(0.2 \pm 0,1$ para $0.9 \pm 0,1, p<$ 0,05). Por outro lado, a expressão da citocina anti-inflamatória IL-10 estava aumentada no pulmão após IR renal e teve sua expressão diminuída após tratamento

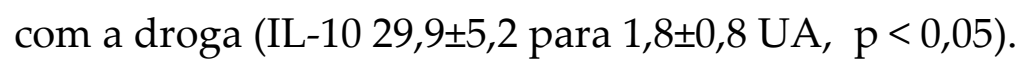




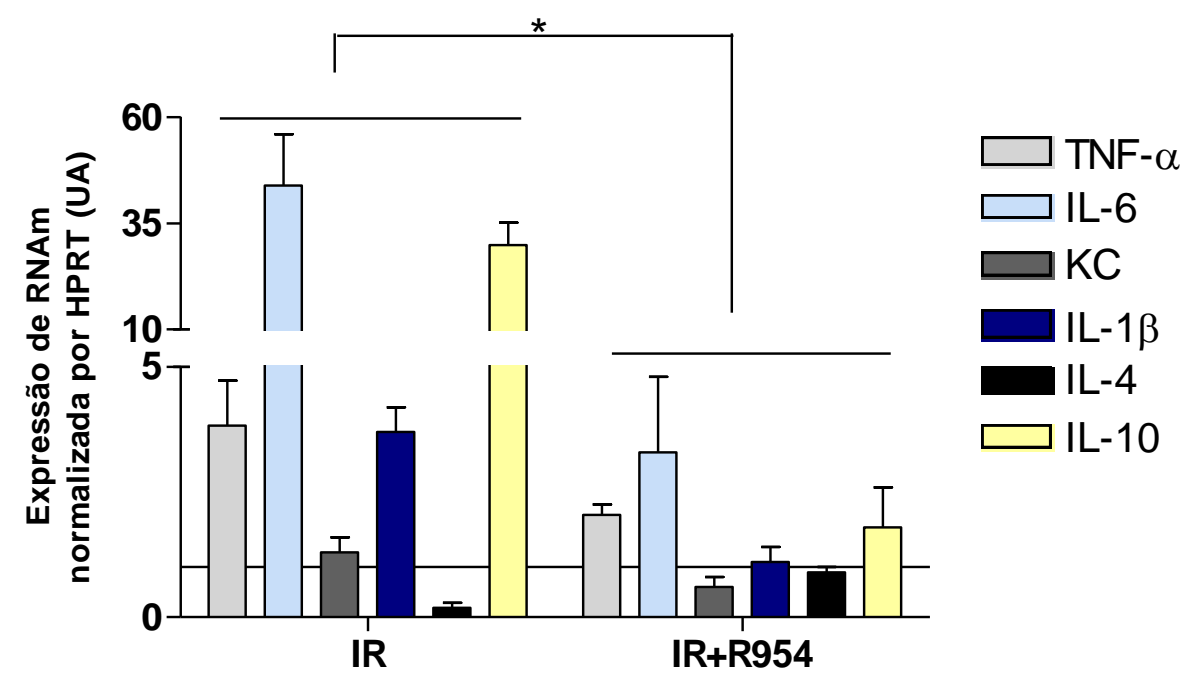

Figura 14. Expressão dos transcritos gênicos de citocinas e quimiocina no pulmão após tratamento com inibidor de B1R (R954) em lesão induzida por IR renal. O pulmão dos animais foi coletado 24 horas após cirurgia de IR renal e tratamento com inibidor de B1R (R954). A quantificação do RNAm foi realizada por PCR em tempo real e normalizada por HPRT. Método utilizado para cálculo 2- $\Delta \Delta$ ct. A expressão de mediadores pró-inflamatórios é significativamente reduzida no pulmão dos animais tratados com inibidor de B1R em relação aos não tratados. Os valores estão expressos em unidades arbitrárias em número de vezes em relação ao grupo controle. Os valores foram expressos em média \pm EPM. * $\mathrm{p}<$ 0,05, n=8. A linha sólida representa a expressão do grupo controle. 


\subsection{LESÃO PULMONAR DIRETA INDUZIDA POR INALAÇÃO DE LPS}

\subsubsection{Estabelecimento do modelo de lesão induzida por LPS}

Para estabelecermos o modelo de lesão por LPS, camundongos C57B1/6 foram anestesiados com cetamina e xilazina e tratados com $20 \mu \mathrm{g} / \mathrm{animal}$ de LPS de E. Coli em $20 \mu \mathrm{l}$ de salina por via intra-nasal. Os animais controles receberam o mesmo volume de salina. Após 6 e 24 horas do tratamento com LPS, a função pulmonar foi avaliada.

\subsubsection{Hiperreatividade Pulmonar}

Após tratamento com LPS, os animais apresentaram um aumento significativo na reatividade pulmonar à metacolina em relação ao grupo controle. As figuras 15A e 15B mostram os valores do penh obtidos com diferentes concentrações de metacolina, 6 horas (A) e 24 horas (B) após inalação de LPS. Os valores obtidos do penh foram expressos na forma de área sob a curva da dose-resposta com metacolina (15C). Tanto com 6 horas $(234 \pm 5$ vs $79 \pm 27$ UA, $p<0,05)$ como 24 horas $(136 \pm 16$ vs $43 \pm 11$ UA, $\mathrm{p}<0,05)$ os animais tratados com LPS apresentaram um aumento significativo na reatividade pulmonar à metacolina em relação ao grupo controle, respectivamente. 

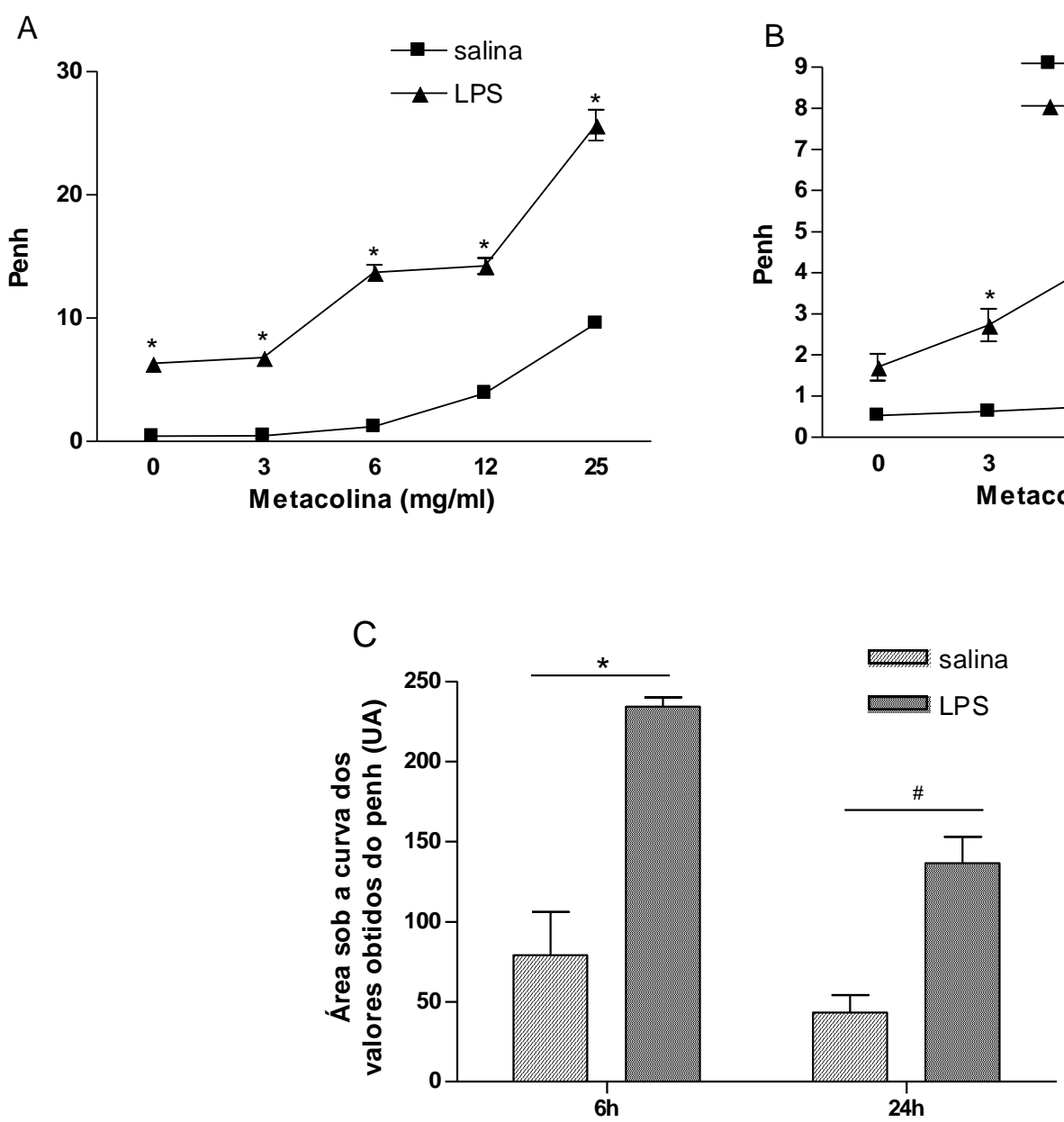

Figura 15. Hiperreatividade pulmonar 6 e 24 horas após inalação de LPS. Animais C57Bl/6 receberam $20 \mu \mathrm{g}$ de LPS ou salina. Após 6 e 24 horas, os animais foram colocados em câmara pletismográfica (BUXCO) e após nebulização com doses crescentes de metacolina $(3,6,12$ e $25 \mathrm{mg} / \mathrm{ml})$ foi medido por 5 minutos o aumento da pausa respiratória (Penh) e feito uma média dos valores observados. Média dos valores de penh obtidos em diferentes concentrações de metacolina 6 horas (A) ou 24 horas (B) após inalação de LPS. (C) Os valores do penh foram expressos na forma de área sob a curva da dose resposta com metacolina. Animais tratados com LPS apresentaram uma maior reatividade brônquica à metacolina em relação ao grupo controle, tanto 6 como 24 horas após inalação. Os valores foram expressos em média \pm EPM. *\# $\mathrm{p}<0,05, \mathrm{n}=5$. 


\subsubsection{Células totais no BAL}

Assim como a hiperreatividade, o LPS também foi capaz de aumentar consideravelmente o número de células totais no BAL após 6 horas $\left(2 \times 10^{4} \pm 1\right.$ vs $\left.123 \times 10^{4} \pm 39, \mathrm{p}<0.05\right)$ e 24 horas $\left(5 \times 10^{4} \pm 1\right.$ vs $\left.60 \times 10^{4} \pm 3, \mathrm{p}<0,05\right)$ de tratamento, como podemos observar na figura 16A. Os neutrófilos foram as células que mais contribuiram para o aumento do infiltrado celular tanto 6 horas $\left(1 \times 10^{4} \pm 0.8\right.$ vs $\left.82 \times 10^{4} \pm 29, \mathrm{p}<0,05\right)$ como $24 \mathrm{~h}\left(0.8 \times 10^{4} \pm 0.8\right.$ vs $\left.33 \times 10^{4} \pm 29, \mathrm{p}<0,050\right)$, como mostra figura 16B. As células mononucleares também estavam aumentadas em relação ao controle (figura 16C), mas em menor quantidade quando comparadas ao aumento de neutrófilos. 
A
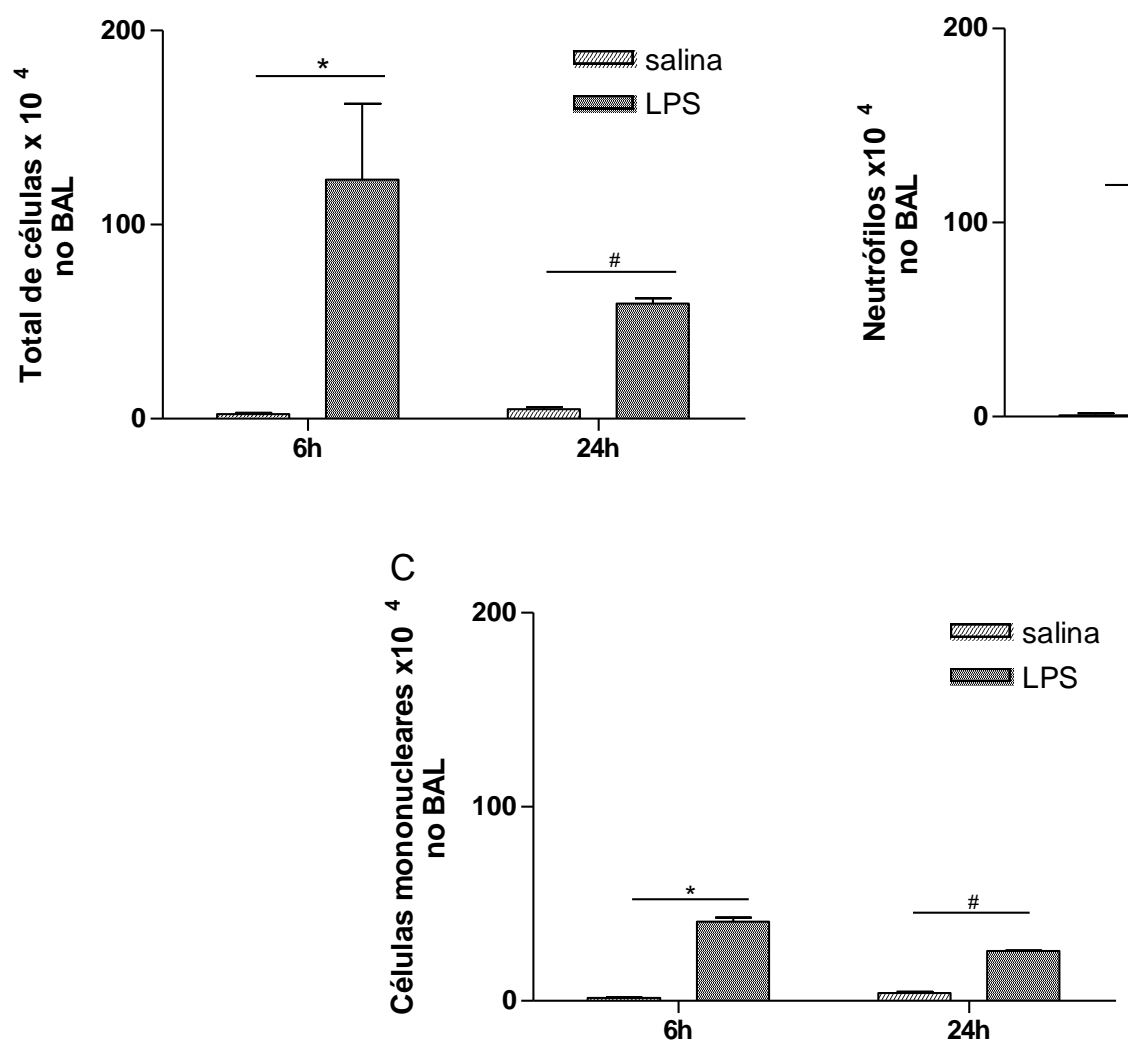

B

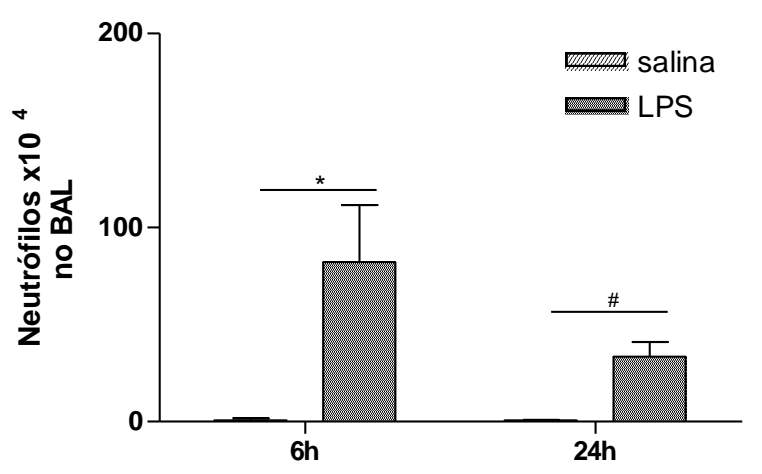

Figura 16. Número total e diferencial de células no BAL 6 e 24 horas após inalação de LPS. O BAL foi coletado no sacrifício dos animais após 6 ou 24 horas de tratamento com LPS. (A) O número de células totais do BAL foi determinado por contagem em câmara de neubauer. As células foram centrifugadas em citocentrifuga e coradas com hematoxilina-eosina para contagem diferencial. (B) Neutrófilos e (C) células mononucleares no BAL. Os animais que receberam LPS apresentaram um aumento significativo no número total de células em relação ao controle com $24 \mathrm{~h}$ após inalação. Isso se deu principalmente pelo aumento no número de neutrófilos. Os valores foram expressos em média \pm EPM. \#* $\mathrm{p}<0,05, \mathrm{n}=5$. 


\subsubsection{Proteína total no BAL}

Com 6 horas após o tratamento, há uma tendência no grupo tratado com LPS em apresentar um aumento da proteína total do sobrenadante do BAL em relação ao controle, mas esta diferença não foi significante estatisticamente $(292 \pm 22$ vs $183 \pm 51$ $\mu \mathrm{g} / \mathrm{ml}$, respectivamente). Entretanto, com 24 horas após tratamento com LPS, houve uma diferença significativa no aumento de proteína total no BAL em relação ao controle ( $456 \pm 28$ vs $206 \pm 61 \mu \mathrm{g} / \mathrm{ml}, \mathrm{p}<0,05$, respectivamente), conforme apresentado na figura 17.

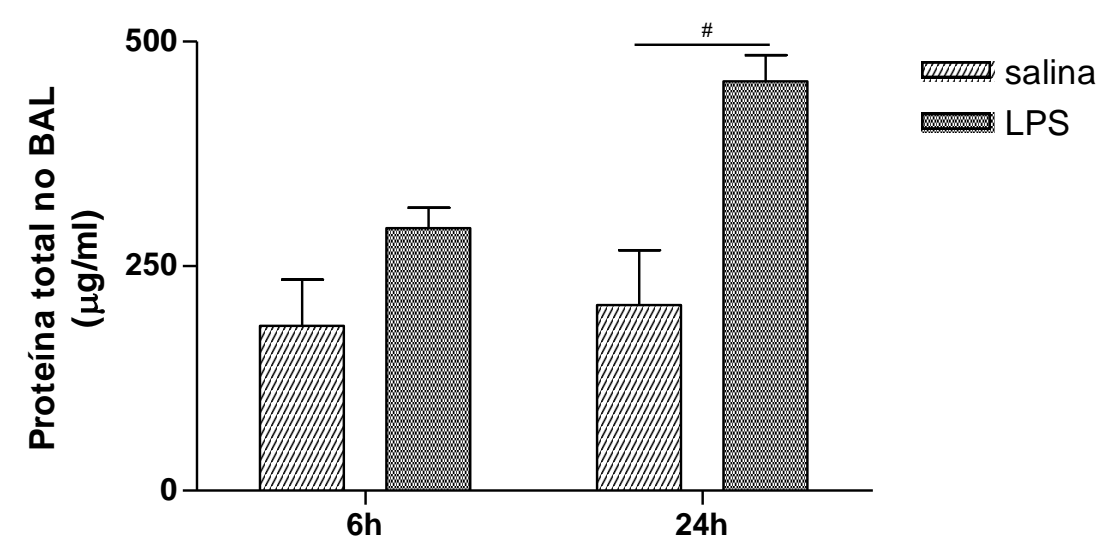

Figura 17. Proteína total no BAL 6 e 24 horas após inalação de LPS. O BAL foi coletado no sacrifício dos animais após 6 ou 24 horas de tratamento com LPS. O sobrenadante foi utilizado para dosagem de proteínas totais. Os animais que receberam LPS apresentaram um aumento significativo nos níveis de proteína total em relação aos controles no grupo de $24 \mathrm{~h}$. Os valores foram expressos em média \pm EPM. * $\mathrm{p}<0,05, \mathrm{n}=5$. 


\subsubsection{Expressão dos receptores B1 e B2 no pulmão após lesão direta induzida por LPS}

Como verificamos anteriormente que os receptores da bradicinina são modulados e podem estar envolvidos numa lesão pulmonar indireta por IR renal, decidimos analisar a expressão destes receptores no pulmão após lesão direta por LPS.

Observamos que 6 horas após o tratamento com LPS, nenhum dos receptores (B1R e B2R) estavam alterados em relação ao grupo controle (figura 18A). Entretanto, vimos que 24 horas após o tratamento com LPS, os camundongos aumentaram significantemente a expressão de B1R em relação ao controle $(14,8 \pm 4,4$ vs 1,0 UA, p < 0,05, respectivamente), como ilustra a figura 18B. Nenhuma significância foi observada nos níveis de B2R em relação ao controle com 24 horas após LPS. 
A

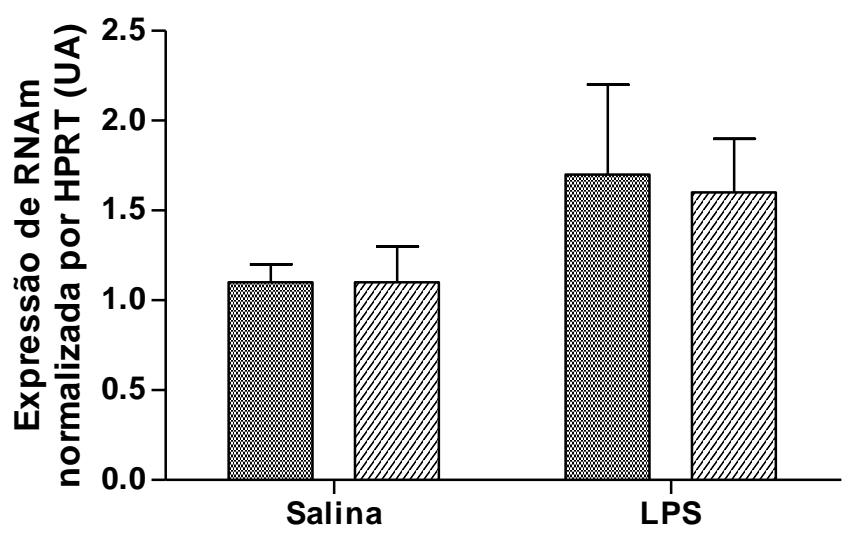

$\mathrm{B} 1 \mathrm{R}$

$\mathrm{B} 2 \mathrm{R}$

B

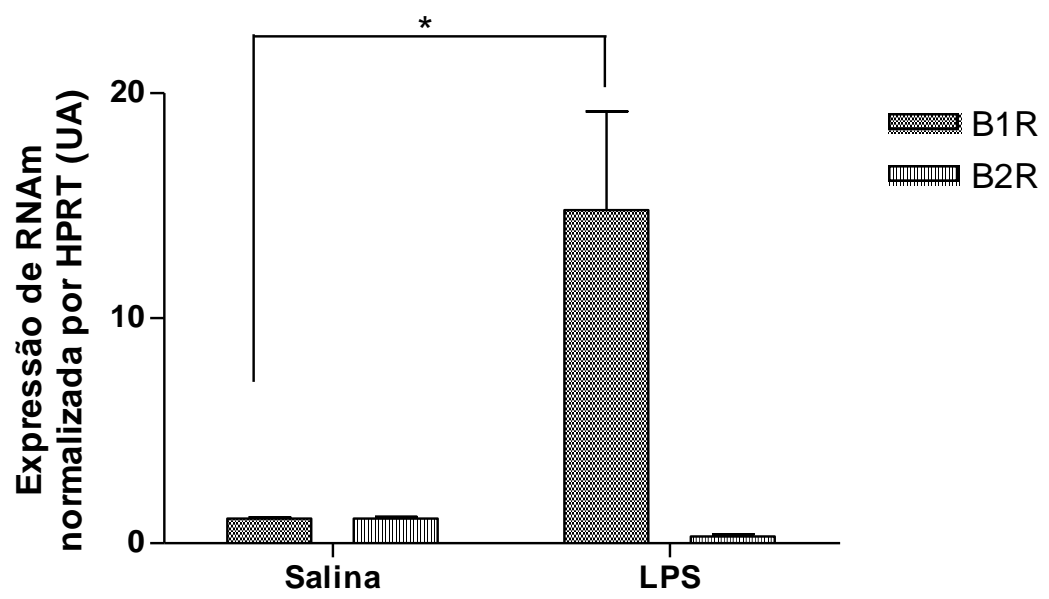

Figura 18. Expressão dos transcritos gênicos dos receptores B1 e B2 no pulmão 6 e 24 horas após inalação de LPS. O pulmão foi coletado 6 horas (A) ou 24 horas (B) após inalação de LPS. A quantificação do RNAm foi realizada por PCR em tempo real e normalizada por HPRT. O método $2^{-\Delta \Delta c t}$ foi utilizado para cálculo. A expressão de B1R estava aumentada 24 horas após tratamento com LPS. Os valores estão expressos em unidades arbitrárias em $\mathrm{N}$-vezes diferente em relação ao grupo controle. Os valores foram expressos em média \pm EPM. ${ }^{*} \mathrm{p}<0,05, \mathrm{n}=5$. 


\subsubsection{Avaliação da função pulmonar após tratamento com antagonista de B1R na lesão induzida por LPS}

Como observamos anteriormente a diminuição da lesão pulmonar secundária à lesão de IR renal com o tratamento pelo antagonista de B1R, e também verificamos que na lesão direta por LPS a expressão dos receptores era modulada, decidimos bloquear o B1R após lesão direta por LPS.

Os camundongos C57Bl/6 receberam $200 \mu \mathrm{g} / \mathrm{kg}$ de antagonista de B1R (R954) em $20 \mu \mathrm{l}$ de salina por via intra-nasal, 30 minutos após o tratamento com LPS. A função pulmonar foi avaliada 24 horas após inalação do LPS.

\subsubsection{Hiperreatividade pulmonar}

O tratamento com inibidor de B1R foi capaz de reduzir significantemente a hiperreatividade pulmonar à metacolina expressa em área sob a curva, de $103 \pm 38$ para 9₫3 UA $(\mathrm{p}<0,05), 24$ horas após tratamento com LPS, conforme podemos verificar na figura 19. 
A

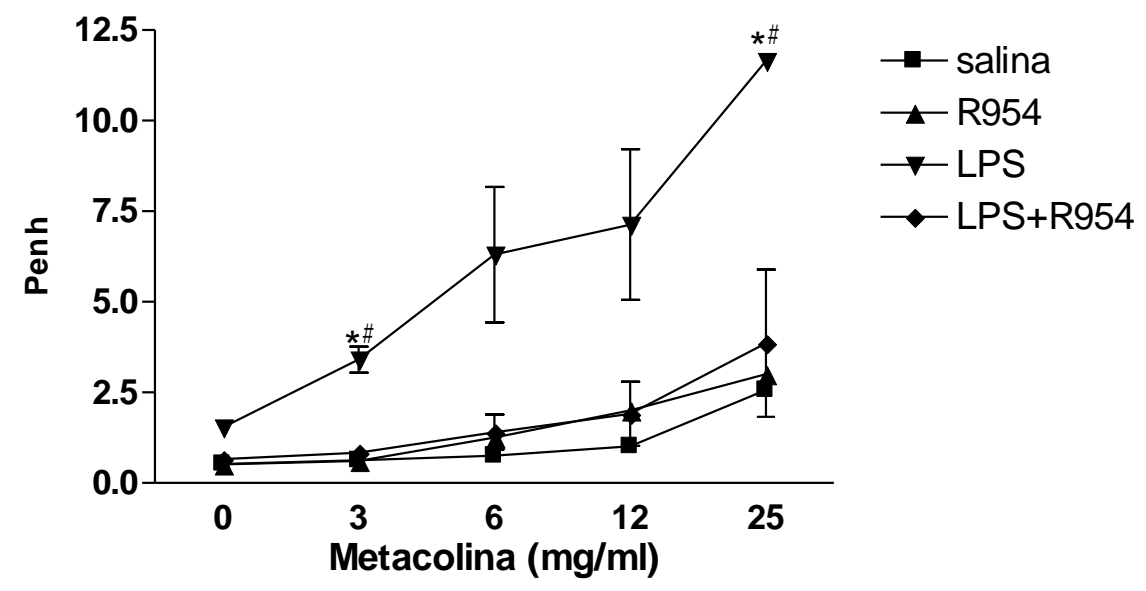

B

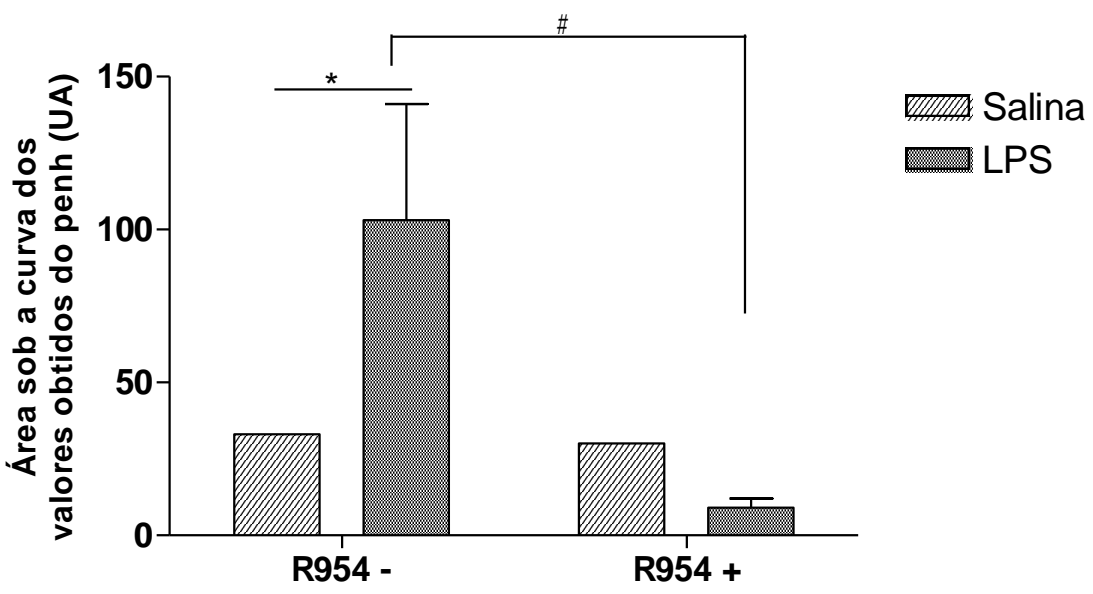

Figura 19. Hiperreatividade pulmonar após tratamento com inibidor de B1R (R954) em lesão por inalação de LPS. Animais C57Bl/6 receberam $20 \mu \mathrm{g}$ de LPS ou salina e 30min depois $200 \mu \mathrm{g} / \mathrm{kg}$ de R954. Após 24 horas, os animais foram colocados em câmara pletismográfica (BUXCO) e após nebulização com doses crescentes de metacolina $(3,6,12$ e $25 \mathrm{mg} / \mathrm{ml})$ foi medido por 5 minutos o aumento da pausa respiratória (Penh) e feito uma média dos valores observados. (A) Média dos valores de penh obtidos em diferentes concentrações de metacolina 24 horas após inalação de LPS. (B) Os valores do penh foram expressos na forma de área sob a curva da dose resposta com metacolina. Animais tratados com R954 apresentaram uma queda na reatividade brônquica à metacolina em relação ao grupo sem tratamento. Os valores foram expressos em média \pm EPM.. *LPS versus salina, \# LPS tratado com R954 versus LPS não tratado. *\# $\mathrm{p}<0,05, \mathrm{n}=5$. 


\subsubsection{Infiltrado celular no BAL e pulmão}

O tratamento com inibidor de B1R, R954, reduziu significantemente o número de células no BAL em relação ao grupo que recebeu apenas LPS (40x104ะ4.6 para $5 \times 104 \pm 0,2 \mathrm{p}<0,05$, respectivamente). Estes resultados podem ser observados na figura 20. Além disso, o tratamento com inibidor de B1R foi capaz de reduzir o infiltrado neutrofílico no parênquima pulmonar na região peribronquiolar, como ilustra a figura 21.

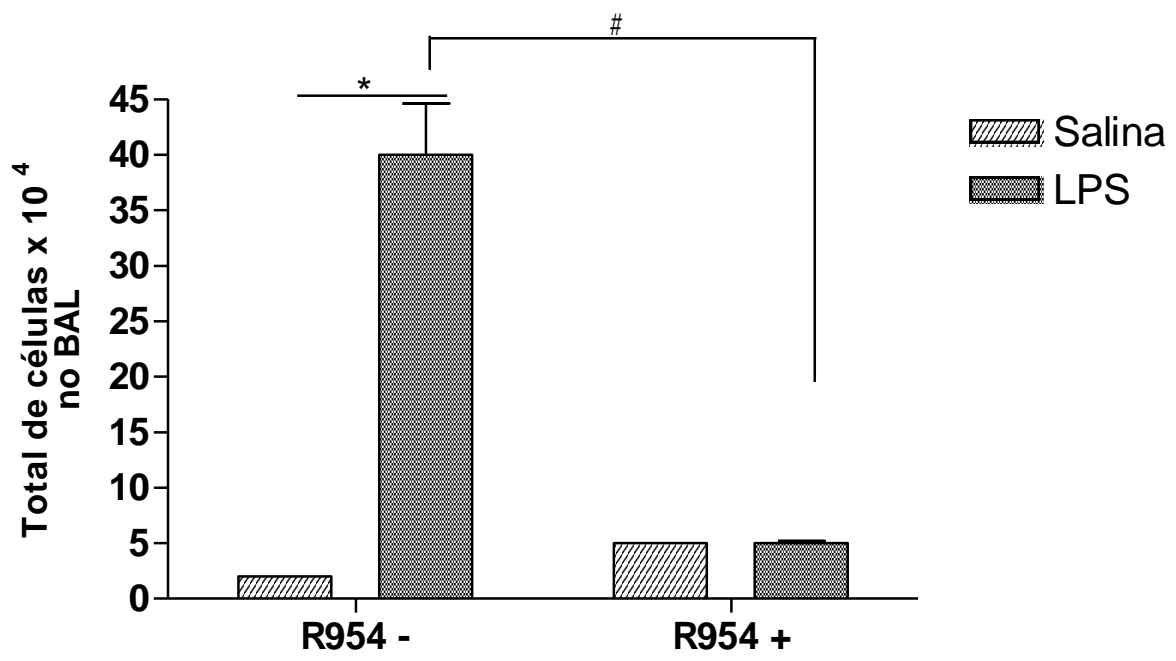

Figura 20. Número total de células no BAL após tratamento com inibidor de B1R em lesão por inalação de LPS. Animais C57Bl/6 receberam por via intra-nasal $20 \mu \mathrm{g}$ de LPS ou salina e 30min depois, foram tratados com $200 \mu \mathrm{g} / \mathrm{kg}$ de R954 ou salina. O BAL foi coletado 24 após o tratamento para contagem do número total de células. Animais tratados com inibidor de B1R não apresentaram aumento de células no BAL quando comparados aos animais não tratados. Os valores foram expressos em média \pm EPM. \#* $\mathrm{p}<0,05, \mathrm{n}=5$. 


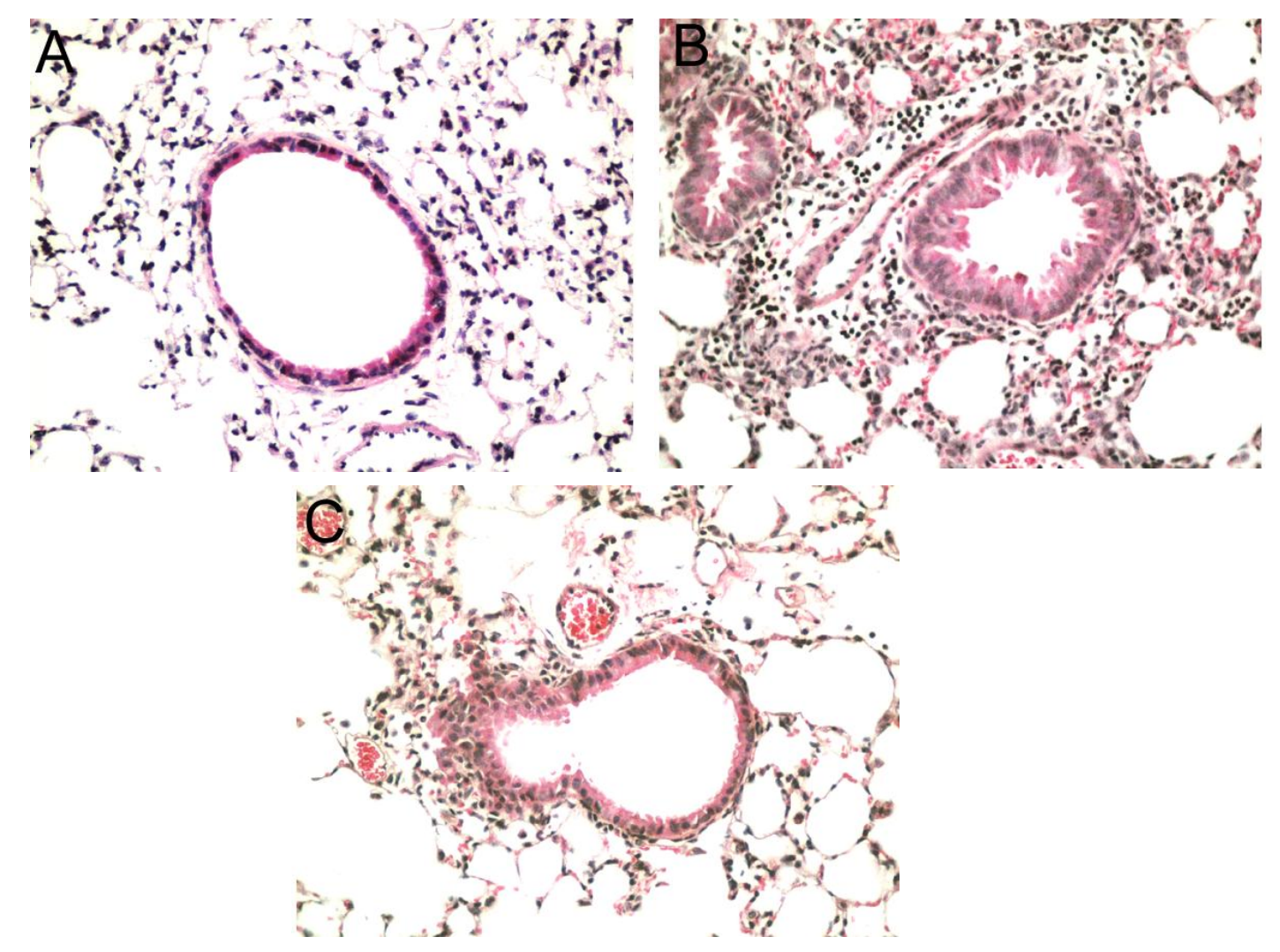

Figura 21. Secção representativa do pulmão de animais tratados com inibidor de B1R (R954) e LPS. Os tecidos foram coletados 24 horas após inalação de LPS, e os cortes foram corados com hematoxilina e eosina. (A) Controle; (B) Tratado com LPS; (C) Tratado com LPS e antagonista de receptor B1 (R954). Animais tratados com inibidor de B1R apresentaram diminuição no infiltrado polimorfonuclear na região peribronquiolar quando comparado aos animais não tratados. As imagens são representativas de cinco animais por grupo. Aumento de 400X. 


\subsubsection{Proteína total no BAL}

A quantidade de proteína total no BAL foi significativamente diminuída no grupo tratado com inibidor de B1R (R954), que passou de 291 \pm 5 no grupo não tratado para $184 \pm 22 \mu \mathrm{g} / \mathrm{ml}$ no grupo tratado $(\mathrm{p}<0,05)$. Isto pode ser observado na figura 22 .

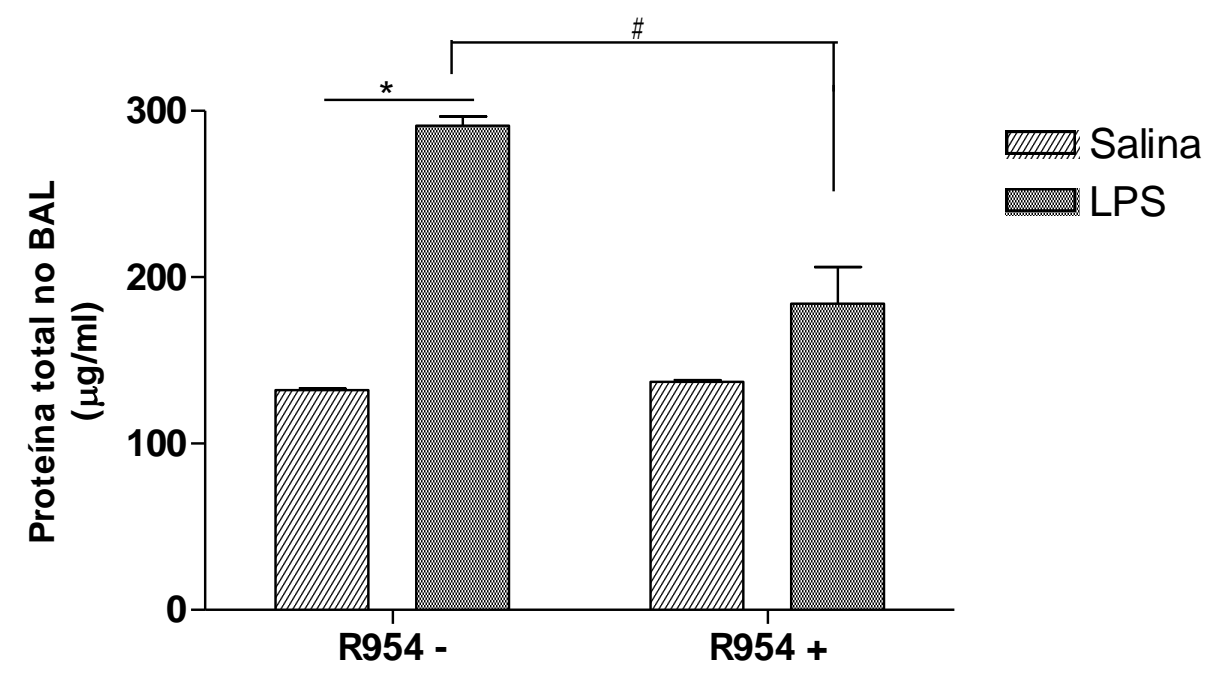

Figura 22. Proteína total no BAL após tratamento com inibidor de B1R em lesão por inalação de LPS. Animais C57Bl/6 receberam por via intra-nasal $20 \mu \mathrm{g}$ de LPS ou salina e 30min depois, foram tratados com $200 \mu \mathrm{g} / \mathrm{kg}$ de $\mathrm{R} 954$ ou salina. O BAL foi coletado no sacrifício dos animais, centrifugado, e o sobrenadante foi usado para dosagem de proteína total. Após 24 horas os animais tratados com R954 apresentaram redução significativa nos níveis de proteína total em relação ao grupo LPS sem tratamento. Os valores foram expressos em média \pm EPM. *\# $\mathrm{p}<0,05, \mathrm{n}=5$. 


\subsubsection{Expressão gênica de citocinas e quimiocina após tratamento com antagonista de B1R na lesão induzida por LPS}

Analisamos a expressão gênica de citocinas e quimiocina pró-inflamatória no tecido pulmonar através de PCR em tempo real 24 horas após tratamento com inibidor de B1R. Como podemos observar na figura 23, o tratamento com LPS induz grande expressão gênica das citocinas e quimiocina pró-inflamatórias analisadas em comparação ao grupo que recebeu apenas salina (TNF- $\alpha 35,0 \pm 8$ vs 1,0 UA ; IFN- $\gamma$

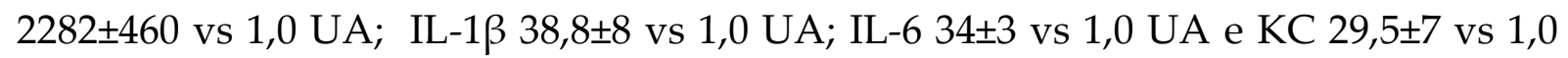
UA; $\quad \mathrm{p}<0,05)$, respectivamente. E este aumento foi praticamente abolido com o tratamento com R954 (TNF- $\alpha$ 35,0 \pm 8 para $0,3 \pm 0,1$ UA ; IFN- $\gamma 2282 \pm 460$ para 58,4 $\pm 2,4$

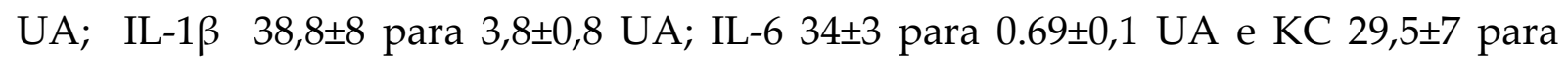

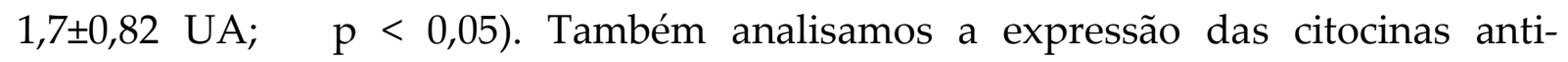
inflamatórias, IL-4 e IL-10, no pulmão após inibição do B1R. A IL-4 estava diminuída nos animais tratados com LPS em relação ao controle $(0,60 \pm 0,05$ vs 1 UA, p < 0,05, respectivamente) enquanto que no grupo tratado com inibidor de B1R, a expressão

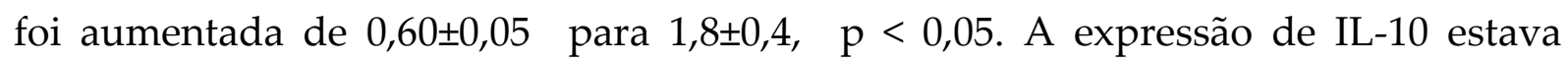
aumentada no pulmão após inalação por LPS e foi diminuída com o bloqueio do B1R. 


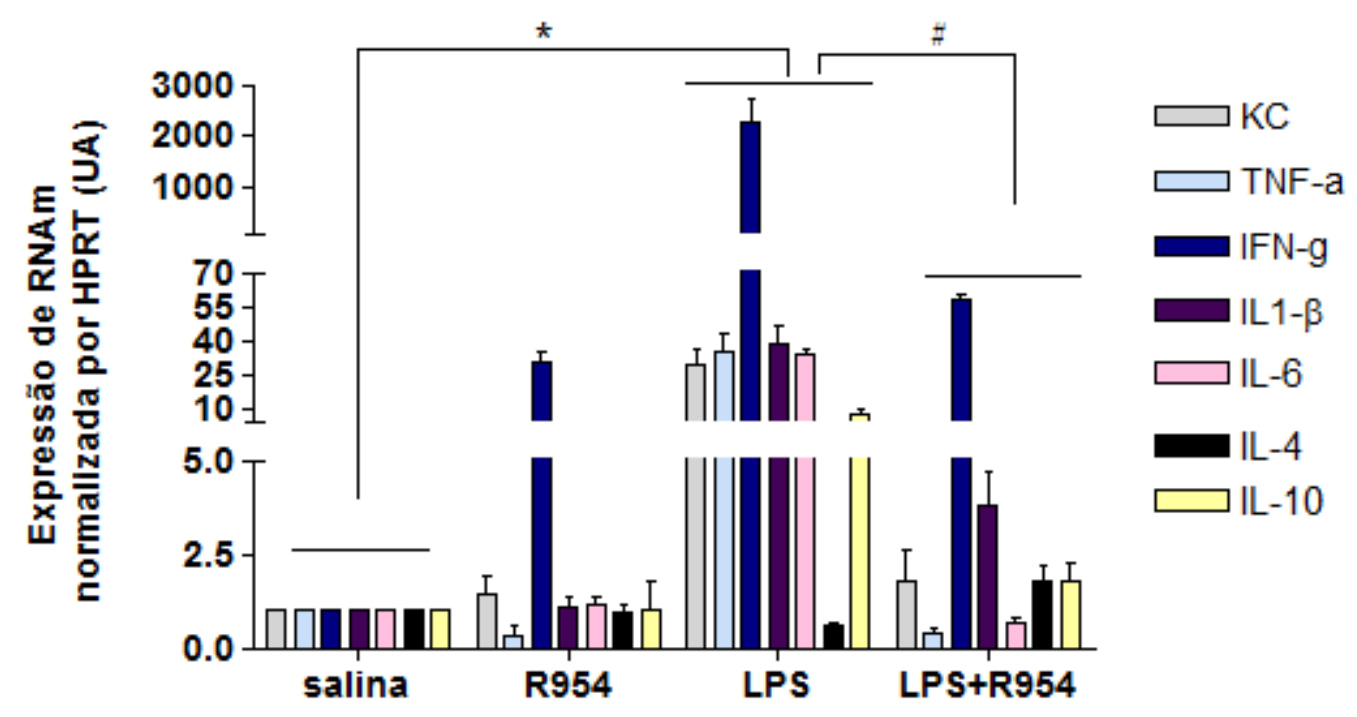

Figura 23. Expressão dos transcritos gênicos de citocinas e quimiocina no pulmão após tratamento com inibidor de B1R (R954) em lesão por inalação de LPS. O pulmão dos animais foi coletado 24 horas após inalação de LPS e tratamento com inibidor de B1R (LPS+R954). A quantificação do RNAm foi realizada por PCR em tempo real e normalizada por HPRT. Método utilizado para cálculo $2^{-\Delta \Delta c t}$. A expressão de mediadores pró-inflamatórios é significativamente reduzida nos animais tratados com inibidor de B1R em relação aos não tratados. Os valores estão expressos em unidades arbitrárias em número de vezes em relação ao grupo controle. Os valores foram expressos em média \pm EPM. ${ }^{*} p<0,05, n=5$. Salina, animais controle tratados apenas com salina; R954, animais controle tratados apenas com inibidor de B1R; LPS, animais tratados com LPS; LPS+R954, animais tratados com LPS e inibidor de B1R. 


\subsubsection{Quantificação de citocinas e quimiocina no BAL após tratamento com inibidor de B1R na lesão induzida por LPS}

Quantificamos citocinas e uma quimiocina no BAL após tratamento com inibidor de B1R (R954). Podemos observar na figura 24, que o LPS induziu a presença de citocinas pró-inflamatórias no BAL, que não são detectadas nos animais controle (TNF- $\alpha$ 63,7 $\pm 20 ;$ IFN- $\gamma$ 322 $\pm 20 ;$ IL-1 $\beta \quad 25,5 \pm 4,5$ e MCP-1 47 \pm 9 pg/ml, p < 0,05). E também, que o tratamento com R954 foi capaz de abolir completamente este aumento de TNF- $\alpha$ e IL-1 $\beta$ causado pelo LPS, e diminuir consideravelmente a presença de IFN- $\gamma \quad(322 \pm 20$ para $2,7 \pm 1 \mathrm{pg} / \mathrm{ml}, \mathrm{p}<0,05)$ e da quimiocina MCP-1 $(47 \pm 9$ para $17 \pm 1$ $\mathrm{pg} / \mathrm{ml}, \mathrm{p}<0,05)$. As citocinas anti- inflamatórias IL-4 e IL-10 não foram detectadas no BAL em nenhum nos grupos.

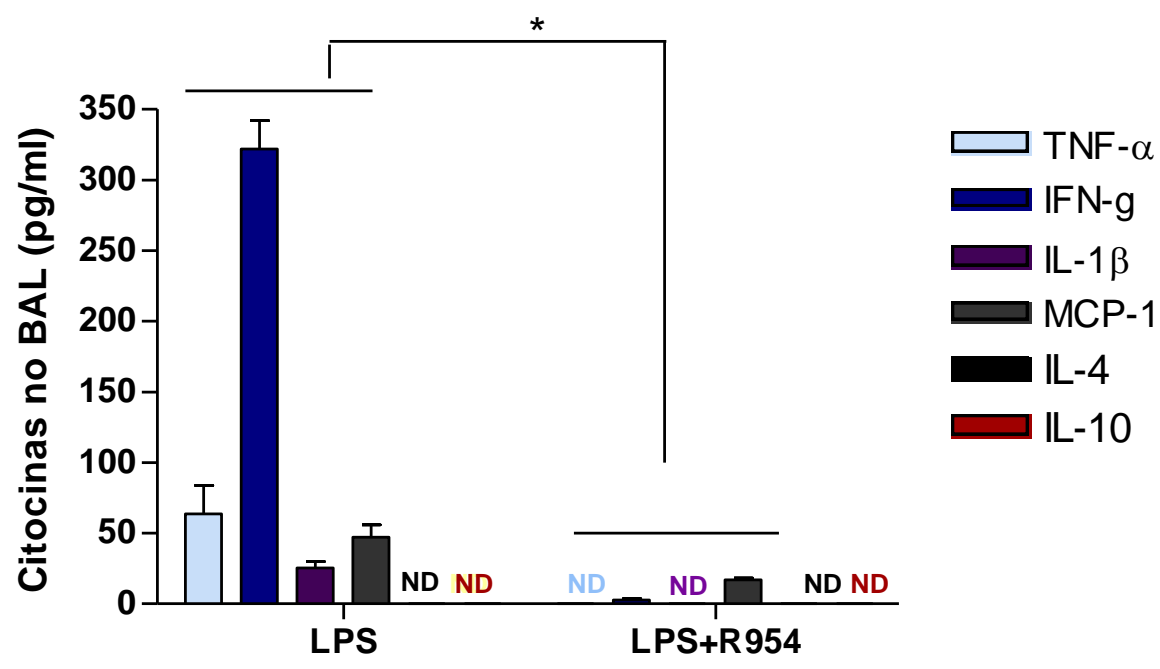

Figura 24. Quantificação de citocinas e quimiocina no BAL após tratamento com inibidor de B1R (R954) em lesão por inalação de LPS. O BAL foi coletado 24 horas após inalação de LPS e inibidor de B1R (R954), e as citocinas foram quantificadas pela técnica de Bioplex da BioRad. Os limites de detecção para cada citocina estão descritos no material e métodos. Os valores foram expressos em média \pm EPM. * $\mathrm{p}$ $<0,05, \mathrm{n}=5$; LPS, animais tratados apenas com LPS; LPS+R954, animais tratados com LPS e inibidor de B1R. ND, não detectada. 


\section{DISCUSSÃO}

A SDRA é a forma mais severa da LPA e é caracterizada por intenso influxo de neutrófilos no pulmão, aumento de mediadores pró-inflamatórios e danos epiteliais e endoteliais. Pode ser classificada em SDRA direta, quando a lesão atinge diretamente o pulmão, como exemplo de sua principal causa, a pneumonia, ou pode ser classificada em SDRA indireta, quando mediadores inflamatórios liberados por uma lesão extra-pulmonar atingem o pulmão, como, por exemplo, órgãos isquemiados [2-4].

Na primeira etapa deste trabalho, nós avaliamos o modelo de LPI, induzida através de IR renal, e o modelo de LPD, induzida através da inalação de LPS.

Para estabelecer o modelo de lesão de IR renal, realizamos cirurgias em camundongos C57Bl/6 de 45 minutos de isquemia seguida de diferentes tempos de reperfusão: 6, 12, 24 e 48h. No sacrifício, coletamos sangue para dosagem de uréia e creatinina sérica, ambos indicadores de função renal. Pudemos observar que 6 horas após a reperfusão, já há um aumento nos níveis destes marcadores, indicando o início de um dano renal. E também que, o pico da lesão renal ocorreu em 24 horas. Com estes resultados, verificamos a eficiência do modelo em causar dano renal. $\mathrm{O}$ tempo de isquemia determina a severidade da lesão renal. Alguns trabalhos utilizam períodos de 30 minutos de isquemia para uma lesão moderada [95], entretanto, nós utilizamos 45 minutos para obtermos uma lesão renal mais severa, e consequentemente um maior dano sistêmico. Já foi demonstrado na literatura que 30 minutos de isquemia renal não é suficiente para levar a grandes alterações pulmonares, enquanto que 60 minutos de isquemia renal leva a considerável alterações pulmonares [43]. No nosso modelo, a taxa de mortalidade com 60 minutos 
de isquemia é alta, por isso, escolhemos 45 minutos de isquemia renal para podermos estudarmos os danos sistêmicos no pulmão.

Escolhemos dois pontos de reperfusão, 6 e 24 horas, para avaliarmos a função pulmonar através da hiperreatividade brônquica à metacolina e quantificação do número de células totais e proteína no BAL. Verificamos que 6 horas após a IR renal, o pulmão não apresentou aumento de nenhum destes parâmetros avaliados. Entretanto, com 24 horas após isquemia, os animais apresentaram aumento de hiperreatividade pulmonar à metacolina, de infiltrado celular, e de extravasamento de proteínas para o espaço alveolar. Em estudos realizados com lesão de IR intestinal, ratos já apresentam infiltração de neutrófilos e aumento de permeabilidade vascular em tempos precoces como 2 e 4h [39]. Entretanto, Hausson e colaboradores [96] realizaram IR renal em camundongos e verificaram que com 6 horas os animais não apresentavam aumento de proteína no BAL e apresentavam pouquíssimo infiltrado neutrofílico no tecido. Já com 36 horas após isquemia, eles verificaram um maior aumento de infiltrado neutrofílico no tecido e extravasamento de proteínas para o BAL. Estes parâmetros não foram avaliados com 24 horas após isquemia. Isso mostra que, a cinética envolvida na lesão pulmonar causada por estes diferentes órgãos isquemiados pode ser diferente a depender do modelo.

Ainda não é totalmente esclarecido o mecanismo que acarreta este aumento de infiltrado celular no pulmão. Uma das possibilidades é a ativação endotelial no pulmão após a liberação sistêmica de citocinas pró-inflamatórias. Nós observamos que citocinas pró-inflamatórias, IL-1 $\beta$ e TNF- $\alpha$, e a quimiocina MCP-1, estavam aumentadas no soro 24 horas após lesão de IR renal, podendo estar envolvidas com a ativação endotelial e infiltrado celular no pulmão. Em modelo de isquemia intestinal, alguns estudos já mostraram que a IL-1 $\beta$ e o TNF liberados após uma isquemia intestinal estão aumentados no soro e podem levar a danos pulmonares [36, 37]. Nós 
dosamos também a citocina IL-6 no soro, mas não observamos um aumento significativo. Um estudo anterior mostrou que a IL-6 atinge o pico no soro com 4 a 8 horas após lesão de IR renal, voltando aos níveis basais 24 horas após o insulto [97].

A ativação endotelial é um dos processos envolvidos na lesão de IR. Uma vez ativado, ele passa a expressar moléculas em sua superfície, como ICAM-1, facilitando a adesão e infiltração de leucócitos no tecido [53]. Já foi demonstrado o importante papel de ICAM-1 na lesão de IR renal. Neste trabalho, o tratamento com anticorpo anti ICAM-1 após a IR renal em ratos preveniu os danos no rim [68]. Para estudarmos a disfunção endotelial pulmonar, avaliamos a expressão de ICAM-1 no pulmão 24 horas após lesão de IR renal. Observamos que a expressão de RNAm de ICAM-1 estava aumentada no pulmão dos animais após IR renal, sugerindo ativação endotelial. Um estudo anterior demonstrou o importante papel de ICAM-1 na lesão pulmonar sistêmica após lesão de IR intestinal. Neste estudo, ratos foram tratados com anticorpo anti ICAM-1 após lesão de IR intestinal e o infiltrado neutrofílico e aumento de permeabilidade microvascular foram diminuídos no pulmão [38].

Quantificamos também a expressão de duas enzimas, COX-2 e iNOS, que poderiam estar envolvidas na disfunção endotelial, infiltração celular e aumento da inflamação. Em condições normais, a expressão das duas enzimas é baixa em células endoteliais e células inflamatórias, como macrófagos, mas é aumentada por citocinas inflamatórias como IL-1 $\beta$ e TNF- $\alpha[98,99]$. A COX-2 é uma enzima que produz mediadores inflamatórios, como as prostaglandinas, à partir do ácido araquidônico. A iNOS produz NO à partir da L-arginina. Nosso laboratório já demonstrou que a COX-2 é importante na lesão de IR renal uma vez que, o bloqueio desta enzima melhora a função renal após IR [100]. Estudos anteriores demonstraram que ambas formas de NOS (induzida e constitutiva) exercem diferentes efeitos no pulmão após lesão de IR intestinal e hepática. A forma induzida é deletéria, contribuindo para a 
disfunção pulmonar, enquanto a forma constitutiva é benéfica [39, 40, 101, 102]. Nós observamos que tanto a COX-2 quanto iNOS estão aumentadas no pulmão 24 horas após lesão de IR renal, e podem estar contribuindo para a infiltração celular e inflamação. Não podemos afirmar se a iNOS está sendo produzida pelas células endoteliais no pulmão ou pelos macrófagos infiltrantes. Um estudo anterior demontrou através de um modelo de LPA induzida por sepse que a iNOS tem um papel importante na disfunção da microcirculação, mas é produzida pelos macrófagos alveolares, e não pelas células endoteliais. Os autores depletaram macrófagos alveolares em camundongos iNOS +/+ e verificaram diminuição no extravasamento de proteína e redução de neutrófilos após indução da sepse. Entretanto, quando os macrófagos alveolares foram reconstituídos a partir de doadores iNOS +/+, a lesão pulmonar foi re-estabelecida. Por outro lado, quando os camundongos foram reconstituídos com macrófagos alveolares de animais iNOS -/-, eles continuaram protegidos após a indução da sepse [103].

Uma vez que a expressão de COX-2 estava aumentada no pulmão, nós dosamos um dos produtos lipídicos da COX-2, a PGE2. Vimos um aumento da PGE2 no BAL 24 horas após lesão de IR renal. Mediadores lipídicos estão envolvidos na patogênese da asma contribuindo para eventos precoces como infiltrado celular, hiperreatividade brônquica e secreção de muco [104]. O papel da produção de prostaglandina no pulmão é controverso, podendo ser deletério ou benéfico dependendo do modelo estudado. Em modelos de alergia, a PGE2 quando inalada por pacientes asmáticos antes da inalação do alérgeno foi relacionada com um efeito protetor [105]. Enquanto outros estudos mostraram um efeito pró-inflamatório da PGE2 por aumentar a sobrevida de eosinófilos [106, 107], e aumentar o influxo de neutrófilos, eosinófilos e linfócitos no BAL dos camundongos após desafio com alérgeno [108]. Em modelos de LPA induzida por LPS e não por alérgenos, a PGE2 
contribui para infiltração de neutrófilos [109]. Acreditamos que no nosso modelo de LPA indireta, com características diferentes de um modelo alérgico, a $\mathrm{PGE}_{2}$ produzida pela COX-2, juntamente com o NO produzido pela iNOS, estão contribuindo para a inflamação local.

Alguns estudos já demonstraram que um padrão Th1 de resposta imunológica é deletério à lesão de IR renal, enquanto o padrão Th2 é protetor [66]. Animais IL-4 nocautes apresentaram uma piora na disfunção renal em relação aos controles [65]. Enquanto animais IL-12KO apresentaram uma proteção na lesão de IR renal [64]. Diversos estudos demonstraram o papel das células $T$ CD4+ na contribuição da lesão de IR renal [110]. Com uma e três horas de reperfusão já encontra-se infiltrado de linfócitos no rim, entretanto, esse infiltrado é diminuido após 24 horas. Acredita-se que os linfócitos infiltram o rim rapidamente após a reperfusão, produzindo citocinas, contribuindo para o início da inflamação e logo depois desaparecem $[111,112]$. Camundongos nocautes para CD4 e CD8 (nu/nu) tiveram diminuição nos danos renais após isquemia. Quando reconstituídos com linfócitos $\mathrm{CD} 4+$, a lesão foi reestabelecida. Entretanto, a reconstituição com CD4+ de animais IFN- $\gamma \mathrm{KO}$ ou CD28KO não foi capaz de reestabelecer a lesão. Mostrando a importância da co-estimulação e um ambiente de padrão Th1 no papel dos linfócitos na contribuição da lesão de IR [63]. Nós quantificamos a expressão gênica de citocinas pró-inflamatórias de padrão Th1, quimiocinas, e citocinas anti-inflamatórias de padrão Th2 no rim e pulmão 24 horas após IR renal. Vimos que tanto no rim quanto no pulmão, as citocinas pró-inflamatórias IL1 $\beta$, TNF- $\alpha$ e IL-6 estavam aumentadas 24 horas após IR renal. Assim como as citocinas, as quimiocinas MCP-1 e KC também estavam aumentadas. A expressão da citocina de padrão Th2, IL-4, estava diminuída tanto no rim quanto no pulmão em relação ao controle. Com isso, 
caracterizamos o padrão de citocinas no pulmão após lesão de IR renal, e vimos que, assim como no rim, a resposta imunológica no pulmão também é de padrão Th1.

Com os resultados obtidos até aqui, sugerimos que a lesão de IR renal libera mediadores inflamatórios no sangue que chegam ao pulmão ativando células endoteliais, aumentando expressão de ICAM-1, COX-2 e iNOS, liberando citocinas de padrão Th1, promovendo infiltração celular, aumentando permeabilidade vascular e hiperreatividade brônquica.

Após analisarmos a LPI induzida por lesão de IR renal, avaliamos o modelo de LPD induzida por inalação de LPS. Apesar da lesão pulmonar ser semelhante no estágio tardio, independentemente do estímulo ter sido direto ou indireto, ela difere no estágio inicial. A LPI causada por IR renal, causaria liberação de mediadores inflamatórios sistêmicos, ativando as células endoteliais, contribuindo para o infiltrado celular e maior inflamação, enquanto uma LPD causada por inalação de LPS causaria danos primeiramente ao epítelio pulmonar, com ativação de macrófagos alveolares, liberação de citocinas, inflamação e infiltração de leucócitos [15]. Por isso nosso interesse em estudar a lesão pulmonar em dois modelos diferentes.

Para isso, camundongos C57Bl/6 foram anestesiados com cetamina e xilazina e tratados por via intra-nasal com $20 \mu \mathrm{g}$ de LPS de E. coli diluídos em $20 \mu \mathrm{l}$ de salina. Avaliamos o infiltrado celular no BAL, hiperreatividade pulmonar à metacolina e aumento de permeabilidade vascular através da dosagem de proteína total no BAL. Vimos que, tanto 6 horas como 24 horas após tratamento com LPS a hiperreatividade pulmonar e o infiltrado de células estavam aumentados no BAL após inalação de LPS. Entretanto, apenas o grupo de 24 horas apresentou um aumento significativo no nível de proteína total no BAL. Diferentemente da lesão pulmonar induzida indiretamente por lesão de IR renal, os animais que inalaram LPS apresentaram um 
robusto aumento de infiltrado celular já com 6 horas após inalação de LPS, e este infiltrado era causado principalmente por neutrófilos. Nossos resultados estão de acordo com trabalhos anteriores [113, 114] que mostram indução de inflamação pulmonar com aumento de neutrófilos no BAL e pulmão, aumento de permeabilidade vascular e hiperreatividade brônquica após inalação por LPS, mostrando a eficiência do nosso modelo em causar lesão pulmonar.

Muitos estudos têm sido feitos para tentar elucidar os possíveis mecanismos para esta lesão pulmonar por LPS. Foi demonstrado que em macrófagos pulmonares de rato, o LPS induz ativação de NF-kB, MAPK, liberação de TNF- $\alpha$ e expressão de iNOS e COX-2 [115]. Além disso, Schnyder-Candrian e colegas demonstraram que a sinalização via p38 MAPK é importante para produção de TNF- $\alpha$ no pulmão de camundongos C57Bl/6 que inalaram LPS, pois utilizando um inibidor de p38, os níveis de TNF foram significantemente reduzidos. $\mathrm{O}$ inibidor de p38 também foi capaz de reduzir a broncoconstrição. Neste trabalho, além de demonstrar que a broncocontrição depende de p38, ele também mostra que é dependente de TNF- $\alpha$ e sinalização via TLR-4 [24]. Por outro lado, a broncoconstriçao não depende de neutrofilia. Camundongos nocautes para TNF- $\alpha$ não apresentaram broncoconstrição após inalação de LPS, mas continuam apresentando neutrofilia [116].

Até esta etapa do trabalho, conseguimos caracterizar a LPI induzida por IR renal e a LPD induzida por LPS. Muitos são os esforços para tentar entendermos os mecanismos envolvidos em ambas as lesões. Tanto na LPI como na LPD, a inflamação teve um papel fundamental promovendo aumento de infiltrado celular e permeabilidade vascular contribuindo para a lesão pulmonar. Nossa hipótese é que a bradicinina (BK), importante mediador inflamatório, estaria contribuindo para o desenvolvimento tanto da LPI como da LPD. 
A BK pode agir em dois receptores, um constitutivo (B2), promovendo principalmente efeitos fisiológicos, como controle da pressão sanguínea e aumento de permeabilidade vascular, e um induzível (B1), promovendo principalmente efeitos pró-inflamatórios, como migração leucocitária, ativação de células do sistema imune e produção de citocinas como IL-1 $\beta$. A expressão de B1R pode ser induzida por IL-1 $\beta$, TNF- $\alpha$ e NF- $\kappa B$ e alguns estudos já demonstraram seu envolvimento em lesões de IR $[69,117]$.

Diante disso, o segundo passo deste trabalho foi verificar a modulação dos receptores da BK em ambas as lesões. Para isso, verificamos a expressão dos receptores $B 1$ (B1R) e B2 (B2R) através de PCR em tempo real no rim e pulmão após IR renal, e no pulmão após inalação de LPS.

Nós verificamos que a isquemia tem um efeito modulador nos receptores B1 e B2 do rim e pulmão. No rim, local onde está sendo causado o insulto, a isquemia aumentou a expressão do receptor B2 já com poucas horas de reperfusão, atingindo o pico em 24 horas. Entretanto, a expressão de B1R não foi aumentada. Isso esta de acordo com resultados anteriores de nosso laboratório, o qual mostraram um aumento na expressão de B2R e nenhum aumento de B1R com 24 horas após IR renal [69]. Além disso, este trabalho demostrou uma regulação cruzada entre os dois receptores. Com 48 horas após a isquemia, há uma inversão da expressão dos receptores, os níveis de B2R estão diminuídos enquanto os níveis de B1R estão aumentados. Já com 120 horas após a IR renal, a expressão de B2R volta a subir e a expressão de B1R volta a diminuir.

Ainda não é totalmente esclarecido o papel e a regulação da expressão dos B1R e B2R. Sabe-se que o receptor B1R não é expresso em condições normais e apresenta na região promotora do gene, sítios de ligação para fatores de transcrição como NF-kB e AP-1, fazendo com que o B1R seja induzido em respostas à citocinas 
inflamatórias, como IL-1 $\beta b$ e TNF- $\alpha$ [117]. A ativação dos receptores B2R pela bradicinina também pode colaborar para o aumento de expressão do B1R. Um estudo anterior demonstrou que a indução de B1R num modelo de isquemia intestinal depende da ativação do receptor $\mathrm{B} 2 \mathrm{R}$, pois quando eles tratam os camundongos com antagonista de B2R, o aumento observado na expressão de B1R é inibido [83]. Entretanto, no nosso laboratório, verificamos que em camundongos B2KO, utilizando um modelo de IR renal, a expressão de B1R está aumentada [69]. Assim como um outro estudo mostrou que a expressão de B1R estava aumentada em camundongos B2KO [118]. Diferentemente do B1R, o B2R é expresso em condições fisiológicas, mas também pode ter sua expressão aumentada em condições inflamatórias [119]. Um estudo demonstrou que a região promotora do gene para B2R em ratos tem sítios de ligação para diversos fatores estimuladores da transcrição como, GATA-1, NF-kb e IL-6, mas também apresenta uma região de ligação para fatores de trasncrição responsáveis pelo silenciamento do gene, que é diferentemente regulada dependendo do tipo de célula, podendo ser responsável pelo controle na expressão transcricional do gene B2R em condições fisiológicas e patológicas [120].

A modulação da expressão dos receptores também está ocorrendo sistemicamente. Nós observamos um aumento na expressão tanto do B2R quanto do B1R no pulmão somente 24 horas após IR renal. Isto esta de acordo com a cinética de disfunção pulmonar que nós observamos após a IR renal. Após 6 horas da lesão de IR renal, não observamos nenhum sinal de inflamação e lesão pulmonar, como aumento no infiltrado celular, permeabilidade vascular e hiperreatividade à metacolina. Só observamos aumento nestes parâmetros, 24 horas após IR renal. Mostrando que, a indução sistêmica dos B1R e B2R no pulmão após IR renal, depende primeiro do estabelecimento da inflamação no pulmão, que então colabora para indução da expressão destes receptores. 
No modelo de LPD, 24h após inalação de LPS, a expressão do B1R estava bem aumentada em relação ao controle, enquanto que a expressão de B2R estava diminuída. Isto está de acordo com alguns estudos que demonstraram que o LPS é capaz de aumentar a expressão do receptor B1 em diferentes células [121-123]. Um estudo avaliou a expressão de B1R e B2R no rim de ratos 18 horas após indução de lesão por LPS. Animais controles expressavam somente B2R no rim. Após tratamento com LPS a expressão do B1R foi induzida em praticamente todos os segmentos do néfron. $\mathrm{O}$ tratamento com LPS também aumento consideravelmente a expressão de B2R em praticamente todos segmentos do rim [124]. Isso mostra como diferentes tecidos e diferentes lesões podem responder diferentemente na regulação destes receptores. No pulmão, o LPS pode induzir expressão somente de B1R, enquanto no rim, é capaz de induzir também o B2R [124]. Já num modelo de lesão pulmonar secundário à IR renal, tanto o B1R quanto B2R podem ser induzidos no pulmão.

Já que houve modulação dos receptores da BK na LPD e LPI, nosso próximo passo foi bloquear o receptor B1R com o uso do antagonista R954 em ambas as lesões. Escolhemos bloquear o receptor induzível (B1R), uma vez que, a expressão deste receptor estava aumentada no pulmão após lesão de IR renal e inalação de LPS, e também, diversos estudos já mostraram seu envolvimento na inflamação, inclusive estudos realizados no nosso laboratório [69].

No modelo de LPI induzida pela lesão de IR renal, camundongos C57Bl/6 passaram por 45 minutos de isquemia renal, e com 30 minutos e 6 horas de reperfusão foram tratados com $200 \mu \mathrm{g} / \mathrm{kg}$ de antagonista de B1R (R954) por via intranasal. Como mostrado anteriormente pelo nosso laboratório, o tratamento com R954 por via IP é capaz de atenuar a lesão de IR renal [69]. Por isso, escolhemos a via de administração intra-nasal, para a droga ter o mínimo efeito possível sistêmicamente não influenciando na lesão renal. Os níveis de uréia sérica foram semelhantes entre o 
grupo tratado e não tratado, mostrando que não houve nenhuma influência da droga administrada por via nasal na função renal. Verificamos que 24 horas após a IR renal, camundongos que tiveram o B1R bloqueado apresentaram uma diminuição na hiperreatividade pulmonar e proteína total no BAL. Entretanto, o tratamento não foi capaz de diminuir o número de células totais no BAL. Isso mostra que o mecanismo de hiperreatividade e infiltração celular podem não estar relacionados. Um trabalho anterior demonstrou que o B1R tem um papel importante na migração de neutrófilos para o sítio de inflamação [125]. Entretanto, no nosso modelo, as células presentes no BAL 24 horas após a IR renal são principalmente mononucleares. Isso seria uma possível explicação do por que não observamos diminuição no número de células no BAL.

No modelo de LPD induzida por inalação de LPS, camundongos C57Bl/6 receberam $200 \mu \mathrm{g} / \mathrm{kg}$ de R954 30 minutos após o tratamento com LPS. Observamos que 24 horas após a inalação de LPS, o bloqueio do B1R foi capaz de inibir a hiperreatividade pulmonar e o infiltrado de células para o BAL, e reduzir significantemente o infiltrado de células no parênquima pulmonar e extravasamento de proteínas para BAL.

Em ambos os modelos de lesão, avaliamos a expressão de citocinas próinflamatórias, anti-inflamatórias, e quimiocinas no pulmão após tratamento com inibidor de B1R. A inibição de B1R foi capaz de reduzir significantemente a expressão de TNF- $\alpha$, IL-1 $\beta$ e IL-6, e quimiocinas, KC e MCP-1, no pulmão 24 horas após a lesão. Além disso, na lesão induzida por LPS, dosamos estas citocinas no BAL e, verificamos que o bloqueio de B1R aboliu completamente o aumento de TNF- $\alpha$ e IL-1 $\beta$. Por outro lado, a expressão da citocina anti-inflamatória IL-4, foi aumentada após inibição de B1R tanto na lesão induzida por IR renal quanto por LPS. Esse aumento na expressão da citocina de padrão Th2, IL-4, e diminuição das citocinas 
pró-inflamatórias, podem sugerir um dos possíveis mecanismos pelo qual o bloqueio de B1R está ajudando a melhorar a lesão pulmonar. Nosso laboratório mostrou anteriormente que a melhora na função renal com o bloqueio de B1R em lesão de IR está associada com diminuição da expressão das citocinas Th1 e aumento das citocinas IL-4 e IL-10 no rim [69]. Já foi demonstrado que linfócitos expressam principalmente B1R e sua ativação pode estar envolvida na migração e contribuição para lesão em esclerose múltipla [126]. Diversos estudos descreveram um padrão heterogêneo de expressão de B2R e B1R em macrófagos. Dependendo do tecido, se está ativado ou não, os macrófagos apresentam diferente padrão na expressão dos receptores de cininas. Mas em geral, os macrófagos apresentam B2R constitutivamente, aumentando a expressão de B1R em resposta à inflamação [127] . Em células dendríticas, o B2R parece ter um papel mais importante do que o B1R na indução de IL-12 e resposta Th1 [128]. Num modelo de infecção subcutânea por Trypanosoma cruzi, Monteiro e colegas [129] mostraram que a BK produzida no local da infecção leva a um aumento na produção de IL-12 por células dendríticas CD11c+ através da sinalização pelo B2R. Nossos resultados mostraram um aumento da citocina IL-4 no bloqueio dos receptores B1R tanto na lesão pulmonar induzida por LPS quanto por IR renal, entretanto a citocina IL-10 estava diminuída. Diferentemente do que havíamos observado anteriormente no rim [69], que o bloqueio de B1R aumentou tanto IL-4 quanto IL-10 no rim. Considerando a diversifisidade na expressão dos receptores de cininas nos macrófagos, uma das possíveis explicações poderia ser que a expressão e o papel dos receptores nos macrófagos alveolares respondem diferentemente dos macrófagos do rim. O bloqueio de B1R também foi importante para a melhora da inflamação num modelo Th2 de asma, sendo capaz de inibir a secreção de muco, hiperreatividade pulmonar, infiltrado eosinofílico no BAL e parênquima pulmonar [90]. Isso mostra a 
versatilidade do B1R, podendo estar envolvido em lesões inflamatórias causadas principalmente por resposta Th1, induzida por lesão de IR ou LPS, ou em lesões inflamatórias causadas por resposta Th2, como na asma.

Diante dos dados apresentados neste trabalho, sugerimos que após a lesão de IR renal, mediadores inflamatórios são liberados na corrente sanguínea, atingem o pulmão contribuindo para ativação endotelial, infiltração celular, aumento de permeabilidade vascular, aumento de expressão de B1R e B2R, promovendo inflamação com padrão de citocinas Th1 com consequentes danos pulmonares. Na lesão induzida diretamente por LPS, observamos um aumento de infiltrado neutrofílico, permeabilidade vascular, hiperreatividade pulmonar à metacolina, aumento da expressão de B1R, e também inflamação com padrão de citocinas Th1. O B1R tem um papel importante na contribuição para a inflamação e lesão pulmonar induzida tanto por IR renal quanto por LPS, uma vez que, com o bloqueio deste receptor, a lesão pulmonar diminui significantemente no modelo de lesão de IR renal, e é praticamente abolida no modelo de lesão induzida por LPS. Ainda mais, com o bloqueio do B1R a expressão de citocinas de padrão Th1 é diminuída e a citocina IL-4 de padrão Th2 é aumentada, podendo ser um dos possíveis mecanismos responsáveis por essa proteção. 


\section{CONCLUSÕES}

$>\quad$ Após lesão de IR renal houve aumento de infiltrado celular, extravasamento de proteínas e liberação de $\mathrm{PGE}_{2}$ no $\mathrm{BAL}$, hiperreatividade pulmonar à metacolina, aumento na expressão de COX-2 e iNOS no pulmão, e aumento das citocinas inflamatórias IL-1 $\beta$ e TNF- $\alpha$ no sangue.

> A inalação de LPS aumentou o infiltrado neutrofílico, extravasamento de proteínas para o BAL e hiperreatividade pulmonar à metacolina;

As citocinas pró-inflamatórias IL-1 $\beta$, TNF- $\alpha$ e IL-6, e quimiocinas MCP-1 e KC, estavam aumentadas no pulmão em ambos os modelos de lesão, enquanto a citocina de padrão Th2, IL-4, estava diminuída;

$>$ A expressão dos receptores B1 e B2 foram modulados em ambas as lesões. Na LPI, tanto a expressão do B1R como do B2R estavam aumentadas no pulmão 24 horas após IR renal, enquanto que no modelo de LPD apenas o B1R estava super expresso após inalação de LPS;

> O bloqueio do B1R com o tratamento do antagonista (R954) atenuou a lesão pulmonar induzida por IR renal, diminuindo a hiperreatividade pulmonar à metacolina e aumento da permeabilidade vascular;

O bloqueio do B1R aboliu a lesão induzida por LPS, inibindo a hiperreatividade pulmonar à metacolina e o infiltrado de células para o BAL, e reduzindo significantemente o infiltrado de células no parênquima pulmonar e aumento de permeabilidade vascular; e

Em ambas as lesões, o bloqueio do B1R diminuiu a expressão de citocinas inflamatórias como IL-1 $\beta$, TNF- $\alpha$, IL-6, e da quimiocina KC, e aumentou a expressão da citocina IL-4. 
Sendo assim, os dados apresentados neste trabalho sugerem que o B1R tem papel fundamental na contribuição tanto para a LPD, induzida por LPS, quanto para a lesão LPI, induzida por IR renal. 


\section{REFERÊNCIAS}

[1] Bhatia M, Moochhala S. Role of inflammatory mediators in the pathophysiology of acute respiratory distress syndrome. J Pathol. 2004 Feb; 202(2):145-56.

[2] Goodman RB, Strieter RM, Martin DP, Steinberg KP, Milberg JA, Maunder RJ, et al. Inflammatory cytokines in patients with persistence of the acute respiratory distress syndrome. Am J Respir Crit Care Med. 1996 Sep;154(3 Pt 1):602-11.

[3] Sibille Y, Reynolds HY. Macrophages and polymorphonuclear neutrophils in lung defense and injury. Am Rev Respir Dis. 1990 Feb;141(2):471-501.

[4] Weiland JE, Davis WB, Holter JF, Mohammed JR, Dorinsky PM, and Gadek JE. Lung neutrophils in the adult respiratory distress syndrome. Clinical and pathophysiologic significance. Am Rev Respir Dis. 1986 Feb;133(2):218-25.

[5] Bernard GR, Artigas A, Brigham KL, Carlet J, Falke K, Hudson L, et al. The American-European Consensus Conference on ARDS. Definitions, mechanisms, relevant outcomes, and clinical trial coordination. Am J Respir Crit Care Med. 1994 Mar;149(3 Pt 1):818-24.

[6] Kramer AA, Postler G, Salhab KF, Mendez C, Carey LC, and Rabb H. Renal ischemia/reperfusion leads to macrophage-mediated increase in pulmonary vascular permeability. Kidney Int. 1999 Jun;55(6):2362-7.

[7] Welborn MB, 3rd, Douglas WG, Abouhamze Z, Auffenburg T, Abouhamze AS, Baumhofer J, et al. Visceral ischemia-reperfusion injury promotes tumor necrosis factor (TNF) and interleukin-1 (IL-1) dependent organ injury in the mouse. Shock. 1996 Sep;6(3):171-6.

[8] Pelosi P, D'Onofrio D, Chiumello D, Paolo S, Chiara G, Capelozzi VL, et al. Pulmonary and extrapulmonary acute respiratory distress syndrome are different. Eur Respir J Suppl. 2003 Aug;42:48s-56s.

\footnotetext{
* De acordo com:

International Committee of Medical Journal Editors. Uniform requirements for manuscripts submitted to Biomedical Journal: sample references. Available from: http://www.icmje.org [2007 May 22].
} 
[9] Wiener-Kronish JP, Albertine KH, and Matthay MA. Differential responses of the endothelial and epithelial barriers of the lung in sheep to Escherichia coli endotoxin. J Clin Invest. 1991 Sep;88(3):864-75.

[10] Terashima T, Matsubara H, Nakamura M, Sakamaki F, Waki Y, Soejima K, et al. Local Pseudomonas instillation induces contralateral lung injury and plasma cytokines. Am J Respir Crit Care Med. 1996 May;153(5):1600-5.

[11] Modelska K, Pittet JF, Folkesson HG, Courtney Broaddus V, and Matthay MA. Acid-induced lung injury. Protective effect of anti-interleukin-8 pretreatment on alveolar epithelial barrier function in rabbits. Am J Respir Crit Care Med. 1999 Nov;160(5 Pt 1):1450-6.

[12] Greene KE, Wright JR, Steinberg KP, Ruzinski JT, Caldwell E, Wong WB, et al. Serial changes in surfactant-associated proteins in lung and serum before and after onset of ARDS. Am J Respir Crit Care Med. 1999 Dec;160(6):1843-50.

[13] Bitterman PB. Pathogenesis of fibrosis in acute lung injury. Am J Med. 1992 Jun 22;92(6A):39S-43S.

[14] Adamson IY, Young L, and Bowden DH. Relationship of alveolar epithelial injury and repair to the induction of pulmonary fibrosis. Am J Pathol. 1988 Feb;130(2):377-83.

[15] Rocco PR, Zin WA. Pulmonary and extrapulmonary acute respiratory distress syndrome: are they different? Curr Opin Crit Care. 2005 Feb;11(1):10-7.

[16] Pelosi P. What about primary and secondary ARDS. Minerva Anestesiol. 2000 Nov;66(11):779-85;785-6.

[17] Brigham KL, Meyrick B. Endotoxin and lung injury. Am Rev Respir Dis. 1986 May;133(5):913-27.

[18] Dauphinee SM, Karsan A. Lipopolysaccharide signaling in endothelial cells. Lab Invest. 2006 Jan;86(1):9-22.

[19] Beutler B. TLR4 as the mammalian endotoxin sensor. Curr Top Microbiol Immunol. 2002 270:109-20.

[20] Hoebe K, Janssen E, and Beutler B. The interface between innate and adaptive immunity. Nat Immunol. 2004 Oct;5(10):971-4. 
[21] Noulin N, Quesniaux VF, Schnyder-Candrian S, Schnyder B, Maillet I, Robert $\mathrm{T}$, et al. Both hemopoietic and resident cells are required for MyD88dependent pulmonary inflammatory response to inhaled endotoxin. J Immunol. 2005 Nov 15;175(10):6861-9.

[22] Lefort J, Motreff L, and Vargaftig BB. Airway administration of Escherichia coli endotoxin to mice induces glucocorticosteroid-resistant bronchoconstriction and vasopermeation. Am J Respir Cell Mol Biol. 2001 Mar;24(3):345-51.

[23] Togbe D, Schnyder-Candrian S, Schnyder B, Couillin I, Maillet I, Bihl F, et al. TLR4 gene dosage contributes to endotoxin-induced acute respiratory inflammation. J Leukoc Biol. 2006 Sep;80(3):451-7.

[24] Schnyder-Candrian S, Quesniaux VF, Di Padova F, Maillet I, Noulin N, Couillin I, et al. Dual effects of p38 MAPK on TNF-dependent bronchoconstriction and TNF-independent neutrophil recruitment in lipopolysaccharide-induced acute respiratory distress syndrome. J Immunol. 2005 Jul 1;175(1):262-9.

[25] Vincent D, Lefort J, Chatelet F, Bureau MF, Dry J, and Vargaftig BB. Intratracheal E. coli lipopolysaccharide induces platelet-dependent bronchial hyperreactivity. J Appl Physiol. 1993 Mar;74(3):1027-38.

[26] Tsikouris JP, Suarez JA, and Meyerrose GE. Plasminogen activator inhibitor-1: physiologic role, regulation, and the influence of common pharmacologic agents. J Clin Pharmacol. 2002 Nov;42(11):1187-99.

[27] Marshall LJ, Ramdin LS, Brooks T, PC DP, and Shute JK. Plasminogen activator inhibitor-1 supports IL-8-mediated neutrophil transendothelial migration by inhibition of the constitutive shedding of endothelial IL8/heparan sulfate/syndecan-1 complexes. J Immunol. 2003 Aug 15;171(4):205765.

[28] Arndt PG, Young SK, and Worthen GS. Regulation of lipopolysaccharideinduced lung inflammation by plasminogen activator Inhibitor-1 through a JNK-mediated pathway. J Immunol. 2005 Sep 15;175(6):4049-59.

[29] Colletti LM, Kunkel SL, Walz A, Burdick MD, Kunkel RG, Wilke CA, et al. Chemokine expression during hepatic ischemia/reperfusion-induced lung injury in the rat. The role of epithelial neutrophil activating protein. J Clin Invest. 1995 Jan;95(1):134-41. 
[30] Takeuchi D, Yoshidome H, Kurosawa H, Kimura F, Shimizu H, Ohtsuka M, et al. Interleukin-18 exacerbates pulmonary injury after hepatic ischemia/reperfusion in mice. J Surg Res. Jan;158(1):87-93.

[31] Yoshidome H, Kato A, Edwards MJ, and Lentsch AB. Interleukin-10 inhibits pulmonary NF-kappaB activation and lung injury induced by hepatic ischemia-reperfusion. Am J Physiol. 1999 Nov;277(5 Pt 1):L919-23.

[32] Schmeling DJ, Caty MG, Oldham KT, Guice KS, and Hinshaw DB. Evidence for neutrophil-related acute lung injury after intestinal ischemia-reperfusion. Surgery. 1989 Aug; 106(2):195-201.

[33] Foulds S, Mireskandari M, Kalu P, Jackson W, Cheshire NJ, Mansfield AO, et al. Visceral ischemia and neutrophil activation in sepsis and organ dysfunction. J Surg Res. 1998 Mar;75(2):170-6.

[34] Koksoy C, Kuzu MA, Kuzu I, Ergun H, and Gurhan I. Role of tumour necrosis factor in lung injury caused by intestinal ischaemia-reperfusion. Br J Surg. 2001 Mar;88(3):464-8.

[35] Zhou JL, Jin GH, Yi YL, Zhang JL, and Huang XL. Role of nitric oxide and peroxynitrite anion in lung injury induced by intestinal ischemia-reperfusion in rats. World J Gastroenterol. 2003 Jun;9(6):1318-22.

[36] Cavriani G, Domingos HV, Soares AL, Trezena AG, Ligeiro-Oliveira AP, Oliveira-Filho RM, et al. Lymphatic system as a path underlying the spread of lung and gut injury after intestinal ischemia/reperfusion in rats. Shock. 2005 Apr;23(4):330-6.

[37] Cavriani G, Domingos HV, Oliveira-Filho RM, Sudo-Hayashi LS, Vargaftig $\mathrm{BB}$, and de Lima WT. Lymphatic thoracic duct ligation modulates the serum levels of IL-1beta and IL-10 after intestinal ischemia/reperfusion in rats with the involvement of tumor necrosis factor alpha and nitric oxide. Shock. 2007 Feb;27(2):209-13.

[38] Kuzu MA, Koksoy C, Kuzu I, Gurhan I, Ergun H, and Demirpence E. Role of integrins and intracellular adhesion molecule-1 in lung injury after intestinal ischemia-reperfusion. Am J Surg. 2002 Jan;183(1):70-4.

[39] Cavriani G, Oliveira-Filho RM, Trezena AG, da Silva ZL, Domingos HV, de Arruda MJ, et al. Lung microvascular permeability and neutrophil recruitment 
are differently regulated by nitric oxide in a rat model of intestinal ischemiareperfusion. Eur J Pharmacol. 2004 Jun 28;494(2-3):241-9.

[40] Lin HI, Chou SJ, Wang D, Feng NH, Feng E, and Chen CF. Reperfusion liver injury induces down-regulation of eNOS and up-regulation of iNOS in lung tissues. Transplant Proc. 2006 Sep;38(7):2203-6.

[41] Simmons EM, Himmelfarb J, Sezer MT, Chertow GM, Mehta RL, Paganini EP, et al. Plasma cytokine levels predict mortality in patients with acute renal failure. Kidney Int. 2004 Apr;65(4):1357-65.

[42] Deng J, Hu X, Yuen PS, and Star RA. Alpha-melanocyte-stimulating hormone inhibits lung injury after renal ischemia/reperfusion. Am J Respir Crit Care Med. 2004 Mar 15;169(6):749-56.

[43] Grigoryev DN, Liu M, Hassoun HT, Cheadle C, Barnes KC, and Rabb H. The local and systemic inflammatory transcriptome after acute kidney injury. J Am Soc Nephrol. 2008 Mar;19(3):547-58.

[44] Thadhani R, Pascual M, and Bonventre JV. Acute renal failure. N Engl J Med. 1996 May 30;334(22):1448-60.

[45] Nolan CR, Anderson RJ. Hospital-acquired acute renal failure. J Am Soc Nephrol. 1998 Apr;9(4):710-8.

[46] Cecka JM. The UNOS Scientific Renal Transplant Registry. Clin Transpl. 1998: $1-16$.

[47] Shoskes DA, Cecka JM. Deleterious effects of delayed graft function in cadaveric renal transplant recipients independent of acute rejection. Transplantation. 1998 Dec 27;66(12):1697-701.

[48] Guyton AC, Hall JE, Medical Physiology. 10th ed. 2000, Philadelphia: Saunders.

[49] Sheridan AM, Bonventre JV. Cell biology and molecular mechanisms of injury in ischemic acute renal failure. Curr Opin Nephrol Hypertens. 2000 Jul;9(4):427-34.

[50] Sheridan AM, Bonventre JV, Cell biology and molecular mechanisms of injury in ischemic acute renal failure, in Curr Opin Nephrol Hypertens. 2000. p.42734. 
[51] Akcay A, Nguyen Q, and Edelstein CL. Mediators of inflammation in acute kidney injury. Mediators Inflamm. 2009: 137072.

[52] Sutton TA, Mang HE, Campos SB, Sandoval RM, Yoder MC, and Molitoris BA. Injury of the renal microvascular endothelium alters barrier function after ischemia. Am J Physiol Renal Physiol. 2003 Aug;285(2):F191-8.

[53] Bonventre JV, Zuk A. Ischemic acute renal failure: an inflammatory disease? Kidney Int. 2004 Aug;66(2):480-5.

[54] Daha MR, van Kooten C. Is the proximal tubular cell a proinflammatory cell? Nephrol Dial Transplant. 2000 15Suppl 6:41-3.

[55] Kapper S, Beck G, Riedel S, Prem K, Haak M, van der Woude FJ, et al. Modulation of chemokine production and expression of adhesion molecules in renal tubular epithelial and endothelial cells by catecholamines. Transplantation. 2002 Jul 27;74(2):253-60.

[56] Safirstein R, Megyesi J, Saggi SJ, Price PM, Poon M, Rollins BJ, et al. Expression of cytokine-like genes JE and $\mathrm{KC}$ is increased during renal ischemia. Am J Physiol. 1991 Dec;261(6 Pt 2):F1095-101.

[57] Segerer S, Nelson PJ, and Schlondorff D. Chemokines, chemokine receptors, and renal disease: from basic science to pathophysiologic and therapeutic studies. J Am Soc Nephrol. 2000 Jan;11(1):152-76.

[58] Friedewald JJ, Rabb H. Inflammatory cells in ischemic acute renal failure. Kidney Int. 2004 Aug;66(2):486-91.

[59] Paller MS. Effect of neutrophil depletion on ischemic renal injury in the rat. J Lab Clin Med. 1989 Mar;113(3):379-86.

[60] Day YJ, Huang L, Ye H, Linden J, and Okusa MD. Renal ischemia-reperfusion injury and adenosine 2A receptor-mediated tissue protection: role of macrophages. Am J Physiol Renal Physiol. 2005 Apr;288(4):F722-31.

[61] Jo SK, Sung SA, Cho WY, Go KJ, and Kim HK. Macrophages contribute to the initiation of ischaemic acute renal failure in rats. Nephrol Dial Transplant. 2006 May;21(5):1231-9.

[62] Yokota N, Daniels F, Crosson J, and Rabb H. Protective effect of T cell depletion in murine renal ischemia-reperfusion injury. Transplantation. 2002 Sep 27;74(6):759-63. 
[63] Burne MJ, Daniels F, El Ghandour A, Mauiyyedi S, Colvin RB, O'Donnell MP, et al. Identification of the $\mathrm{CD} 4(+) \mathrm{T}$ cell as a major pathogenic factor in ischemic acute renal failure. J Clin Invest. 2001 Nov;108(9):1283-90.

[64] de Paiva VN, Monteiro RM, Marques Vde P, Cenedeze MA, Teixeira Vde P, dos Reis MA, et al. Critical involvement of Th1-related cytokines in renal injuries induced by ischemia and reperfusion. Int Immunopharmacol. 2009 Jun;9(6):668-72.

[65] Marques VP, Goncalves GM, Feitoza CQ, Cenedeze MA, Fernandes Bertocchi $\mathrm{AP}$, Damiao MJ, et al. Influence of TH1/TH2 switched immune response on renal ischemia-reperfusion injury. Nephron Exp Nephrol. 2006 104(1):e48-56.

[66] Yokota N, Burne-Taney M, Racusen L, and Rabb H. Contrasting roles for STAT4 and STAT6 signal transduction pathways in murine renal ischemiareperfusion injury. Am J Physiol Renal Physiol. 2003 Aug;285(2):F319-25.

[67] Kumar S, Allen DA, Kieswich JE, Patel NS, Harwood S, Mazzon E, et al. Dexamethasone ameliorates renal ischemia-reperfusion injury. J Am Soc Nephrol. 2009 Nov;20(11):2412-25.

[68] Kelly KJ, Williams WW, Jr., Colvin RB, and Bonventre JV. Antibody to intercellular adhesion molecule 1 protects the kidney against ischemic injury. Proc Natl Acad Sci U S A. 1994 Jan 18;91(2):812-6.

[69] Wang PH, Campanholle G, Cenedeze MA, Feitoza CQ, Goncalves GM, Landgraf RG, et al. Bradykinin B1 receptor antagonism is beneficial in renal ischemia-reperfusion injury. PLoS ONE. 2008 3(8):e3050.

[70] Moreau ME, Garbacki N, Molinaro G, Brown NJ, Marceau F, and Adam A. The kallikrein-kinin system: current and future pharmacological targets. J Pharmacol Sci. 2005 Sep;99(1):6-38.

[71] Regoli D, Nsa Allogho S, Rizzi A, and Gobeil FJ. Bradykinin receptors and their antagonists. Eur J Pharmacol. 1998 May 1;348(1):1-10.

[72] Calixto JB, Cabrini DA, Ferreira J, and Campos MM. Kinins in pain and inflammation. Pain. 2000 Jul;87(1):1-5.

[73] Pesquero JB, Pesquero JL, Oliveira SM, Roscher AA, Metzger R, Ganten D, et al. Molecular cloning and functional characterization of a mouse bradykinin B1 receptor gene. Biochem Biophys Res Commun. 1996 Mar 7;220(1):219-25. 
[74] Campos MM, Cabrini DA, Cardozo AH, Rae GA, Toro JH, and Calixto JB. Changes in paw oedema triggered via bradykinin $\mathrm{B}(1)$ and $\mathrm{B}(2)$ receptors in streptozotocin-diabetic rats. Eur J Pharmacol. 2001 Mar 23;416(1-2):169-77.

[75] Marceau F, Hess JF, and Bachvarov DR. The B1 receptors for kinins. Pharmacol Rev. 1998 Sep;50(3):357-86.

[76] Merino VF, Silva JA, Jr., Araujo RC, Avellar MC, Bascands JL, Schanstra JP, et al. Molecular structure and transcriptional regulation by nuclear factorkappaB of the mouse kinin B1 receptor gene. Biol Chem. 2005 Jun;386(6):51522.

[77] Dray A, Perkins M. Bradykinin and inflammatory pain. Trends Neurosci. 1993 Mar;16(3):99-104.

[78] Perretti M, Appleton I, Parente L, and Flower RJ. Pharmacology of interleukin1-induced neutrophil migration. Agents Actions. 199338 Spec No: C64-5.

[79] Ahluwalia A, Perretti M. Calcitonin gene-related peptides modulate the acute inflammatory response induced by interleukin-1 in the mouse. Eur J Pharmacol. 1994 Nov 3;264(3):407-15.

[80] Tiffany CW, Burch RM. Bradykinin stimulates tumor necrosis factor and interleukin-1 release from macrophages. FEBS Lett. 1989 Apr 24;247(2):189-92.

[81] Sato E, Koyama S, Nomura H, Kubo K, and Sekiguchi M. Bradykinin stimulates alveolar macrophages to release neutrophil, monocyte, and eosinophil chemotactic activity. J Immunol. 1996 Oct 1;157(7):3122-9.

[82] Kuhr F, Lowry J, Zhang Y, Brovkovych V, and Skidgel RA. Differential regulation of inducible and endothelial nitric oxide synthase by kinin B1 and B2 receptors. Neuropeptides. Apr;44(2):145-54.

[83] Souza DG, Lomez ES, Pinho V, Pesquero JB, Bader M, Pesquero JL, et al. Role of bradykinin B2 and B1 receptors in the local, remote, and systemic inflammatory responses that follow intestinal ischemia and reperfusion injury. J Immunol. 2004 Feb 15;172(4):2542-8.

[84] Hashimoto N, Takeyoshi I, Tsutsumi H, Sunose Y, Tokumine M, Totsuka O, et al. Effects of a bradykinin $\mathrm{B}(2)$ receptor antagonist on ischemia-reperfusion injury in a canine lung transplantation model. J Heart Lung Transplant. 2004 May;23(5):606-13. 
[85] Su J, Cui M, Tang Y, Zhou H, Liu L, and Dong Q. Blockade of bradykinin B2 receptor more effectively reduces postischemic blood-brain barrier disruption and cytokines release than B1 receptor inhibition. Biochem Biophys Res Commun. 2009 Oct 16;388(2):205-11.

[86] Austinat M, Braeuninger S, Pesquero JB, Brede M, Bader M, Stoll G, et al. Blockade of bradykinin receptor $\mathrm{B} 1$ but not bradykinin receptor $\mathrm{B} 2$ provides protection from cerebral infarction and brain edema. Stroke. 2009 Jan;40(1): 285-93.

[87] Hara DB, Leite DF, Fernandes ES, Passos GF, Guimaraes AO, Pesquero JB, et al. The relevance of kinin B1 receptor upregulation in a mouse model of colitis. Br J Pharmacol. 2008 Jul;154(6):1276-86.

[88] Lu DY, Leung YM, Huang SM, and Wong KL. Bradykinin-induced cell migration and COX-2 production mediated by the bradykinin B1 receptor in glioma cells. J Cell Biochem. May;110(1):141-50.

[89] Vasquez-Pinto LM, Nantel F, Sirois P, and Jancar S. Bradykinin B(1) receptor antagonist R954 inhibits eosinophil activation/proliferation/migration and increases TGF-beta and VEGF in a murine model of asthma. Neuropeptides. Apr;44(2):107-13.

[90] Gama Landgraf R, Sirois P, and Jancar S. Differential modulation of murine lung inflammation by bradykinin B1 and B2 selective receptor antagonists. Eur J Pharmacol. 2003 Jan 26;460(1):75-83.

[91] Abraham WM, Scuri M, and Farmer SG. Peptide and non-peptide bradykinin receptor antagonists: role in allergic airway disease. Eur J Pharmacol. 2006 Mar 8;533(1-3):215-21.

[92] Wang PH, Cenedeze MA, Pesquero JB, Pacheco-Silva A, and Camara NO. Influence of bradykinin $\mathrm{B} 1$ and $\mathrm{B} 2$ receptors in the immune response triggered by renal ischemia-reperfusion injury. Int Immunopharmacol. 2006 Dec 20;6(13-14):1960-5.

[93] Bascands JL, Bachvarova M, Neau E, Schanstra JP, and Bachvarov D. Molecular determinants of LPS-induced acute renal inflammation: Implication of the kinin B1 receptor. Biochem Biophys Res Commun. 2009 Aug 21;386(2):407-12. 
[94] Keller AC, Mucida D, Gomes E, Faquim-Mauro E, Faria AM, Rodriguez D, et al. Hierarchical suppression of asthma-like responses by mucosal tolerance. J Allergy Clin Immunol. 2006 Feb;117(2):283-90.

[95] Yang L, Besschetnova TY, Brooks CR, Shah JV, and Bonventre JV. Epithelial cell cycle arrest in G2/M mediates kidney fibrosis after injury. Nat Med. May; 16(5):535-43.

[96] Hassoun HT, Grigoryev DN, Lie ML, Liu M, Cheadle C, Tuder RM, et al. Ischemic acute kidney injury induces a distant organ functional and genomic response distinguishable from bilateral nephrectomy. Am J Physiol Renal Physiol. 2007 Jul;293(1):F30-40.

[97] Kielar ML, John R, Bennett M, Richardson JA, Shelton JM, Chen L, et al. Maladaptive role of IL-6 in ischemic acute renal failure. J Am Soc Nephrol. 2005 Nov;16(11):3315-25.

[98] Crofford LJ. COX-1 and COX-2 tissue expression: implications and predictions. J Rheumatol Suppl. 1997 Jul;49:15-9.

[99] Bogdan C. Nitric oxide and the immune response. Nat Immunol. 2001 Oct;2(10):907-16.

[100] Feitoza CQ, Camara NO, Pinheiro HS, Goncalves GM, Cenedeze MA, Pacheco-Silva A, et al. Cyclooxygenase 1 and/or 2 blockade ameliorates the renal tissue damage triggered by ischemia and reperfusion injury. Int Immunopharmacol. 2005 Jan;5(1):79-84.

[101] Turnage RH, Wright JK, Iglesias J, LaNoue JL, Nguyen H, Kim L, et al. Intestinal reperfusion-induced pulmonary edema is related to increased pulmonary inducible nitric oxide synthase activity. Surgery. 1998 Aug;124(2):457-62.

[102] Turnage RH, Kadesky KM, Bartula L, and Myers SI. Intestinal reperfusion upregulates inducible nitric oxide synthase activity within the lung. Surgery. 1995 Aug;118(2):288-93.

[103] Farley KS, Wang LF, Razavi HM, Law C, Rohan M, McCormack DG, et al. Effects of macrophage inducible nitric oxide synthase in murine septic lung injury. Am J Physiol Lung Cell Mol Physiol. 2006 Jun;290(6):L1164-72. 
[104] Barnes PJ, Chung KF, and Page CP. Inflammatory mediators of asthma: an update. Pharmacol Rev. 1998 Dec;50(4):515-96.

[105] Gauvreau GM, Watson RM, and O'Byrne PM. Protective effects of inhaled PGE2 on allergen-induced airway responses and airway inflammation. Am J Respir Crit Care Med. 1999 Jan;159(1):31-6.

[106] Peacock CD, Misso NL, Watkins DN, and Thompson PJ. PGE 2 and dibutyryl cyclic adenosine monophosphate prolong eosinophil survival in vitro. J Allergy Clin Immunol. 1999 Jul;104(1):153-62.

[107] Profita M, Sala A, Bonanno A, Riccobono L, Siena L, Melis MR, et al. Increased prostaglandin E2 concentrations and cyclooxygenase-2 expression in asthmatic subjects with sputum eosinophilia. J Allergy Clin Immunol. 2003 Oct;112(4):709-16.

[108] Landgraf RG, Nossi DF, Sirois P, and Jancar S. Prostaglandins, leukotrienes and PAF selectively modulate lymphocyte subset and eosinophil infiltration into the airways in a murine model of asthma. Prostaglandins Leukot Essent Fatty Acids. 2007 Oct-Nov; 77(3-4):163-72.

[109] Alba-Loureiro TC, Martins EF, Miyasaka CK, Lopes LR, Landgraf RG, Jancar $S$, et al. Evidence that arachidonic acid derived from neutrophils and prostaglandin E2 are associated with the induction of acute lung inflammation by lipopolysaccharide of Escherichia coli. Inflamm Res. 2004 Dec;53(12):65863.

[110] Linfert D, Chowdhry T, and Rabb H. Lymphocytes and ischemia-reperfusion injury. Transplant Rev (Orlando). 2009 Jan;23(1):1-10.

[111] Ascon DB, Lopez-Briones S, Liu M, Ascon M, Savransky V, Colvin RB, et al. Phenotypic and functional characterization of kidney-infiltrating lymphocytes in renal ischemia reperfusion injury. J Immunol. 2006 Sep 1;177(5):3380-7.

[112] Jang HR, Rabb H. The innate immune response in ischemic acute kidney injury. Clin Immunol. 2009 Jan;130(1):41-50.

[113] Yi ES, Remick DG, Lim Y, Tang W, Nadzienko CE, Bedoya A, et al. The intratracheal administration of endotoxin: $X$. Dexamethasone downregulates neutrophil emigration and cytokine expression in vivo. Inflammation. 1996 Apr;20(2):165-75. 
[114] Seki H, Tasaka S, Fukunaga K, Shiraishi Y, Moriyama K, Miyamoto K, et al. Effect of Toll-like receptor 4 inhibitor on LPS-induced lung injury. Inflamm Res. Apr 13.

[115] Martins JO, Ferracini M, Ravanelli N, Landgraf RG, and Jancar S. Insulin suppresses LPS-induced iNOS and COX-2 expression and NF-kappaB activation in alveolar macrophages. Cell Physiol Biochem. 2008 22(1-4): 279-86.

[116] Togbe D, Schnyder-Candrian S, Schnyder B, Doz E, Noulin N, Janot L, et al. Toll-like receptor and tumour necrosis factor dependent endotoxin-induced acute lung injury. Int J Exp Pathol. 2007 Dec;88(6):387-91.

[117] Marceau F, Bachvarov DR. Kinin receptors. Clin Rev Allergy Immunol. 1998 Winter; 16(4):385-401.

[118] Duka I, Kintsurashvili E, Gavras I, Johns C, Bresnahan M, and Gavras H. Vasoactive potential of the $b(1)$ bradykinin receptor in normotension and hypertension. Circ Res. 2001 Feb 16;88(3):275-81.

[119] Schmidlin F, Scherrer D, Daeffler L, Bertrand C, Landry Y, and Gies JP. Interleukin-1beta induces bradykinin $\mathrm{B} 2$ receptor gene expression through a prostanoid cyclic AMP-dependent pathway in human bronchial smooth muscle cells. Mol Pharmacol. 1998 Jun;53(6):1009-15.

[120] Baptista HA, Avellar MC, Araujo RC, Pesquero JL, Schanstra JP, Bascands JL, et al. Transcriptional regulation of the rat bradykinin B2 receptor gene: identification of a silencer element. Mol Pharmacol. 2002 Dec;62(6):1344-55.

[121] Calixto JB, Medeiros R, Fernandes ES, Ferreira J, Cabrini DA, and Campos MM. Kinin B1 receptors: key G-protein-coupled receptors and their role in inflammatory and painful processes. Br J Pharmacol. 2004 Dec;143(7):803-18.

[122] Campos MM, Souza GE, and Calixto JB. Upregulation of B1 receptor mediating des-Arg9-BK-induced rat paw oedema by systemic treatment with bacterial endotoxin. Br J Pharmacol. 1996 Mar;117(5):793-8.

[123] deBlois D, Horlick RA. Endotoxin sensitization to kinin B(1) receptor agonist in a non-human primate model: haemodynamic and pro-inflammatory effects. Br J Pharmacol. 2001 Jan;132(1):327-35.

[124] Marin-Castano ME, Schanstra JP, Praddaude F, Pesquero JB, Ader JL, Girolami JP, et al. Differential induction of functional B1-bradykinin receptors 
along the rat nephron in endotoxin induced inflammation. Kidney Int. 1998 Dec;54(6):1888-98.

[125] Araujo RC, Kettritz R, Fichtner I, Paiva AC, Pesquero JB, and Bader M. Altered neutrophil homeostasis in kinin B1 receptor-deficient mice. Biol Chem. 2001 Jan;382(1):91-5.

[126] Bockmann S, Paegelow I. Kinins and kinin receptors: importance for the activation of leukocytes. J Leukoc Biol. 2000 Nov; 68(5):587-92.

[127] Schulze-Topphoff U, Prat A, Bader M, Zipp F, and Aktas O. Roles of the kallikrein/kinin system in the adaptive immune system. Int Immunopharmacol. 2008 Feb;8(2):155-60.

[128] Aliberti J, Viola JP, Vieira-de-Abreu A, Bozza PT, Sher A, and Scharfstein J. Cutting edge: bradykinin induces IL-12 production by dendritic cells: a danger signal that drives Th1 polarization. J Immunol. 2003 Jun 1;170(11):5349-53.

[129] Monteiro AC, Schmitz V, Svensjo E, Gazzinelli RT, Almeida IC, Todorov A, et al. Cooperative activation of TLR2 and bradykinin B2 receptor is required for induction of type 1 immunity in a mouse model of subcutaneous infection by Trypanosoma cruzi. J Immunol. 2006 Nov 1;177(9):6325-35. 